\title{
EFICÁCIA DA INTERVENÇÃO FONOAUDIOLÓGICA EM CRIANÇAS COM DISTÚRBIO ESPECÍFICO DE LINGUAGEM
}

DÁPHINE LUCIANA COSTA GAHYVA

Dissertação apresentada à Faculdade de Odontologia de Bauru, da Universidade de São Paulo, como parte dos requisitos para obtenção do título de Mestre em Fonoaudiologia.

BAURU

2007 


\section{EFICÁCIA DA INTERVENÇÃO FONOAUDIOLÓGICA EM CRIANÇAS COM DISTÚRBIO ESPECÍFICO DE LINGUAGEM}

DÁPHINE LUCIANA COSTA GAHYVA

Dissertação apresentada à Faculdade de Odontologia de Bauru, da Universidade de São Paulo, como parte dos requisitos para obtenção do título de Mestre em Fonoaudiologia.

Orientadora: Prof ${ }^{\mathrm{a}} \mathrm{Dr}^{\mathrm{a}}$ Simone Rocha de Vasconcellos Hage 


\begin{tabular}{|c|c|}
\hline G123e & $\begin{array}{l}\text { Gahyva, Dáphine Luciana Costa } \\
\text { Eficácia da intervenção fonoaudiológica em crianças com } \\
\text { Distúrbio Específico de Linguagem / Dáphine Luciana Costa } \\
\text { Gahyva. -- Bauru, } 2007 .\end{array}$ \\
\hline & xvii 130 p.: il. ; $30 \mathrm{~cm}$. \\
\hline & $\begin{array}{l}\text { Dissertação (Mestrado) -- Faculdade de Odontologia de } \\
\text { Bauru. Universidade de São Paulo. }\end{array}$ \\
\hline Hage & Orientadora: $\operatorname{Prof}^{\mathrm{a}} \operatorname{Dr}^{\mathrm{a}}$ Simone Rocha de Vasconcellos \\
\hline
\end{tabular}

Autorizo, exclusivamente para fins acadêmicos e científicos, a reprodução total ou parcial desta dissertação/tese, por processos fotocopiadores e outros meios eletrônicos.

Assinatura:

Data:

Comitê de Ética da FOB: Projeto de pesquisa aprovado em 26 de outubro de 2005.

No do Protocolo: 109/2005. 


\section{DADOS CURRICULARES}

\section{DÁPHINE LUCIANA COSTA GAHYVA}

28 de abril de 1980

Filiação

$1999-2002$

$2003-2004$

$2004-2005$

$2005-2007$
Nascimento / Cuiabá - MT

Gesner Leôncio Gahyva Filho

Mirian Costa Gahyva

Graduação em Fonoaudiologia - Faculdade de Odontologia de Bauru / Universidade de São Paulo - Bauru - SP

Curso de Especialização na área de Linguagem, pela Faculdade de Odontologia de Bauru, da Universidade de São Paulo, Bauru - SP.

Curso de Aprimoramento Profissional em Fonoaudiologia, pelo Hospital de Base da Faculdade de Medicina de São José do Rio Preto, São José do Rio Preto - SP.

Curso de Pós-Graduação em Fonoaudiologia, nível de Mestrado, pela Faculdade de Odontologia de Bauru da Universidade de São Paulo, Bauru - SP. 
"Por trás de cada informação dada com tanta simplicidade em sala de aula existem as lágrimas, as aventuras e a coragem dos cientistas." (Augusto Cury) 


\section{DEDICATÓRIA}

DEDICO este trabalho...

...aos meus pais, Mírian e Gesner, Mestres da minha vida, pelos ensinamentos de amor, respeito, luta, confiança, dignidade e felicidade que me proporcionaram. Obrigada por respeitarem minhas escolhas, por acreditarem em meus sonhos e por terem se esforçado, junto a mim, para que eles se concretizassem!

"A vocês, que deixaram seus sonhos para que eu sonhasse.

Que derramaram lágrimas para que eu fosse feliz.

Que perderam noites de sono para que eu dormisse tranqüilo.

Que acreditaram em mim apesar dos meus erros, TODO MEU AMOR, CARINHO, RESPEITO E GRATIDÃO!" 


\section{AGRADECIMENTOS ESPECIAIS}

Aos meus queridos irmãos Déco, Binho e Nine. Obrigada pela amizade, pela cumplicidade, pelos cuidados, pelo incentivo e por serem pessoas tão especiais em minha vida!

À minha querida avó e madrinha Dulce, pela presença constante em minha vida, sempre acompanhada de muita doçura e carinho!

Ao Marcel, grande amor, companheiro e amigo. Obrigada pelo seu apoio, compreensão, incentivo e, sobretudo, por me fazer feliz! 


\section{AGRADECIMENTO ESPECIAL}

À minha querida orientadora, Profa. Dra. Simone Rocha de Vasconcellos Hage, pessoa e profissional por quem tenho profunda admiração e carinho.

Obrigada por acreditar neste estudo, por confiar em meu trabalho, por me acolher com toda sua humildade, pela imensa amizade, pelo carinho e dedicação incansável com que orientou este estudo e por ter acalmado meu coração com a sua serenidade nos momentos difíceis.

Serei eternamente grata por tudo!!

"Uma alma elegante e superior sempre estimulará com verdadeira alegria e satisfação o crescimento de seus companheiros. Realçar o brilho de alguém só faz reluzir mais ainda o brilho próprio."

(autor desconhecido) 


\section{AGRADECIMENTOS}

À Faculdade de Odontologia de Bauru, referencial em Educação e grande responsável por me propiciar um ensino de qualidade durante toda a minha formação profissional.

À CAPES, pelo suporte financeiro.

Às crianças participantes deste estudo, que o tornaram ainda mais especial e, aos seus familiares, pela confiança, disponibilidade e exemplo de força e dedicação.

À Dra. Maria Inês Pegoraro-Krook, coordenadora do Programa de Pós Graduação em Fonoaudiologia pela dedicação ao Programa, sempre visando o aperfeiçoamento do curso de mestrado da FOB-USP.

Às Professoras Patrícia Abreu Pinheiro Crenitte e Vera Lúcia Garcia pelas valiosas sugestões no Exame de Qualificação.

Aos demais professores do Departamento de Fonoaudiologia da FOB-USP, pelos ensinamentos e convívio.

Às fonoaudiólogas Ana Paola Nicolielo e Graciela Fernandes, queridas companheiras de trabalho, pela colaboração durante a realização deste estudo.

Ao Prof. Dr. José Roberto Pereira Lauris, pelo auxílio e orientação na realização da análise estatística.

Ao serviço de Biblioteca e documentação da FOB-USP, pela atenção dispensada e dedicação em prol dos trabalhos de pós-graduação.

Aos funcionários do Departamento e da Clínica de Fonoaudiologia da FOB-USP, sempre prontos a auxiliar e facilitar o nosso cotidiano. 
À I Turma de Mestrado em Fonoaudiologia da FOB-USP, Vanessa, Mariana, Maria Cecília, Luciana Silva, Simone, Isabel, Ana Dolores, Josilene, Daniela e Luciana Biral, por conhecer, conviver e aprender com cada uma de vocês.

Às minhas amadas amigas Thaís, Maga, Mariana e Vanessa, pela amizade, carinho, companheirismo tão sincero e por todo o apoio nas horas mais difíceis. Mesmo distante, sei que sempre poderei contar com vocês. Tenham certeza que a convivência com vocês foi essencial para o meu amadurecimento!

Às amigas Raquel, Marina e Priscila, por todos os momentos super agradáveis e descontraídos que compartilhamos e por terem me acolhido com tanto carinho na minha volta a Bauru. Obrigada pela amizade e por terem tornado esta jornada, se não menos árdua, com certeza mais prazerosa e alegre!

A todos os demais, que de alguma forma contribuíram com o desenvolvimento deste trabalho e com minha formação, meus mais sinceros agradecimentos. 


\section{SUMÁRIO}

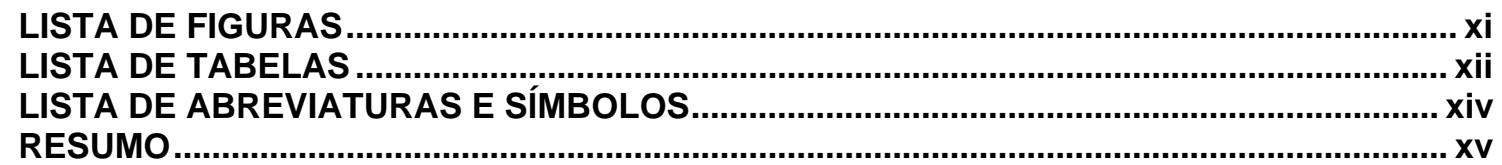

1 - INTRODUÇÃO

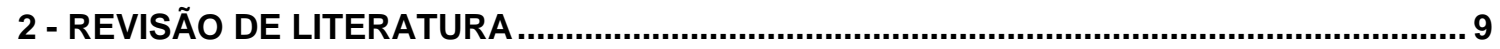

2.1 Comparação da eficácia terapêutica de Procedimentos estruturados, interacionais e/ou

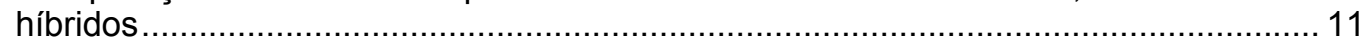

2.2 Programas de intervenção com base no processamento da informação........................ 15

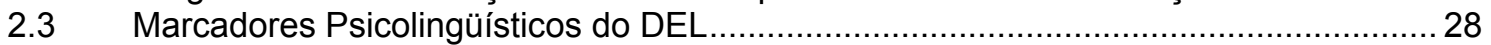

2.4 Comparação da eficácia da intervenção baseada em Modelos tradicionais e Modelos com base no processamento da informação lingüística ............................................. 34

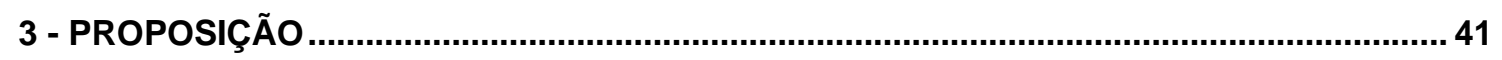

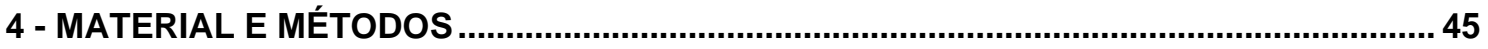

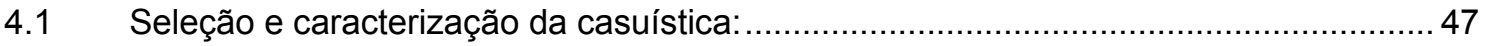

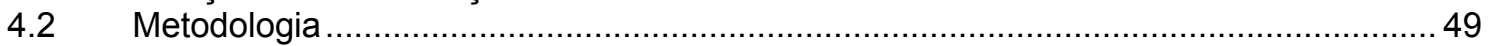

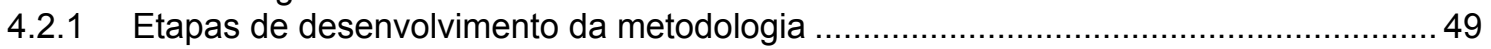

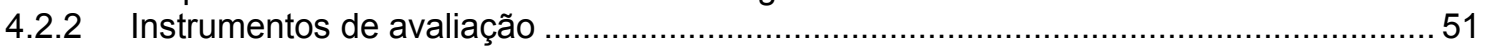

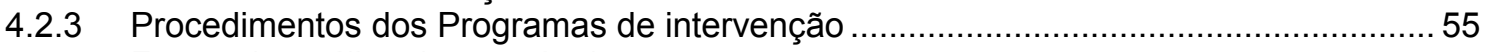

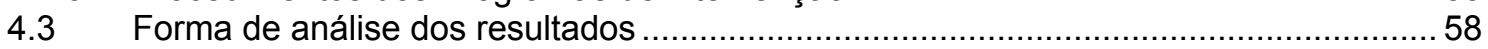

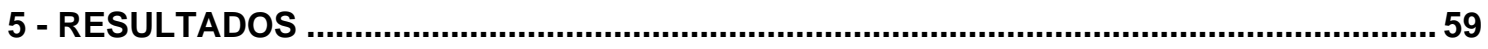

5.1 Comparação do desempenho psicolingüístico dos grupos experimental (GE) e controle

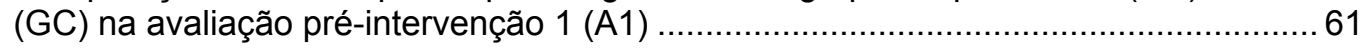

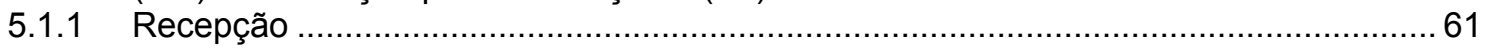

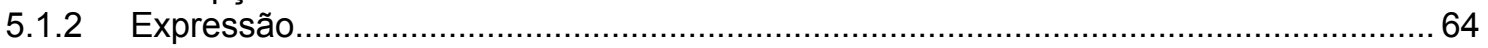

5.1.3 Memória de Curto Prazo / Subteste Memória Seqüencial Auditiva do ITPA ..................69 69

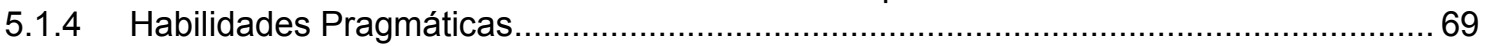

5.2 Comparação do desempenho psicolingüístico do GE entre a avaliação pré-intervenção

1 (A1) e avaliação pré-intervenção 2 (A2) .............................................................. 71

5.3 Comparação do desempenho psicolingüístico dos sujeitos do GE após o Programa de

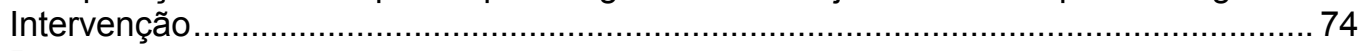

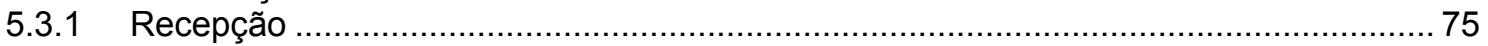

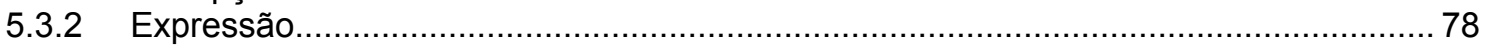

5.3.3 Memória de Curto Prazo / Subteste Memória Seqüencial Auditiva do ITPA .................. 84

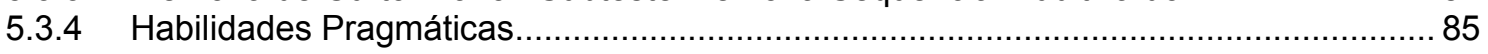

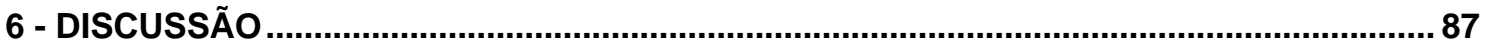

6.1 Comparação do desempenho psicolingüístico dos grupos experimental (GE) e controle

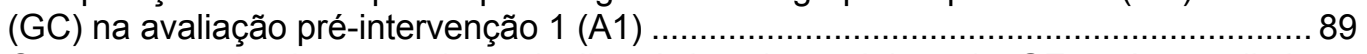

6.2 Comparação do desempenho psicolingüístico dos sujeitos do GE após os distintos Programas de intervenção ....................................................................................... 94

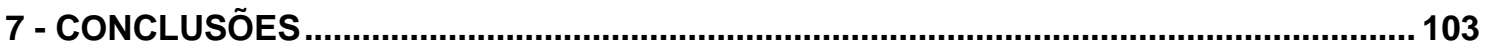

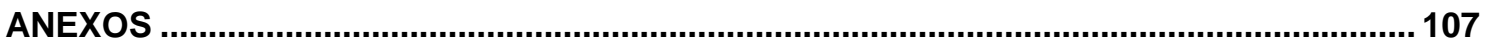

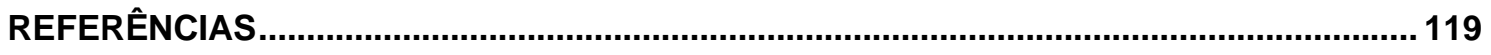

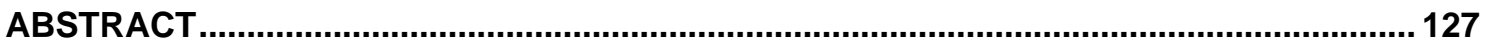




\section{LISTA DE FIGURAS}

FIGURA 1 - Comparação entre os Procedimentos de intervenção interacionais e estruturados... 15

FIGURA 2 - Esquema representativo do Modelo Neuropsicolingüístico, vertente receptiva .. 26 FIGURA 3 - Esquema representativo do Modelo Neuropsicolingüístico, vertente expressiva 27

FIGURA 4 - Fluxograma representativo da metodologia do estudo 51

FIGURA 5 - Comparação entre o procedimento semi-estruturado com ED nos subsistemas de linguagem e o procedimento estruturado com enfoque no PIL 95 


\section{LISTA DE TABELAS}

TABELA 1 - Comparação entre a média de idade dos grupos (em meses)

TABELA 2 - Caracterização do grupo controle e experimental quanto à idade cronológica e gênero.......

TABELA 3 - Comparação do desempenho dos grupos na prova de discriminação auditiva .. 62

TABELA 4 - Comparação entre os grupos na avaliação da Consciência Fonológica ......

TABELA 5 - Comparação entre Grupo Experimental e Controle na avaliação da recepção morfossintática

TABELA 6 - Comparação entre Grupo Experimental e Controle na avaliação da recepção lexical.

TABELA 7 - Comparação entre o Grupo Experimental e Controle na avaliação da compreensão semântica .

TABELA 8 - Descrição dos fonemas presentes no inventário fonético dos pré-escolares do Grupo Experimental.

TABELA 9 - Comparação entre Grupo Experimental e Controle na avaliação das praxias articulatórias e buco-faciais

TABELA 10 - Descrição dos processos fonológicos produtivos não esperados para a idade apresentados pelos sujeitos do GE......

TABELA 11 - Comparação entre Grupo Experimental e Controle na avaliação do vocabulário expressivo.

TABELA 12 - Comparação entre Grupo Experimental e Controle na avaliação da semântica (subteste Associação Auditiva do ITPA)

TABELA 13 - Comparação entre Grupo Experimental e Controle na avaliação da memória de curto termo (subteste Memória Seqüencial Auditiva do ITPA)

TABELA 14 - Comparação entre Grupo Experimental e Controle na avaliação das habilidades pragmáticas

TABELA 15 - Resultados da comparação do desempenho psicolingüístico do GE

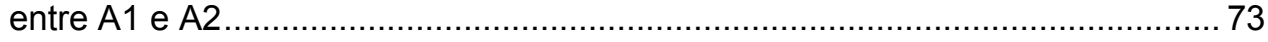

TABELA 16 - Comparação entre as duas testagens pré-intervenção na avaliação das habilidades pragmáticas.

TABELA 17 - Pontuação e desenvolvimento obtido no reconhecimento auditivo-fonético após os ciclos de intervenção

TABELA 18 - Pontuação e desenvolvimento obtido na análise fonológica, nível terciário da análise lingüística, após os ciclos de intervenção. 
TABELA 19 - Pontuação e desenvolvimento obtido na recepção morfossintática, nível terciário da análise lingüística, após os ciclos de intervenção.

TABELA 20 - Pontuação e desenvolvimento obtido na recepção lexical, nível terciário da análise lingüística, após os ciclos de intervenção

TABELA 21 - Pontuação e desenvolvimento obtido na compreensão semântica, nível terciário da análise lingüística, após os ciclos de intervenção.

TABELA 22 - Inventário fonético dos sujeitos e número de fonemas apresentados em cada testagem, nível primário da produção lingüística, nas diferentes testagens ...

TABELA 23 - Comparação do nível de desenvolvimento fonológico apresentado pelo sujeito 1 ao fim de cada ciclo de intervenção.

TABELA 24 - Comparação do nível de desenvolvimento fonológico apresentado pelo sujeito 2 ao fim de cada ciclo de intervenção.

TABELA 25 - Comparação do nível de desenvolvimento fonológico apresentado pelo sujeito 3 ao fim de cada ciclo de intervenção.

TABELA 26 - Comparação do nível de desenvolvimento fonológico apresentado pelo sujeito 4 ao fim de cada ciclo de intervenção.

TABELA 27 - Comparação do nível de desenvolvimento obtido na produção lexical ao fim de cada ciclo de intervenção

TABELA 28 - Comparação do nível de desenvolvimento obtido na associação auditiva ao fim de cada ciclo de intervenção

TABELA 29 - Comparação do nível de desenvolvimento obtido na avaliação da memória seqüencial auditiva ao fim de cada ciclo de intervenção

TABELA 30 - Comparação do nível de desenvolvimento obtido no desenvolvimento das habilidades pragmáticas ao fim de cada ciclo de intervenção 86 


\section{LISTA DE ABREVIATURAS E SÍMBOLOS}

DEL - Distúrbio Específico de Linguagem

MNPL - Modelo Neuropsicolingüístico

DTL - Desenvolvimento Típico de Linguagem

$x$ : $y$ - idade em $x$ anos : $y$ meses

$x-y-$ idade entre $x$ e $y$ anos

GC - Grupo-Controle

GE - Grupo Experimental

GE1 - Grupo Experimental 1

GE2 - Grupo Experimental 2

PIL - Intervenção com enfoque no Processamento da Informação Lingüística

ED - Intervenção com Enfoque Direto nos subsistemas de linguagem

A1 - Avaliação pré-intervenção 1

A2 - Avaliação pré-intervenção 2

A3 - Avaliação pós-intervenção 1

A4 - Avaliação pós-intervenção 2

IPL - Idade Psicolingüística

TTV - Total de Turnos Verbais

TTNV - Total de Turnos Não Verbais

ITC - Iniciou a Conversação

RMC - Respondeu ou Manteve a Conversação

UTS - Uso de Turnos Simples

UTE - Uso de Turnos Expansivos

FUN - Funções comunicativas

DP - Desvio-Padrão

p - Nível de significância

PART - Praxias Articulatórias

PLAB - Praxias de Lábios

PLIN - Praxias de Língua

PFAC - Praxias de Face

DVU - Desinência Verbal Usual

ND - Não-Designação

PS: Processo de Substituição

MSA - Memória Seqüencial Auditiva 


\section{RESUMO}

O objetivo deste estudo foi comparar o desempenho psicolingüístico de crianças com Distúrbio Específico de Linguagem (DEL) com o de crianças que apresentam desenvolvimento típico de linguagem (DTL), apontando os marcadores psicolingüísticos mais significativos do distúrbio e também comparar a eficácia de dois métodos de intervenção - Modelo de Intervenção no Meio e Modelo Neuropsicolingüístico - no desempenho psicolingüístico das crianças com DEL. Participaram desta investigação 12 pré-escolares de ambos os gêneros, com idade entre 4:0 - 6:11 anos, sendo metade deles pertencentes ao grupo experimental - crianças com DEL, submetidos à intervenção - e os demais ao grupo controle - crianças com DTL, não submetidos à intervenção. A quantificação do rendimento dos sujeitos nas distintas dimensões psicolingüísticas foi obtida mediante a utilização de diversos instrumentos, com o propósito de avaliar o nível primário, secundário e terciário da recepção e produção lingüística. Posteriormente às avaliações préintervenção, o grupo experimental foi distribuído aleatoriamente em dois grupos e submetido a dois diferentes modelos terapêuticos (primeiro ciclo), com duração de quatro meses. Ao fim deste ciclo foi reavaliado, submetido a quatro meses de terapia em que os Modelos foram alternados e os grupos novamente reavaliados. A análise estatística revelou a existência de diferença estatisticamente significante entre o desempenho do grupo experimental e controle em vários níveis de análise e produção lingüística, sendo os marcadores mais significativos encontrados os que envolvem a discriminação auditiva, análise fonológica, recepção e organização morfossintática, memória de curto prazo e habilidades pragmáticas quanto ao uso de turnos expansivos. Já a comparação da eficácia dos dois Modelos de intervenção propostos revelou que as distintas habilidades psicolingüísticas responderam de forma diferente aos mesmos, sugerindo que a combinação das estratégias dos Modelos investigados possa ser o melhor caminho quando se deseja intervir 
nos quadros de crianças cujas dificuldades encontram-se situadas nos níveis de análise e produção lingüística investigados neste trabalho.

Palavras-chave: Transtornos do desenvolvimento da linguagem. Terapia da linguagem. Distúrbio Específico de Linguagem. Testes de Linguagem. 
1 - INTRODUÇÃO 


\section{INTRODUÇÃO}

Dentre os distúrbios de linguagem, o quadro conhecido como Distúrbio Específico de Linguagem (DEL) tem despertado o interesse de muitos pesquisadores em decorrência da particularidade desse distúrbio, que se refere à grande dificuldade em desenvolver as habilidades lingüísticas na ausência de comprometimentos auditivos, motores, deficiência mental, danos neurológicos, distúrbios abrangentes do desenvolvimento, insultos cerebrais adquiridos, interação social restrita, distúrbio do comportamento e emocionais significativos.

As manifestações clínicas encontradas na esfera da linguagem são heterogêneas e mutáveis, variando segundo a gravidade de cada quadro, de modo a comprometer um ou mais subsistemas lingüísticos, bem como a compreensão. Em linhas gerais, as mais comuns são as simplificações fonológicas, freqüentemente desviantes, ou seja, não observadas no processo normal de aquisição de linguagem; vocabulário restrito, com uso demasiado de dêiticos, perífrases e gestos representativos, dificuldade em adquirir novas palavras; estruturação gramatical simplificada e pouco variada e ordenação de palavras não usual. Quando a compreensão está comprometida, observam-se dificuldades em entender sentenças ou palavras específicas como marcadores espaciais ou temporais, realização de comando lingüístico de forma incorreta, fornecimento de respostas incorretas sob questionamento e dificuldades em manter o tópico de conversação (HAGE; GUERREIRO ${ }^{27}$, 2004).

Ao contrário do que ocorre nos atrasos de linguagem, em que a defasagem observada respeita as etapas normais do desenvolvimento e reduz, progressivamente, com o tempo, com ou sem intervenção, nos casos de distúrbio as alterações são persistentes e, na maioria dos casos, com desdobramentos sobre a aprendizagem da leitura e escrita.

Ao longo dos anos, diversos trabalhos vêm apresentando hipóteses explicativas para as limitações lingüísticas dos sujeitos com DEL, sendo destacadas dentre elas, o déficit no módulo especializado na aprendizagem da 
linguagem; alteração nos mecanismos expressivos; conseqüência de alterações perceptivas auditivas; alteração dos mecanismos lingüísticos especializados no processamento da linguagem oral e o déficit de memória $\left(\mathrm{BISHOP}^{6}, 1992\right)$.

Essas hipóteses também têm gerado diversos Programas de intervenção com base em diferentes orientações teóricas sobre o processo de aquisição e desenvolvimento de linguagem.

Em linhas gerais, é nas teorias sociais e nas contribuições do condicionamento operante "skinneriano" que encontramos os aspectos procedimentais e metodológicos em que se baseia, na atualidade, a maioria dos Programas de tratamento. Esses Programas se estendem ao longo de um contínuo que oscila entre os procedimentos altamente estruturados e os procedimentos com base nos aspectos sociais e interacionais da linguagem. No extremo estruturado do contínuo, se encontram as técnicas elaboradas para ensinar os aspectos formais da linguagem seguindo um Modelo de base comportamentalista. No outro extremo, se encontram os procedimentos que facilitam o desenvolvimento da comunicação social e dirigem-se basicamente a proporcionar Modelos lingüísticos durante as interações com adultos. No centro deste contínuo, se encontram os procedimentos ditos "híbridos" que integram princípios comportamentalistas em contextos conversacionais (MENDOZA ${ }^{35}$, 2006).

Os Programas de intervenção altamente estruturados permitem ao clínico focalizar partes isoladas da linguagem, que podem ser úteis para algumas crianças que não conseguem lidar com interações complexas de forma, conteúdo e uso, assim como permitem, ao clínico, controlar o nível de dificuldades de tarefas para que a criança experimente sucesso precoce nas estruturas-alvo de linguagem. Como a imitação é a principal técnica de ensino, o ritmo de resposta é geralmente alto; porém a criança atua apenas como um respondedor às técnicas operantes. Pode-se dizer, então, que a estruturação do ambiente e dos objetivos, a passividade da criança no processo de desenvolvimento e conhecimento e a submissão aos princípios do 
condicionamento operante são as características que melhor definem esses Programas.

Já nos Programas com base nas teorias sociais (Teoria da Aprendizagem Social e Teoria Sócio-Interacionista), o foco da sessão incide na intenção do falante e no uso da linguagem durante a interação, de modo que a criança tenha uma participação ativa no processo de abstração das regras lingüísticas. As situações comunicativas do mundo real são enfatizadas, o que garante a variabilidade da estrutura das sessões. Assim, a flexibilidade ambiental, a aplicação individual e a participação ativa da criança no processo de abstração das regras são as características que melhor definem esses Programas.

A descontextualização proposta pelos praticantes da abordagem comportamentalista conduziu a resultados não aplicáveis da ação terapêutica e à desvalorização dessas técnicas de intervenção, sobretudo no que se refere às dificuldades de generalização decorrentes da implantação das condutas lingüísticas em ambientes totalmente artificiais. A partir dos anos setenta, então, os terapeutas começaram a utilizar os Programas baseados em procedimentos interacionais, como uma forma de reação àqueles mais rígidos derivados de toda a linha "behaviorista", dando início a uma forte polêmica em torno da maior ou menor eficácia de cada um deles e sobre as vantagens e inconvenientes das distintas formas de atuação. Contudo, os resultados das investigações que têm estudado as diferenças entre esses dois tipos de procedimentos de tratamento não têm conseguido ser suficientemente esclarecedores, o que levou ao delineamento de outra abordagem terapêutica, conhecida como "Modelo de Ensino sobre o Meio" ou "Intervenção no Meio", que integra algumas técnicas do "behaviorismo" em contextos comunicativos do mundo real (MENDOZA $\left.{ }^{35}, 2006\right)$.

O Modelo de Intervenção no Meio foi proposto por HART; ROGERWARREN $^{29}$, 1978 apud MENDOZA ${ }^{35}$, 2006, surgiu em decorrência da constatação da importância do papel do contexto na aquisição da linguagem, das limitações dos Programas interacionais em oferecer um guia real a respeito dos conteúdos em que se deve basear o tratamento e das limitações dos 
Procedimentos tradicionais para conseguir a generalização das aprendizagens a situações naturais contextualizadas. Desse modo, faz-se uso de Procedimentos híbridos que reconhecem algumas das técnicas comportamentalistas integradas aos Procedimentos do Interacionismo forte (Sócio-interacionismo) ou da Teoria da Aprendizagem Social. Em geral, realçam a figura do adulto como a pessoa que intervém ativamente na construção das representações mentais da criança, utilizando-se de instruções verbais, estimulação concentrada e reforços funcionais, bem como o papel da linguagem em situações de eventos rotineiros e familiares, com o propósito de obter o êxito comunicativo em contextos naturais.

Por fim, tem-se desenvolvido uma série de teorias sobre a aquisição de linguagem derivada dos Modelos de processamento da informação - como os Modelos Psicolingüísticos ou Neuropsicolingüístico - as quais dirigem-se principalmente à consideração das bases perceptivas e cognitivas subjacentes à linguagem e seu possível papel na origem do DEL (CHEVRIE-MULLER ${ }^{11}$, 2005; MENDOZA $\left.{ }^{35}, 2006\right)$. Neste contexto, a influência das intervenções que enfocam os problemas do processamento temporal, da memória de trabalho e de consciência fonológica tem recebido destaque. Esses Programas seguem uma orientação "bottom-up" que tende a modificar as bases perceptivas, cognitivas ou de integração sensorial, para possibilitar a aprendizagem da linguagem. Em teoria, consideram que, ao se eliminar a barreira que impede $o$ desenvolvimento normal da linguagem, a criança estará apta a adquiri-la com êxito e, então, mais benefícios serão obtidos em comparação aos Programas tradicionais de tratamento.

As teorias do processamento da informação também têm gerado controvérsias nos últimos anos. Tem-se apontado que, mesmo que uma criança aprenda e domine perfeitamente a execução das tarefas de processamento básico, ela não vai necessariamente melhorar as suas dificuldades lingüísticas (MENDOZA $\left.{ }^{35}, 2006\right)$. Todavia, mesmo com toda a corrente crítica, os Programas desenvolvidos, seguindo essa orientação, têm alertado os fonoaudiólogos sobre a necessidade de se investigar e tentar melhorar alguns dos fatores perceptivos e cognitivos, subjacentes à linguagem, e sobre a necessidade de integrar, em intervenção, alguns aspectos não 
considerados previamente, como o treinamento da discriminação auditiva, consciência fonológica, velocidade de processamento e memória de curto prazo.

Como pôde ser observado, a literatura destaca várias possibilidades de formas de intervenção junto ao DEL. Entretanto, a determinação do procedimento terapêutico mais adequado ainda não é um consenso, em função das manifestações lingüísticas tão heterogêneas, pelo não esclarecimento dos mecanismos neuropsicolingüísticos explicativos do distúrbio e até mesmo pela carência de estudos a respeito. Desse modo, esta dissertação vem trazer contribuições para as investigações a respeito dos processos implicados com a atividade lingüística em crianças com DEL e sobre a efetividade dos Modelos de Intervenção nestes quadros. 
2 - REVISÃO DE LITERATURA 


\section{REVISÃO DE LITERATURA}

$\mathrm{Na}$ introdução deste trabalho, foi comentado que uma boa parcela dos Programas de tratamento para as alterações de linguagem tem sustentação teórica nos princípios do condicionamento operante, tendo a imitação como a principal técnica de ensino. Por outro lado, existem Procedimentos de intervenção que se apóiam em teorias de aprendizagem social da linguagem ou em teorias fortemente interacionistas, assim como também existem os Procedimentos híbridos, situados numa posição intermediária, que integram algumas técnicas do "behaviorismo" em contextos comunicativos do mundo real. Neste contexto, serão apresentados, inicialmente, estudos que buscaram comparar a eficácia de Programas de intervenção que fizeram uso de Procedimentos estruturados, interacionais, e/ou híbridos.

\subsection{Comparação da eficácia terapêutica de Procedimentos estruturados, interacionais elou híbridos}

CONNELL $^{13}, 1987$, comparou a efetividade de duas técnicas de intervenção comumente utilizadas, modelagem e imitação, como forma de aprendizagem de morfemas inventados para dois grupos de crianças - normais e com alterações de linguagem. As 40 crianças do grupo com DEL e as 40 crianças sem DEL, apresentavam média de idades similares, variando entre 44 e 72 meses. Foram aleatoriamente distribuídas em cada um dos métodos de ensino, formando um total de quatro subgrupos, com 20 crianças cada uma. Para a realização do trabalho, cada criança passou por três sessões de 20 minutos cada uma, realizadas num período de 2 semanas. Todas foram submetidas a um pré-teste, a treinamento e a um pós-teste, quando foram analisadas as generalizações feitas pelas crianças. As duas formas de ensino apresentaram resultados distintos nos grupos sem e com alteração de linguagem. O grupo com Desenvolvimento Típico de Linguagem teve um aprendizado, significativamente, maior a partir do método de modelagem em 
contextos naturais. Já as crianças com DEL aprenderam mais com uso da imitação. Para os autores, esses achados sugerem que as crianças com distúrbio de linguagem podem aprender mais efetivamente por meio de estratégias distintas das crianças normais. Como a imitação mostrou-se mais eficiente para as crianças com DEL, os autores sugeriram o uso dessa abordagem pelos clínicos, como primeiro passo nos Programas de treinamento para o ensino das regras da língua.

FEY et al. ${ }^{21}$, 1993, compararam a efetividade da intervenção realizada por pais e por clínicos na aprendizagem gramatical de crianças com dificuldades de linguagem. Cada forma de intervenção teve duração de quatro meses e meio. Trinta crianças, com idade entre 5:8 - 5:10 (cinco anos:oito meses a cinco anos:dez meses), e com dificuldades na aquisição gramatical foram aleatoriamente distribuídas em três grupos: um que recebeu o tratamento por clínico, outro pelos pais e um terceiro que não foi submetido a nenhuma forma de intervenção. As crianças que receberam tratamento por meio do clínico receberam atendimento individual de uma hora e dois atendimentos em grupo, também com uma hora de duração. Nas duas formas de tratamento, os objetivos morfossintáticos foram selecionados e trabalhados em ciclos, por meio da estimulação concentrada. $O$ tratamento feito pelo clínico ainda contou com atividade altamente estruturada no início de cada sessão individual, que envolveu a imitação da estrutura trabalhada naquele ciclo. Todas as crianças, inclusive as que não receberam intervenção, realizaram um pré e um pós-teste. As crianças sem intervenção não apresentaram ganhos durante esse período. Ao contrário, as crianças tratadas, fossem pelo clinico, fossem pelos pais, foram beneficiadas em três das quatro medidas de expressão gramatical (exceto para uso de pronomes). Mesmo que uma diferença estatística não tenha diferençado o desenvolvimento desses grupos, os ganhos obtidos pelas crianças que receberam tratamento pelo clínico evidenciaram uma tendência de terem sido as mais beneficiadas com a intervenção.

Num outro trabalho, FEY et al. ${ }^{22}$, 1994, apresentaram os resultados de dois tipos de intervenção, com enfoque morfossintático, aplicados em crianças com distúrbio de fala e de linguagem, com o propósito de investigar a 
ocorrência de efeitos indiretos na produção fonológica delas. Vinte e seis préescolares com alteração de linguagem na produção fonológica e morfossintática, com média de idade de 55 meses, foram aleatoriamente designadas a não realizar tratamento (8 sujeitos), a participar do tratamento desenvolvido por clínicos (10 sujeitos) ou por parentes (8 sujeitos), sendo todos submetidos ao mesmo Modelo de Intervenção - terapia de ciclos com estimulação concentrada - por um período de 5 meses. $O$ tratamento realizado por clínico ainda contou com uma atividade altamente estruturada, no início de cada sessão individual, que envolveu a imitação da estrutura trabalhada naquele ciclo. As comparações pré e pós-teste demonstraram um efeito significante de ambas formas de realizar a intervenção, por clinico e por parentes, no desenvolvimento sintático dos sujeitos. Contudo, nenhum dos tipos de intervenção propiciou melhora na produção fonológica, mesmo das crianças que apresentaram um sistema fonológico menos comprometido. Sugeriu-se que os Procedimentos de intervenção desenvolvidos para crianças de 4-6 anos devem enfocar os problemas fonológicos diretamente quando se espera uma mudança significativa desse subsistema.

NELSON et al. ${ }^{40}$, 1996, compararam a efetividade de duas formas de tratamento - imitação (Modelo estruturado) e conversação (Modelo interacionista) - na aquisição sintática de sete crianças com DEL e sete com desenvolvimento normal de linguagem. As crianças com distúrbio de linguagem (idade entre 4:7-6:7 / quatro anos e sete meses a seis anos e sete meses) e as com desenvolvimento normal (idade entre 2:2-4:2 / dois anos e dois meses a quatro anos e dois meses) foram submetidas aos dois métodos de tratamento e, após isso, os resultados terapêuticos foram comparados entre os grupos. No tratamento baseado na imitação, os objetivos selecionados foram trabalhados em sessões estruturadas, enquanto no outro procedimento de intervenção as sessões foram mais interativas, em que o papel do terapeuta foi fornecer Modelos corretos sobre as estruturas sintáticas trabalhadas, sem contudo, exigir resposta das crianças. Os resultados indicaram que as crianças com DEL a as com desenvolvimento típico atingiram progressos gramaticais similares, seja sob conversação ou imitação. Contudo, para ambos grupos, a intervenção baseada na conversação promoveu resultados mais rápidos especificamente 
para as estruturas que já haviam sido parcialmente adquiridas antes da intervenção. Esses achados sugerem que as crianças com DEL podem adquirir a gramática de forma tão eficiente quanto às com desenvolvimento normal de linguagem, desde que submetidas ao "input" lingüístico relativo ao seu nível de desenvolvimento lingüístico.

KOURY ${ }^{31}$, 2005, estudou a aquisição lexical de crianças submetidas a duas abordagens diferentes de intervenção. O objetivo foi verificar qual delas promoveria maior produção e generalização lexical. Vinte e nove crianças, com idade entre 19 e 36 meses participaram da pesquisa, sendo oito diagnosticadas com DEL, duas com Transtorno Invasivo de Desenvolvimento e as demais com Atraso de Linguagem. Todas foram aleatoriamente designadas a participar de um processo de intervenção ou outro, sendo 14 submetidas à abordagem de modelagem com "bombardeio auditivo" (mod-AB) e as demais, ao Modelo terapêutico baseado na imitação induzida (MEI). A intervenção ocorreu duas vezes por semana, com duração de 50 minutos, por um período de cinco a sete semanas. Os dois Procedimentos de intervenção foram implementados em contextos interativos, entrementes para todas as crianças, algumas palavras foram selecionadas como alvo da intervenção. A análise dos resultados demonstrou que os participantes submetidos ao MEl adquiriram maior número de palavras, produziram maior número de palavras espontâneas e que, para este grupo, um maior número de palavras foi introduzido durante o tratamento, apesar da pequena significância na diferença entre os resultados dos grupos. Em relação à ocorrência de generalização, a análise estatística não indicou diferença estatística entre os participantes do MEl e do mod-AB. Ou seja, a condição de treinamento não determinou maior ocorrência de generalização. As crianças do grupo mod-AB produziram maior número de palavras no contexto de generalização do que na situação de terapia. Segundo os autores, uma possível explicação para esse achado está nas diferentes demandas pragmáticas solicitadas em cada abordagem terapêutica, que é muito maior no $\mathrm{MEI}$ comparado ao mod-AB. Concluíram os autores que, apesar de as duas abordagens terem sido bem sucedidas, no que tange a facilitar as habilidades de produção lexical das crianças, uma série de fatores deve ser 
ainda considerada para determinar qual das abordagens é, realmente, mais eficaz para o treinamento lexical.

A Figura 1 apresenta a comparação das características dos Programas de intervenção que fazem uso de Procedimentos interacionais e sociais e aqueles altamente estruturados, segundo COLE; DALE ${ }^{12}, 1986$.

\begin{tabular}{|cc|}
\hline Procedimentos interacionais e sociais & Procedimentos estruturados \\
\hline Objetivos lingüísticos individualizados & Objetivos lingüísticos pré-determinados \\
A estrutura e seqüência da instrução são & A estrutura e seqüeiseiscia da instrução \\
são pré-determinadas & \\
Enfatiza os contextos naturais & Pouca ênfase em contextos naturais \\
A criança é estimulada a iniciar a & A interação é dirigida prioritariamente \\
interação & pelo terapeuta \\
A criança participa ativamente do & A criança atua como um respondedor às \\
processo de abstração das regras & estratégias de intervenção \\
lingüísticas & O ritmo de resposta é alto \\
O ritmo de resposta é geralmente baixo &
\end{tabular}

FIGURA 1 - Comparação entre os Procedimentos de intervenção interacionais e estruturados

\subsection{Programas de intervenção com base no processamento da informação}

Se por um lado existem trabalhos que enfocam diretamente a organização dos subsistemas lingüísticos (fonologia, sintaxe, semântica e pragmática), sejam eles altamente estruturados, interacionais ou híbridos; por outro, há uma série de trabalhos que vem salientando as relações entre o desenvolvimento cerebral, $o$ desenvolvimento da linguagem e $o$ desenvolvimento das demais funções cognitivas envolvidas com esta função.

Tais relações dizem respeito aos vários processos mentais que permitem a compreensão de um enunciado e antecedem o ato de falar, mais especificamente se referem ao funcionamento de falantes reais em atividades de percepção, compreensão, memória, produção e metalinguagem (LE NORMAND $\left.{ }^{32}, 2005\right)$.

Os autores que se interessaram pelo entendimento da linguagem seguindo essa perspectiva apoiaram-se, num momento, nas teorias 
lingüísticas, e, noutro, nos métodos de análise das teorias psicológicas. Servindo-se assim, de conceitos e metodologias das duas disciplinas, a abordagem psicolingüística fundamentou-se e se desenvolveu, com o propósito de propiciar o estabelecimento de hipóteses sobre os mecanismos subjacentes ao desenvolvimento da linguagem - tanto em um funcionamento normal como num patológico - e de definir estratégias de intervenção que não sejam guiadas unicamente por uma observação de superfície (CHEVRIE-MULLER ${ }^{11}$, 2005). Com esse mesmo objetivo, diversos Modelos e metodologias de atuação diagnóstica e terapêutica vêm sendo propostos.

Para demonstrar como a estrutura do Modelo Psicolingüístico é organizada e como pode ser empregada na avaliação e elaboração dos princípios terapêuticos básicos, STACKHOUSE; WELLS ${ }^{47}$, 1993, apresentaram um estudo de caso de uma criança com distúrbio de linguagem severo e persistente, a qual apresentou um padrão complexo de déficits na cadeia de processamento da linguagem. Uma avaliação da linguagem oral, realizada entre os 5:11 anos (cinco anos e onze meses), revelou déficit no desenvolvimento lexical e gramatical aos níveis receptivo e expressivo, pobre desempenho em memória auditiva imediata, entretanto desempenho satisfatório de compreensão verbal. A análise do sistema fonológico demonstrou a ocorrência de simplificações, levantando as possíveis hipóteses sobre o nível de processamento afetado e responsável pelo padrão de linguagem apresentado. A primeira hipótese, proposta e testada, procurou correlacionar os erros fonológicos com problemas no processamento receptivo (“input”). Um problema na acuidade auditiva foi descartado; a avaliação da discriminação auditiva indicou dificuldades alusivas ao traço de sonoridade; uma prova de decisão lexical revelou que algumas das confusões fonológicas, feitas pela criança, eram reflexo da confusão nas representações das palavras.

A avaliação da consciência fonológica de rima e aliteração revelou que a criança ainda não havia desenvolvido as habilidades, em questão, e não estava apta a manipular os constituintes fonológicos das palavras com 0 propósito de produção (tarefa exige que a criança execute a segmentação da palavra apresentada, realize uma busca fonológica no seu léxico para encontrar outras palavras que compartilhem a rima e produza as palavras). A 
não-melhora na repetição de algumas palavras indicou dificuldades na recuperação da informação fonológica no léxico mental ou no nível de representação ou semelhantemente dificuldades de programação motora. De modo geral, as dificuldades da criança encontravam-se centradas em três níveis do processamento: 1). as representações mal estabelecidas em decorrência da dificuldade de discriminação auditiva justificaram o ensurdecimento de plosivas e fricativas; 2). Algumas omissões e substituições de consoantes estavam relacionadas a dificuldades na recuperação das formas fonológicas das palavras ou na programação motora; 3). Outros erros eram resultados de problemas articulatórios. A partir dessas relações, a terapia foi planejada de modo a abordar os diferentes níveis de processamento implicados: percepção auditiva, exercícios articulatórios e atividades metafonológicas. Os autores concluíram que o uso de Procedimentos de avaliação que abordam os diferentes níveis de processamento, quando bem empregados, possibilitam a compreensão da natureza dos distúrbios de fala e linguagem.

CERVERA; YGUAL ${ }^{9}$, 1994, descreveram uma metodologia para a intervenção fonoaudiológica juntos aos distúrbios fonológicos, baseada em Modelos Psicolingüísticos, justificando a escolha dessa abordagem com o argumento de que por trás de um transtorno de fala/linguagem pode existir mais de uma causa que o produza. Defenderam que o trabalho do fonoaudiólogo consiste em determinar, mediante um diagnóstico diferencial, qual é a causa da sintomatologia apresentada, quais são os fatores psicolingüísticos implicados nesses processos e desenhar um Programa de Intervenção que tente eliminar não só a sintomatologia manifestada, mas também os processos psicolingüísticos que a produzem. O Modelo Psicolingüístico utilizado propõe que a aquisição de um determinado segmento fonológico supõe a interação entre a capacidade de percepção, de produção e de atribuir-Ihe um significado dentro do código fonológico.

Respeitando a hierarquia desses processos dentro desse Modelo, sugeriram que seja avaliada a percepção auditiva, a capacidade de realizar a análise fonológica e as habilidades de produção das crianças com o intuito de determinar a origem do distúrbio. As provas e tarefas de percepção auditiva 
sugeridas consistem em apresentar estímulos contrastivos ou idênticos, que possam ser comparados na memória de curto prazo. Os autores acreditam que para a execução desse tipo de tarefa a memória de curto prazo não constitui um fator limitante, já que é solicitado à criança, unicamente, que compare os estímulos breves que podem ser repetidos caso haja necessidade. A avaliação da conceitualização fonológica baseia-se na capacidade da criança para reter um estímulo e compará-lo com outros na memória de longo prazo. Desse modo, quando trabalhada em intervenção deve-se utilizar tarefas que obriguem a criança a selecionar ou classificar os estímulos apresentados relativos a categoria fonológica dada. Obviamente, a capacidade de percepção é imprescindível para a realização correta desse tipo de atividade. No nível da produção, nos casos puramente fonológicos, os autores sugerem que o treino tenha início a partir do momento em que a criança atinja resultados positivos nos Programas anteriores. Os autores deixam claro também, a importância de se determinar em quais níveis do processamento a criança apresenta um bom rendimento, para utilizá-los como suporte do Programa de Intervenção.

WATERS; HOWKES; BURNETT ${ }^{50}$, 1998, relataram um caso de investigação e intervenção de uma criança de 5 anos, com fala ininteligível, em que o Modelo Psicolingüístico do processamento de fala foi empregado no processo de avaliação e planejamento das metas terapêuticas. A discriminação de não-palavras e palavras (igual/diferente) e julgamento de rima de não palavras apresentaram-se adequados, o julgamento correto de palavras versus não palavras e a identificação de pares mínimos a partir da apresentação auditiva, sugeriu a precisão das representações fonológicas. A boa performance em rima e aliteração indicou o surgimento da consciência a respeito da estrutura fonológica das palavras. Na avaliação do processamento, no nível expressivo, a criança demonstrou dificuldades para imitar alguns sons da fala não presentes em seu inventário fonético e também para imitar alguns movimentos articulatórios e buco-faciais. A análise dos níveis de processamento de fala, tanto receptivo quanto expressivo, revelou então, que as dificuldades fonológicas da criança eram resultantes de alterações no "output" lingüístico, mais precisamente, no planejamento e execução motora. Diante desses dados, os autores sugeriram a utilização da boa capacidade de 
processamento e análise auditiva, bem como do desenvolvimento da consciência fonológica, para alcançar a modificação do padrão motor apresentado.

HIRSCHMAN $^{30}, 2000$, numa tentativa de aprimorar as habilidades sintáticas de crianças com DEL, desenvolveu, junto a elas, um Programa de remediação metalingüística, de modo a fazê-las compreender a natureza das relações estabelecidas pelo uso de diferentes conjunções, tanto na linguagem oral quanto na escrita. Dois grupos de crianças, divididos consoante a escolaridade, com idade entre 9:4-10:6 anos (nove anos e quatro meses a dez anos e seis meses), foram submetidos a duas sessões de terapia semanais, por um período de nove meses, num total de 55 sessões (GEs). Outros dois grupos de crianças com DEL, mas que não receberam a remediação, constituíram os grupos controle (GCs). Todas foram avaliadas antes e após o desenvolvimento do Programa. Os resultados demonstraram que o uso de sentenças complexas atingiu o nível de normalidade para os GEs, aumentando significativamente nas modalidades oral e escrita, em relação aos GCs, os quais revelaram poucas mudanças ao longo do mesmo período. Além disso, as crianças dos GEs, que haviam apresentado pior desempenho gramatical, demonstraram uma tendência a se beneficiarem mais com o Programa de remediação. Os autores concluíram que o aprimoramento das habilidades metalingüísticas consiste num método eficaz para a superação das dificuldades de linguagem das crianças com DEL.

BAKER et al. ${ }^{4}, 2001$, referiram que os Modelos Psicolingüísticos de aquisição e desenvolvimento de linguagem visam explicar o modo pelo qual a criança processa a fala e a linguagem no nível cognitivo e psicológico para, assim, poder formular hipóteses sobre os componentes ou processos psicológicos que se encontram comprometidos. Relataram que os Modelos psicolingüísticos destacam três componentes chaves ou processos psicológicos envolvidos com a recepção e produção da linguagem que correspondem ao processamento das palavras no nível receptivo, o armazenamento ou a representação das palavras no léxico mental e os processos envolvidos com a sua produção. De modo simplista, enfocam a percepção, o armazenamento, o planejamento e a produção da fala/linguagem. 
Assim, para que esses Modelos sejam aplicados de forma adequada, os autores aconselham que o clínico reflita sobre três fatores: inicialmente, que selecione um Modelo para guiar o processo de avaliação e intervenção. Dentro do processo de avaliação, é imprescindível que este seja desenvolvido de uma forma detalhada, que permita a descrição dos processos diretamente envolvidos com a linguagem, assim como a interação entre eles e os processos cognitivos subjacentes. No tocante ao processo de intervenção, este deve enfocar os níveis comprometidos previamente identificados, de modo a possibilitar que a hipótese inicial sobre a natureza do déficit de linguagem seja testada. Se for observado desenvolvimento dos aspectos previamente comprometidos, sinaliza que a hipótese levantada realmente condiz com as habilidades e deficiências da criança. Caso contrário, significa que a hipótese inicial estava incorreta, que a intervenção não abordou efetivamente os aspectos comprometidos ou que o Modelo selecionado requer um maior aprimoramento.

STACKHOUSE et al. ${ }^{48}$, 2002, explicaram, em revisão de literatura, como o treino da consciência fonológica, originalmente desenvolvido para desenvolver as habilidades de leitura e escrita, propicia o desenvolvimento da fala e linguagem. Baseados no Paradigma Psicolingüístico, afirmaram que, para um Programa ser bem desenvolvido, e render bons resultados, é imprescindível que o terapeuta saiba, inicialmente, quais os níveis do processamento da informação que se encontram comprometidos para então, selecionar atividades que vão ao encontro das necessidades do paciente. Isso porque as atividades de consciência fonológica, mesmo que inseridas dentro de uma mesma categoria, requerem diferentes demandas de processamento, em diferentes níveis. Algumas atividades envolvem o processamento no nível receptivo e/ou expressivo, outras exigem que a criança acesse o léxico mental ou podem utilizar estímulos não familiares, enquanto outras exigem, inclusive, a participação da memória de trabalho e a manipulação das unidades fonológicas. Fazendo uma relação com os Modelos de Intervenção fonológica já desenvolvidos - Pares-mínimos, "Metaphon" e, até mesmo, o Modelo tradicional baseado na fonética-articulatória - os autores relataram que todos eles, de uma forma mais implícita ou explícita, envolvem o trabalho da 
consciência fonológica, porém, com enfoque em um ou outro nível do processamento da informação, o que pode não ir ao encontro das necessidades do paciente, principalmente nos casos de alterações fonológicas persistentes e desviantes. É nesse contexto que reforçam a implementação de programas de intervenção baseado em Modelos Psicolingüísticos e sugerem a implementação de estratégias individuais para o desenvolvimento das habilidades fonológicas.

GILLON $^{24}$, 2002, investigou os benefícios da intervenção com enfoque nas habilidades metafonológicas aplicada em crianças com distúrbio de linguagem, consideradas de risco para a aquisição da leitura e escrita. Vinte crianças com distúrbio de linguagem, submetidas à intervenção proposta (GE), tiveram seu desempenho em atividades de consciência fonológica comparado ao de um grupo de crianças com distúrbio, mas que receberam intervenção (GC) com enfoque na produção de fala e outras habilidades de linguagem expressiva e, ao de um grupo de crianças com Desenvolvimento Típico de Linguagem. Todas passaram por três etapas de avaliação, sendo pré e pósintervenção, além de uma avaliação de acompanhamento. Os resultados sugeriram que a remediação metafonológica estruturada levou ao desenvolvimento sustentado da consciência de fonema e reconhecimento de palavras, já que na avaliação de acompanhamento, a maioria das crianças que recebeu esse tipo de intervenção estava lendo de acordo, ou até melhor, em relação no nível esperado para a idade. O GC que recebeu outro tipo de intervenção demonstrou pouco desenvolvimento na consciência fonêmica, sendo que a maioria permaneceu com dificuldades de leitura. Com relação à produção da fala, as crianças de ambos os grupos apresentaram melhora a cada avaliação. Todavia, o GE demonstrou desenvolvimento significativamente maior. Para os autores, ensinar as crianças a segmentar palavras em fonemas e a manter a informação sobre a estrutura fonológica das palavras na memória pode auxiliá-las a formar representações fonológicas das palavras mais precisas, o que pode acarretar melhoras na produção da fala, na decodificação e codificação do material escrito.

Em um artigo de revisão de literatura, MONTGOMERY ${ }^{36}, 2003$, apresentou evidências sugestivas de que as dificuldades lexicais, 
morfossintáticas, de compreensão e de processamento da linguagem oral das crianças com DEL estão relacionadas ao funcionamento deficiente da memória de trabalho. Grande parte da literatura apresentada aponta para uma correlação positiva entre a memória de trabalho e o aprendizado/processamento da linguagem, indicando que essa habilidade realmente se encontra prejudicada nas crianças com DEL, de modo a comprometer, principalmente, a compreensão de enunciados de maior complexidade sintática. A dificuldade em controlar as funções duplas de armazenamento e processamento da informação também pode, em parte, ser responsável pela dificuldade de aquisição lexical e morfológica. Atinente ao processo terapêutico, $\mathrm{O}$ autor defende que as intervenções mais bem sucedidas são aquelas dirigidas às influências bidirecionais entre linguagemmemória, enfatizando para pré-escolares, atividades que destaquem a estrutura fonológica da língua, de modo a desenvolver as habilidades de codificação e representação fonológica e, para crianças em idade escolar e adolescentes, atividades que exijam o uso mais eficiente da memória de trabalho funcional, com a intenção de propiciar a compreensão/processamento de linguagem mais eficientes.

De acordo com CERVERA-MÉRIDA; YGUAL-FÉRNANDEZ ${ }^{10}$, 2003, o Modelo Psicolingüístico tem influenciado decisivamente, na última década, a forma de conceber, avaliar e afrontar a intervenção nas dificuldades fonológicas. O Modelo cognitivo de processamento da fala é o que tem se revelado mais útil no campo dos transtornos de linguagem, já que tenta explicar como os seres humanos processam a informação que chega aos seus sentidos - auditivo e visual - para acessar as palavras armazenadas em seu léxico e usar as representações mentais que codificam as informações em vários níveis. O Modelo assume que a informação sensorial ativa representações mentais armazenadas, previamente, na memória, em níveis de progressiva complexidade, para acessar o significado das palavras conhecidas. Assim, quando conhecemos quais os níveis implicados, podemos compreender e avaliar em que nível o sujeito apresenta dificuldade.

Considerando o esquema psicolingüístico, o autor propôs um Programa de Intervenção para a recepção, dois Programas centrais de 
organização e consciência fonológica e três Programas periféricos, para as dificuldades de expressão, os quais se devem combinar em cada caso, em função da semiologia e dos níveis de processamento afetados. Os Programas para treinamento da percepção auditiva buscam estimular a capacidade da criança para focalizar a atenção aos estímulos sonoros adequados. A eficácia desses Programas pode ser notável quando acompanhados de outros Programas que incidem em outros aspectos da organização fonológica e da produção. O Programa de organização fonológica representa o núcleo da intervenção. Trata-se de melhorar a capacidade global da criança para organizar as seqüências fonológicas ao formar palavras. No que tange aos programas metafonológicos, o autor sugere iniciar a contar do desenvolvimento da consciência silábica até os 6 anos e por Programas de desenvolvimento da consciência fonêmica para crianças em idade escolar. Os Programas periféricos para a expressão envolvem o domínio psicomotor articulatório, a implantação de fonemas e a terapia miofuncional.

PASCOE; STACKHOUSE; WELLS ${ }^{42}, 2005$, apresentaram um caso de uma criança de 6,5 anos, com alterações severas de linguagem, submetida à intervenção fonoaudiológica baseada no Modelo Psicolingüístico. Na avaliação pré-intervenção ela apresentou dificuldades no processamento lingüístico tanto no nível receptivo como expressivo (discriminação auditiva de palavras e pseudopalavras, nomeação de figuras, manipulação fonológica, repetição de pseudopalavras, em algumas atividades oromotoras e no planejamento motor). Ao fim da intervenção, que enfocou a produção da fala com o intuito de melhorar o processamento no nível receptivo, apresentou melhora na produção de palavras isoladas, na fala encadeada e na discriminação auditiva de palavras. Os autores concluíram que, quando bem definida, a terapia de fala e linguagem pode ter efeitos positivos para crianças com alterações persistentes.

CHEVRIE-MULLER ${ }^{11}, 2005$ fez referência a um Modelo Neuropsicolingüístico (MNPL), que contempla o funcionamento neurolingüístico associado aos processos psicológicos de compreensão e expressão da linguagem oral. Esse Modelo está organizado segundo dois eixos verticais, correspondentes às vertentes da recepção (compreensão) e da realização 
(expressão); e horizontalmente estão organizados os três níveis de tratamento lingüístico.

O nível primário ou sensório-motor corresponde à entrada e saída da informação verbal, mais especificamente, na vertente receptiva corresponde ao processamento da informação auditiva que ocorre da orelha interna ao córtex auditivo primário e na vertente da produção, corresponde ao processo de articulação (do córtex motor aos músculos envolvidos com fala). O nível secundário consiste da integração gnósica e práxica, que corresponde às zonas de associação ou córtex associativo secundário. O nível terciário é o nível das operações cognitivas lingüísticas ou do funcionamento da linguagem que, de um ponto de vista anátomo-funcional, corresponde ao córtex associativo terciário. $\mathrm{Na}$ vertente receptiva, a consulta ao léxico-fonológico permite o reconhecimento dos sons característicos de cada idioma, identificando os fonemas que compõe as palavras. Ocorre então a identificação léxica e, posteriormente, ainda é preciso consultar os léxicos sintático e semântico para que a compreensão se estabeleça. A produção da fala começa com a fase de conceitualização, quando planejamos o conteúdo da mensagem e acontece uma busca ao léxico semântico, para encontrarmos os conceitos apropriados que desejamos veicular. Segue-se então uma segunda etapa, denominada de formulação, que corresponde à busca dos fonemas, palavras e regras sintáticas apropriadas ao conteúdo que desejamos expressar. Na figura 2 e figura 3 encontra-se representado o MNPL proposto por CHEVRIEMULLER ${ }^{11}$, 2005, considerando as vertentes receptiva e expressiva, respectivamente.

A representação do Modelo no nível terciário é complexa. $\mathrm{Na}$ verdade, não se pode conceber o processo de maneira puramente hierárquica e linear de um módulo ou unidades de tratamento. Segundo o autor, os trabalhos experimentais em psicolingüística confirmam a hipótese, no que tange à compreensão da linguagem, de um funcionamento em paralelo em vários níveis, com as unidades de tratamento trabalhando de maneira encaixada e não independente, que permitem a representação em termos de esquema por setas bidirecionais. Quando se trata da vertente expressão, 
processos mais simples podem ser postulados com a utilização de setas unidirecionais.

Segundo o mesmo autor, quer se trate de distúrbios do desenvolvimento quer de distúrbios adquiridos da linguagem, o clínico deve prestar atenção à disposição vertical do Modelo e à hierarquização dos níveis. Efetivamente, os déficits dos níveis mais periféricos condicionam amplamente o desenvolvimento e/ou o funcionamento dos níveis mais centrais. Assim, as conseqüências de um déficit auditivo sobre a compreensão (e, evidentemente, sobre a expressão) são bem conhecidas, mas o prejuízo do nível gnósico (integração/percepção-auditiva), com uma audição intacta, terá conseqüências análogas sobre a decodificação da mensagem e não permitirá que o nível terciário do processamento ocorra adequadamente. Na vertente da expressão, um distúrbio importante da motricidade, no nível primário, pode impedir qualquer expressão inteligível, mas o dano no nível práxico constituirá também uma incapacidade para a expressão. 


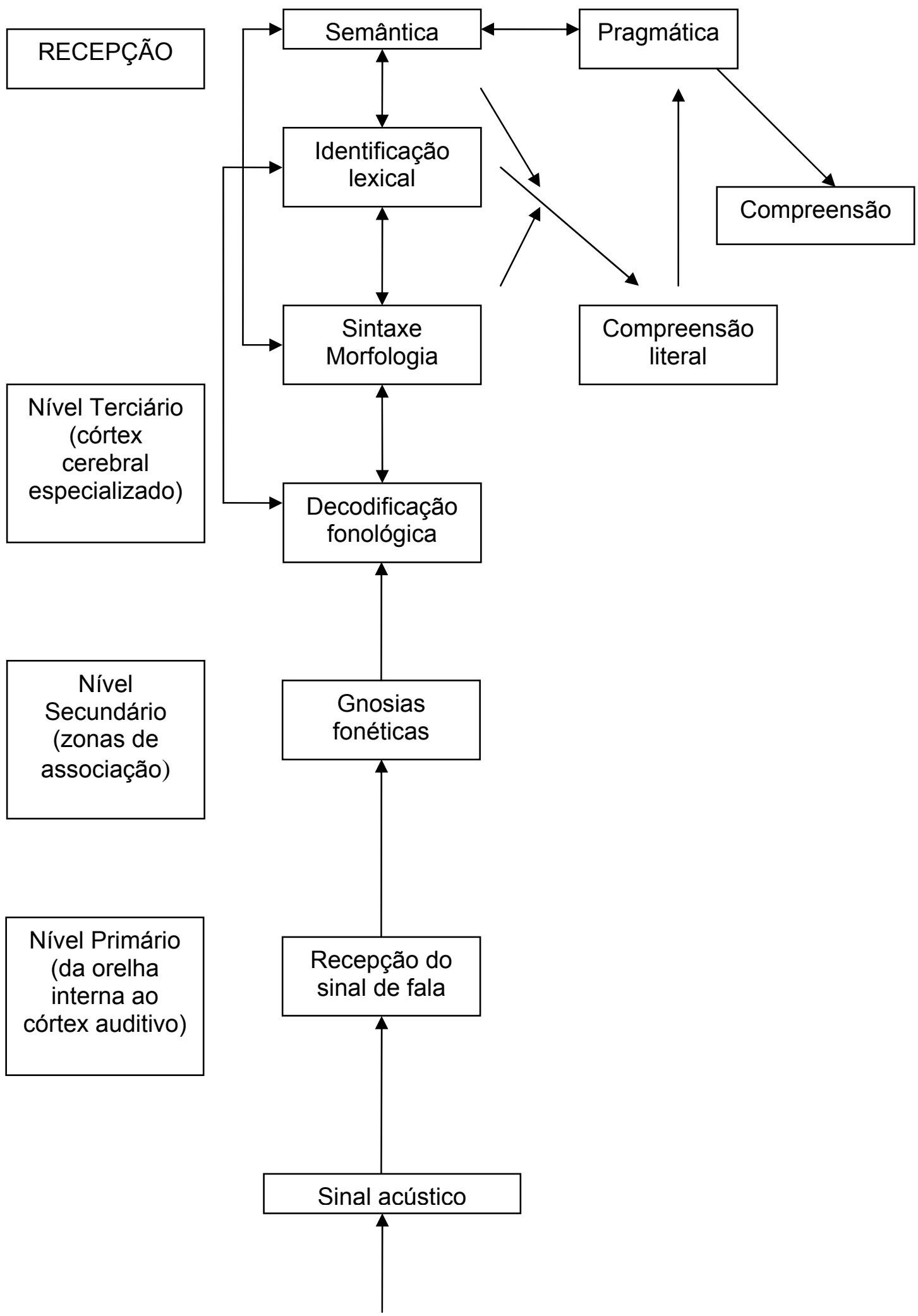

FIGURA 2 -Esquema representativo do Modelo Neuropsicolingüístico, vertente receptiva 


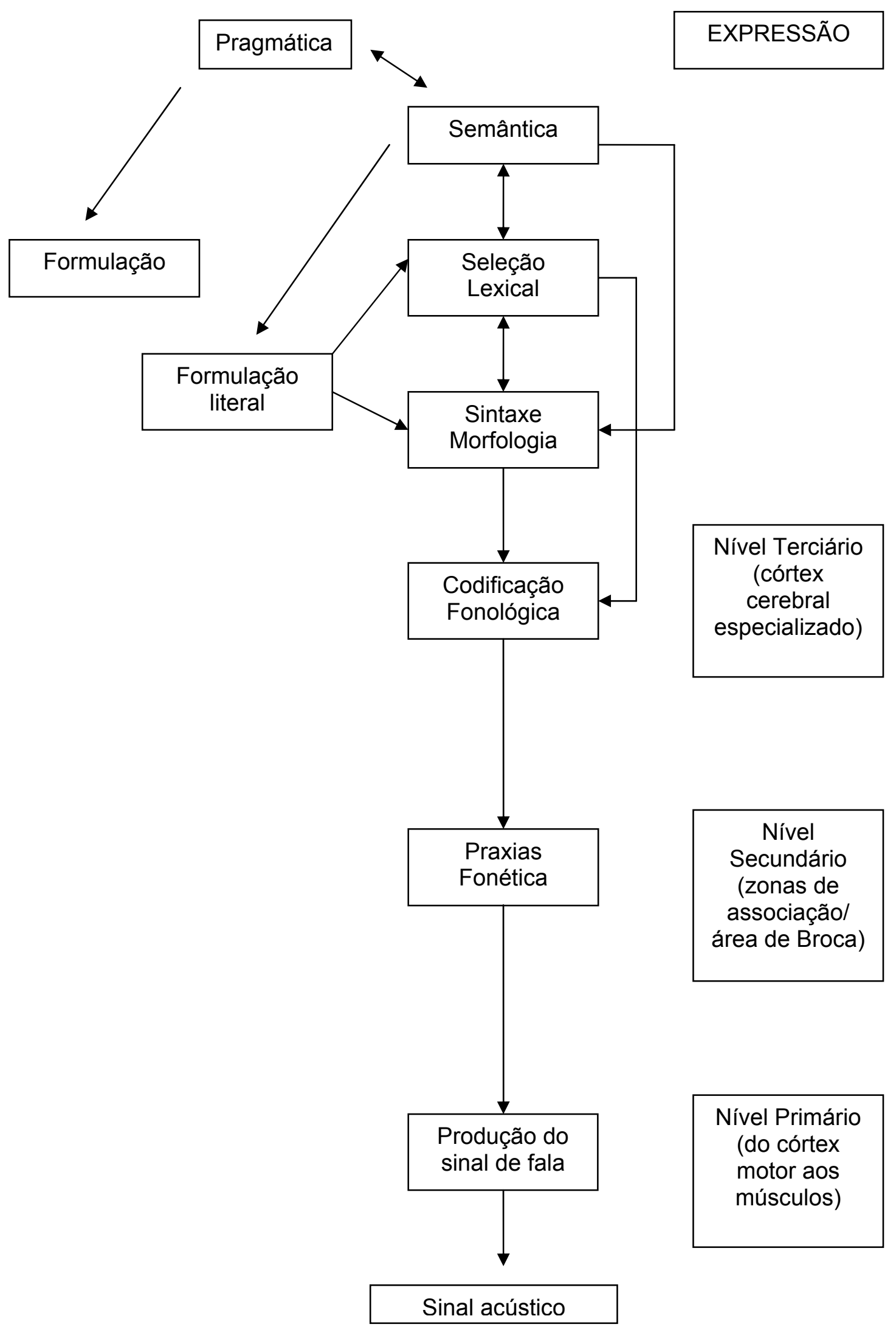

FIGURA 3 -Esquema representativo do Modelo Neuropsicolingüístico, vertente expressiva 


\subsection{Marcadores Psicolingüísticos do DEL}

Os estudos sobre os mecanismos subjacentes ao desenvolvimento da linguagem, tanto no que tange ao funcionamento normal, como ao patológico, levou não só ao desenvolvimento de estratégias de intervenção voltadas para estes mecanismos, mas também, à verificação da existência de marcadores psicolingüísticos responsáveis pelos déficits lingüísticos. Nesta linha de raciocínio diversos trabalhos vêm sendo desenvolvidos.

O interesse pelo estudo dos mecanismos subjacentes ao DEL levou CONTI-RAMSDEN; BOTTING; FARAGHER ${ }^{14}$, 2001, a estudar a possibilidade de algumas tarefas constituírem marcadores do distúrbio, ou seja, serem eficientes na identificação de indivíduos com o distúrbio. Foram avaliadas 160 crianças, com 11 anos de idade e com histórico de DEL e, 100 crianças com Desenvolvimento Típico de Linguagem. Todas realizaram quatro tarefas consideradas potentes marcadores do distúrbio: repetição de pseudopalavras, uso de verbos no passado, repetição de sentenças e uso de terceira pessoa do singular. A análise da sensibilidade e especificidade de tarefa revelou que elas variaram em precisão, sendo a repetição de sentenças o marcador mais eficaz, com um alto nível de sensibilidade (90\%), sensitividade (85\%) e precisão total (85\%), sendo capaz de identificar a maioria das crianças com histórico de DEL. Com relação à combinação de marcadores para a identificação do distúrbio, o aumento da sensibilidade, especificidade e precisão foi obtido pela associação entre repetição de pseudopalavras ou sentenças, sugerindo que as tarefas que envolvem a memória de curto prazo constituem os melhores marcadores do DEL.

Com o intento de estudar os marcadores do DEL, CONTIRAMSDEN $^{15}, 2003$, aplicou duas tarefas lingüísticas (uso de verbo no passado e plural) e duas tarefas de processamento (repetição de pseudopalavras e dígitos) em 32 crianças com DEL (média de idade de 5:1 / cinco anos e um mês) e 32 com desenvolvimento normal de linguagem (média de idade de 4:9 / quatro anos e nove meses). As crianças com DEL tiveram desempenho significativamente abaixo do que as demais em todas as tarefas realizadas. A 
análise individual da sensitividade e da especificidade de cada tarefa revelou que a repetição de pseudopalavras e o uso de verbos no passado foram as atividades mais precisas na identificação das crianças com DEL.

CRESPO-EGUÍLAZ; NARBONA ${ }^{16}$, 2003, estudaram as características clínicas e evolutivas dos diferentes subtipos de DEL. Numa amostra de 42 crianças com a patologia, avaliaram a linguagem em diferentes momentos evolutivos. No nível receptivo de processamento, foram avaliados a discriminação fonológica, closura auditiva, vocabulário receptivo e compreensão sintática. Já no nível expressivo, foram avaliados as praxias articulatórias e buco-faciais, articulação de palavras e logotomas, fonologia, vocabulário e sintaxe. Os seguintes aspectos funcionais foram analisados: fluência verbal, expressão verbal e associação auditiva. Seguindo o diagnóstico clínico inicial, cada sujeito foi incluso num dos subtipos de DEL e, a partir das médias e pontuações de todos os integrantes dos grupos, em todas e em cada uma das dimensões avaliadas, foi elaborado um perfil psicolingüístico grupal. 0 subtipo fonológico-sintático foi o mais comum, caracterizado por dificuldades de discriminação auditiva; de compreensão sintática (mais grave à medida que as estruturas sintáticas tornam-se mais complexas); dificuldades fonológicas mais severas na vertente expressiva e no vocabulário expressivo. As crianças da amostra apresentaram características psicolingüísticas que variaram seu curso evolutivo. Assim, em um momento dado, seu perfil clínico correspondeu a um grupo diagnóstico e posteriormente, a outro. Segundo os autores, apesar dos perfis clínicos de cada uma das variantes da patologia, esta categoria não deve ser utilizada de maneira rígida. É necessário um diagnóstico flexível que facilite a intervenção centrada na sintomatologia da criança em cada momento evolutivo.

Tendo em vista a heterogeneidade de características e teorias explicativas vinculadas ao DEL, NAVARRETE et al. $^{39}$, 2004, realizaram um estudo empírico com um grupo de crianças espanholas com o distúrbio, de modo a determinar os principais indicadores psicolingüísticos que o caracterizam. Vinte e sete procedimentos foram aplicados em 82 crianças, metade com DEL e metade com Desenvolvimento Típico de Linguagem, com idade entre 5-12 anos. Os Procedimentos foram agrupados em seis blocos, os 
quais enfocaram a memória verbal, fonologia (discriminação auditiva, consciência fonológica, decisão lexical, repetição de palavras e pseudopalavras, registro fonológico, diadococinesia verbal), morfologia (closura gramatical), sintaxe (extensão média de orações, elaboração de sentenças, compreensão de sentenças), semântica (correspondência figura-palavra, sinônimos, associação semântica, identificação de absurdos, linguagem figurada, denominação de figuras, uso de palavras funcionais, definição) e pragmática (narração e linguagem contextual). As crianças com DEL tiveram desempenho significativamente aquém em 25 dos testes avaliados, o que não ocorreu somente para a tarefa de correspondência figura-palavra (acesso ao léxico) e registro fonológico. Com esses resultados, concluíram que a combinação dos marcadores representa uma ferramenta diagnóstica eficaz para diferenciar as crianças com o distúrbio.

ORTIZ; TIRAPEGUI ${ }^{41}$, 2004, estudaram algumas habilidades metafonológicas básicas em pré-escolares com DEL expressivo, com déficits fonológico e sintático, a fim de identificar as dificuldades específicas que essas crianças podem apresentar no desenvolvimento da consciência fonológica. $O$ grupo experimental (GE), composto por 26 crianças com DEL, com média de idade de 4:7 anos (quatro anos e sete meses), teve o seu desempenho, em tarefas relacionadas à rima, sílabas e fonemas, comparado ao de um grupo de crianças normais (grupo controle / GC), com média de idade de 4:8 anos (quatro anos e oito meses). Os resultados mostraram que o GE teve uma performance defasada em relação ao GC, sendo essa diferença evidenciada em tarefas nas quais a unidade constituinte era a sílaba. Nas tarefas que envolviam fonemas o rendimento de ambos os grupos foi semelhante. Os autores consideraram de fundamental importância inserir, nos Programas de intervenção fonoaudiológica, a avaliação e estimulação dessas habilidades, não só para possibilitar a superação das dificuldades na consciência fonológica, mas também para preparar para a aprendizagem da leitura e escrita.

MUÑOZ-LÓPEZ; CARBALLO-GARCIA ${ }^{38}$, 2005, em artigo de revisão de literatura, apresentaram as principais alterações lingüísticas dos quadros de DEL fazendo uma relação entre as diferentes dimensões da linguagem e 
determinados aspectos psicolingüísticos. As alterações fonológicas, morfossintáticas e lexicais foram relacionadas às dificuldades de discriminação auditiva, dificuldades em habilidades metalingüísticas, dificuldades em estabelecer as representações fonológicas das palavras, e déficit na memória de trabalho. Apresentaram evidências sugestivas de que o desenvolvimento da morfologia verbal guarda relação com a aquisição lexical e de que no nível lexical existem dificuldades para aprender novas palavras de modo incidental, problemas para armazenar na memória de curto prazo as formas fonológicas de palavras novas e para criar e armazenar representações lexicais elaboradas, assim como dificuldades de processamento auditivo. Concluíram que as habilidades lingüísticas das crianças não podem ser consideradas como sistemas autônomos, na medida em que todos os níveis da linguagem encontram-se inter-relacionados.

Um experimento realizado por MONTGOMERY ${ }^{37}, 2006$, investigou se a lentidão para processar a informação presente em crianças com DEL ocorre em decorrência da limitação no processamento acústico-fonético, de uma limitação no processamento lingüístico ou ambos. Para tanto, ele avaliou o tempo utilizado por crianças para desempenhar duas tarefas de processamento lexical, sendo que uma delas envolveu o processamento de palavras isoladas e a outra, o processamento de palavras em frases. Dezesseis escolares com DEL (média de idade de 8:7anos) e 32 escolares com desenvolvimento normal realizaram as duas tarefas. As crianças com desenvolvimento normal foram divididas em dois grupos e pareadas ao grupo DEL, conforme a idade cronológica (grupo idade-controle) e conhecimento sintático (grupo Sintaxecontrole). Assim, a média de idade dos demais grupos foi de 8:4 anos e 6:6 anos, respectivamente. Para a determinação das tarefas utilizadas, o autor supôs que se a limitação ocorresse em função do processamento acústicofonético, seria esperado um maior tempo de processamento para as tarefas de palavras isoladas. Caso o processamento lingüístico fosse o responsável pelo processamento lento, seria esperado, em relação aos grupos controle, um tempo de processamento semelhante para as palavras isoladas, porém, inferior para as sentenças. Se a limitação ocorresse em função da limitação associada acústico-fonética/lingüística, o grupo experimental deveria se desempenhar de 
modo pior em ambas as tarefas. O grupo de crianças com DEL e o grupo idade-controle apresentaram tempos de processamento comparáveis na atividade de processamento lexical isolado, e ambos os grupos foram mais rápidos que o grupo sintaxe-controle. Contudo o grupo DEL foi mais lento que os demais para realizar o processamento lexical em sentenças. Desse modo, a lentidão apresentada pelas crianças com DEL para processar a informação parece estar relacionada a um nível mais alto de processamento. Ou seja, não se encontra vinculado a uma dificuldade em converter o sinal acústico numa representação armazenada no léxico mental, mas sim, a atividades em que é necessário realizar o processamento em outros níveis simultaneamente, como a identificação léxica, compreensão sintática e semântica.

ARCHIBALD; GATHERCOLE ${ }^{3}, 2006$, investigaram a performance de 20 escolares com DEL misto, com idade entre 7-11 anos (sete e onze anos), em testes padronizados de memória auditiva de curto prazo, memória de trabalho, memória vísuo-espacial e consciência fonológica. A maior parte das crianças apresentou deficiências em memória auditiva de curto prazo (70\%) e memória de trabalho (95\%), enquanto o comprometimento na consciência fonológica e memória vísuo-espacial esteve presente na minoria das crianças (menos que 50\%). Segundo os autores, a limitação na memória de curto prazo, neste caso, seria responsável pelo comprometimento em aprender a forma fonológica das palavras, prejudicando o aprendizado de palavras novas, já que esse tipo de memória trabalha como um mediador para a construção das representações fonológicas permanentes na memória de longo prazo. Já a limitação na capacidade da memória de trabalho resultaria em quebras dentro e entre os diferentes domínios lingüísticos, de modo a aumentar a demanda necessária para o processamento semântico e sintático, resultando em erros nesses e outros domínios. Atribuíram a performance em consciência fonológica ao fato de as crianças estarem em fase escolar e inseridas em Programas de intervenção, que, provavelmente, propiciaram um treinamento específico de tais habilidades, garantindo o desenvolvimento delas. O desempenho em memória vísuo-espacial, para os autores, confirma a natureza específica das alterações manifestadas pelo grupo. Baseado nesses resultados, os autores confirmaram a necessidade de inserir, nos Programas de intervenção, métodos 
que minimizem as conseqüências adversas da limitação da memória de trabalho.

AGUADO et al. ${ }^{1}, 2006$, analisaram se a repetição de pseudopalavras (RPP) constitui uma tarefa que diferencia bem as crianças com DEL falantes do espanhol em relação às crianças com Desenvolvimento Típico de Linguagem e crianças com distúrbio articulatório e se as características silábicas e fonológicas do espanhol são compatíveis com a explicação do DEL baseada na limitação do processamento temporal. Dezoito crianças com desenvolvimento típico, 19 com DEL do subtipo fonológico-sintático e 19 com distúrbio articulatório, com idade entre 5-6 anos, realizaram tarefas de RPP, memória numérica direta e inversa, repetição de palavras e frases, memória de relato e vocabulário receptivo. Com exceção da memória de relatos e do desempenho em prova de vocabulário receptivo, todas as demais tarefas foram significativas na diferenciação entre os grupos, sendo a RPP a tarefa que melhor diferençou as crianças com DEL. Todos os grupos de crianças apresentaram melhores resultados na RPP formadas por sílabas freqüentes em comparação às não freqüentes, sendo essa diferença menor, à medida que a extensão das pseudopalavras aumentava (ou seja, com o aumento da extensão o desempenho para pseudopalavras com sílabas freqüentes piorou). Esses resultados sugerem, primeiramente, que o déficit da memória das crianças com DEL não se encontra relacionado somente ao material puramente fonológico, uma vez que a repetição de palavras e frases - uma tarefa em que é possível reter o material verbal utilizando informação léxico-semântica - também constituiu um diferencial entre os grupos. Indicam também que a maior quantidade de informação repercute mais que a familiaridade dessa informação na qualidade da memória de trabalho. Por último, sugerem que as crianças falantes do espanhol manejam representações fonológicas baseando-se em sílabas mais que em fonemas, o que não tornou possível aplicar a explicação do déficit no processamento temporal a elas. 


\subsection{Comparação da eficácia da intervenção baseada em Modelos tradicionais e Modelos com base no processamento da informação lingüística}

Como foi salientado na introdução, os Modelos de Intervenção com base no processamento da informação, também têm gerado controvérsias e levado diversos pesquisadores a desenvolverem trabalhos que comparem a eficácia desse tipo de intervenção com os Modelos tradicionais, que enfocam diretamente um ou vários subsistemas lingüísticos, seja com estratégias comportamentalistas, fortemente interacionistas ou intermediárias entre elas. A seguir encontram-se descritos alguns destes estudos.

MAJOR; BERNHARDT ${ }^{34}, 1998$, estudaram as relações entre habilidades fonológicas e metafonológicas de crianças com distúrbio fonológico moderado e severo, bem como os efeitos da intervenção fonológica no desenvolvimento metafonológico delas. Dezenove crianças, com idade entre 35 anos (três e cinco anos) realizaram atividades de produção de aliteração e rima, segmentação de frases e palavras monossilábicas e dissílabas antes da intervenção (T1), depois da intervenção fonológica (T2) e depois da intervenção fonológica associada à metafonológica (T3). Na avaliação préintervenção, as crianças com o sistema fonológico menos prejudicado tiveram melhor desempenho metafonológico. As habilidades metafonológicas também se relacionaram ao desempenho no nível sintático. A comparação do desempenho fonológico e metafonológico entre T1 - T2 e T2 - T3 revelou que ambos os tipos de intervenção resultaram num aumento significativo do desempenho metafonológico das crianças. Contudo, após a intervenção fonológica, muitas crianças demonstraram dificuldades metafonológicas, sugerindo que, mesmo que a intervenção fonológica seja eficaz, um treino metafonológico específico ainda é necessário para desenvolver as habilidades de algumas crianças. Os resultados também apontaram uma correlação entre o desenvolvimento fonológico e morfossintático das crianças, uma vez que as com desordem fonológica mais severa associada ao comprometimento sintático desenvolveram menos suas habilidades, possivelmente por apresentarem recursos limitados de aprendizagem. 
DODD; BRADFORD ${ }^{19}, 2000$, compararam os efeitos de três diferentes Programas de remediação fonoaudiológica na produção de fala de crianças com desordens fonológicas de naturezas distintas: terapia com enfoque nos contrastes fonológicos (metafonológica); com enfoque no vocabulário funcional e com enfoque na produção articulatória (PROMPT). Os três métodos foram testados em três crianças. Após a avaliação prétratamento, deu-se início ao tratamento 1. Três semanas após o fim deste, iniciou-se o tratamento $2 \mathrm{e}$, após o mesmo intervalo, o tratamento 3 teve início. Cada etapa consistiu-se de 12 sessões individuais de meia hora, realizadas num período de 6 semanas. Ao fim de todo o tratamento, foi possível observar melhora na precisão e inteligibilidade da fala encadeada das crianças. A intervenção com enfoque nos contrastes fonológicos foi mais eficiente para a criança que apresentava processos fonológicos desviantes consistentes, confirmando a hipótese de que as crianças que apresentam esse padrão fonológico possuem um déficit cognitivo-lingüístico para abstrair as regras fonológicas da língua. A criança que apresentava produções inconsistentes beneficiou-se da terapia que fez uso do vocabulário funcional, a qual enfocou a produção consistente de determinadas palavras para minimizar o déficit no planejamento fonológico. Para o terceiro caso, que também apresentava produções inconsistentes, tanto a terapia baseada nos contrastes fonológicos quanto aquela baseada no vocabulário funcional foram eficientes, o que deve ter ocorrido em decorrência de fatores individuais. Como nenhuma criança manifestou desordem motora, era esperado que o método PROMPT não surtisse efeitos em nenhum dos casos. Os resultados dessa investigação indicaram que diferentes níveis do processamento da fala podem responder de modo diferente a vários tipos de tratamento com diferentes enfoques.

GILLON $^{23}, 2000$, investigou os efeitos da intervenção baseada na consciência fonológica (CF), em crianças com DEL, no desempenho da leitura e da linguagem oral. Um total de 91 crianças, com idades entre 5:6 a 7:6 (cinco anos e seis meses a sete anos e seis meses), foram distribuídas em dois grupos, sendo um composto por 61 crianças com DEL e outro por 30 crianças com desenvolvimento normal de linguagem (DNL). As crianças com DEL foram distribuídas em três grupos, a serem submetidos a diferentes formas de 
intervenção: 1). Grupo: composto de 23 crianças sujeitas à intervenção baseada na CF e promoção do discurso, com duas sessões individuais de 1 hora por semana, até completar um total de 20 horas de intervenção; 2). Grupo 2: 23 crianças submetidas à intervenção tradicional, com enfoque na promoção do discurso, mais especificamente aos déficits fonológicos, mediante os resultados de avaliação, com total de 20 horas, sendo 1 hora/semana; 3). Grupo 3: 15 crianças que receberam controle mínimo de tratamento, em que o clínico realizou orientações aos pais e professores visando melhorar as habilidades lingüísticas. O Grupo 4, composto de crianças com DNL, foi submetido às atividades escolares normais.

Os resultados do Programa no desenvolvimento das habilidades fonológicas demonstraram que as crianças do grupo 1 alcançaram significativas melhoras na consciência no nível de fonema em comparação às crianças do grupo 2 e 3, obtendo, inclusive, consciência fonêmica similar à do grupo com DNL. Também apresentaram melhores resultados que os demais grupos na decodificação de palavras (evidenciado na leitura de palavras e nãopalavras), leitura e compreensão de texto. A intervenção baseada na CF também melhorou a produção do discurso quanto aos aspectos fonéticofonológico. Esses dados indicaram que a intervenção fonológica integrada pode ter um efeito significativo no desenvolvimento da consciência fonêmica, produção do discurso, leitura e compreensão de texto das crianças com DEL, sendo o tipo de intervenção que teria melhores benefícios para 0 desenvolvimento de leitura das crianças. Além disso, os resultados sugerem que, apesar de serem consideradas de risco para a alfabetização, as crianças com DEL têm potencial para obter ganhos no desenvolvimento das habilidades básicas para a aquisição da leitura e escrita, indicando que a presença de dificuldades fonológicas expressivas não restringe o acesso de uma criança aos benefícios da intervenção baseada na CF. O autor também alerta para o fato de que, embora a intervenção baseada na CF seja importante para capacitá-las na aquisição da leitura, a intervenção também deve enfocar as dificuldades lingüísticas apresentadas no nível sintático, semântico, pragmático. 
Com o propósito de investigar a importância do treino auditivo (identificação de sons produzidos correta ou incorretamente) na intervenção fonológica, WOLFE; PRESLEY; MESARIS ${ }^{52}$, 2003, compararam o desenvolvimento obtido no sistema fonológico de pré-escolares submetidos a duas formas diferentes de tratamento. Também investigaram se a habilidade de identificação sonora prévia interferiria nos resultados obtidos com a intervenção. Nove pré-escolares, com distúrbio fonológico severo e idade entre 41-50 meses, foram distribuídos aleatoriamente, de modo a participar de terapia com enfoque somente na produção fonológica ou com enfoque na produção e no treino auditivo. Todos os participantes realizaram duas sessões individuais semanais de 30 minutos cada, somando um total de 41 sessões e, para cada um deles foram selecionados 3 fonemas-alvo a serem trabalhados. Para verificar a efetividade do tratamento, os pré-escolares executaram duas avaliações de fala/linguagem e da habilidade de identificação sonora, sendo uma pré e outra pós-tratamento. Não foi encontrada diferença nos resultados de fala/linguagem dos grupos após intervenção, exceto para os fonemas cuja taxa de identificação havia sido baixa antes do tratamento, os quais responderam melhor quando a remediação foi combinada. Todos os sujeitos submetidos ao treino auditivo apresentaram significativos resultados na tarefa de identificação sonora no pós-teste, o que não aconteceu com todo o grupo, que trabalhou apenas a produção, mas só com alguns sujeitos. Esses dados sugerem que a habilidade de perceber sons produzidos incorretamente antes do tratamento afeta o grau de desenvolvimento fonológico de sujeitos que realizam intervenção com enfoque apenas na produção e que esse treino isolado também possibilita a melhora da capacidade de percepção. Concluíram então, que a avaliação perceptiva realizada previamente constitui um procedimento útil na determinação do modo de tratamento mais efetivo.

SEGERS; VERHOEVEN ${ }^{45}$, 2004, realizaram um estudo com a finalidade de verificar se crianças holandesas com DEL desenvolveriam suas habilidades de consciência fonológica (CF) usando um Programa de computador e se a manipulação do discurso, como parte da instrução da CF, produziria aprendizagem adicional dessas habilidades. Participaram do estudo 36 crianças, sendo 31 meninos e 5 meninas, com média de idade no início do 
estudo de 5:9 anos (cinco anos e nove meses). Para verificar a eficácia da intervenção terapêutica, todos os participantes foram submetidos a três testes, realizadas em diferentes momentos: pré-teste, antes do início da intervenção; pós-teste 1, imediatamente após a intervenção; pós-teste 2, realizado 18 semanas após o término do processo terapêutico, sendo aplicados cinco testes de CF (consciência de palavras, síntese silábica, consciência de rima, análise e síntese fonêmica). As crianças foram divididas em três grupos de 12 e combinadas entre os grupos, de acordo com a idade cronológica, pontuação nas habilidades não verbais e nas habilidades metafonológicas. Assim, o grupo experimental 1 (GE1) recebeu intervenção baseada na consciência fonológica, sem manipulação do discurso; o grupo experimental 2 (GE2) foi submetido à intervenção baseada na consciência fonológica, entrementes com a manipulação do discurso e o grupo experimental (GE3) recebeu intervenção com enfoque no aspecto lexical. Os achados do estudo mostraram que as crianças com DEL se beneficiaram de um a intervenção fonológica intensiva com uso de um Programa de computador e que, a manipulação do discurso não promoveu ganho adicional na intervenção.

RVACHEW; NOWAK; CLOUTER ${ }^{44}$, 2004, investigaram os benefícios do treino perceptivo no tratamento do distúrbio fonológico. Trinta e quatro crianças, com distúrbio fonológico moderado ou severo, algumas com grave comprometimento morfossintático, com idade entre 41 a 59 meses, foram distribuídas, aleatoriamente, em um GE e noutro GC. Associado à terapia fonológica, o GE recebeu 16 sessões de treinamento perceptivo - que enfocou a percepção fonêmica - enquanto o GC trabalhou com histórias. Após o período de tratamento (que teve duração de 6 meses) nenhum dos grupos apresentou ganhos significativos na morfossintaxe. Apesar de o GEter apresentado desempenho significativamente melhor do que o GC na avaliação da percepção fonêmica (identificação de palavras pronunciadas de forma correta ou não) e na porcentagem de consoantes corretas emitidas em palavras isoladas e fala encadeada, ambos os grupos desenvolveram, na mesma proporção, as habilidades metafonológicas (rima e aliteração). Concluiu-se que o treino da percepção fonêmica é efetivo no tratamento do distúrbio fonológico, porém não beneficia automaticamente o desenvolvimento 
da consciência de outras unidades da palavra, já que a criança deve reorganizar as representações contidas no léxico para refletir sobre as similaridades e diferenças entre palavras na base de unidades subsilábicas tais como aliteração e rima, o que possivelmente só é obtido com um treino intensivo e explícito ou após um certo tempo.

Considerando que os diferentes subgrupos de distúrbio de linguagem apresentam diferentes fatores subjacentes, CROSBIE; HOLM, DODD $^{17}, 2005$, avaliaram os efeitos de dois diferentes tipos de intervenção no desenvolvimento fonológico de crianças com distúrbio fonológico de naturezas distintas. Dezoito pré-escolares, com idade entre 4 e 6 anos, participaram de dois Programas de intervenção, um com enfoque no vocabulário funcional e outro com enfoque nos contrastes fonológicos. No Programa baseado nos contrastes fonológicos, foi utilizado o Modelo de Pares Mínimos, para reorganizar o sistema fonológico das crianças, associado a atividades de discriminação auditiva. Já o outro tipo de intervenção, fez uso de um vocabulário rotineiro/funcional, associado a atividades de segmentação silábica e imitação, de modo alcançar a consistência das produções. Todas as crianças apresentaram aumento na porcentagem de consoantes emitidas corretamente após a intervenção. Porém a terapia que fez uso de vocabulário funcional teve melhores resultados para crianças cujo distúrbio de fala caracterizava-se pela inconsistência das produções, enquanto o outro Programa beneficiou as crianças que faziam uso de processos desviantes e consistentes. Os resultados evidenciam que o tratamento que enfoca o nível do processamento da fala subjacente ao distúrbio manifestado resulta numa eficiente mudança no sistema fonológico. 
3 - PROPOSIÇÃO 


\section{PROPOSIÇÃO}

- Comparar o desempenho psicolingüístico de crianças com DEL com o de crianças que apresentam desenvolvimento típico de linguagem (DTL), apontando os marcadores psicolingüísticos mais significativos.

- Comparar a eficácia de dois métodos de intervenção - Modelo de Intervenção no Meio e Modelo Neuropsicolingüístico - no desempenho psicolingüístico das crianças com DEL 
4 - MATERIAL E MÉTODOS 


\section{MATERIAL E MÉTODOS}

Este trabalho foi previamente aprovado pelo Comitê de Ética em Pesquisa da Faculdade de Odontologia de Bauru, da Universidade de São Paulo, processo $n^{\circ} 109 / 2005$, e todos os pais e/ou responsáveis autorizaram a participação do(a) filho(a) na pesquisa, mediante assinatura de Termo de Consentimento Livre e Esclarecido (Anexo 1), conforme Resolução 196/96CNS/MS.

\subsection{Seleção e caracterização da casuística:}

Participaram desse estudo 12 pré-escolares, de ambos os gêneros, com idade entre 48 (4:0 anos) e 83 meses (6:11 anos).

Metade deles $(n=6)$, que constituíram o Grupo Experimental (GE), foram selecionados dentre aqueles que receberam o diagnóstico de Distúrbio Específico de Linguagem, por meio da Clínica de Diagnóstico dos Distúrbios da Comunicação Humana (USP-Bauru), nos anos de 2003 e 2004, anterior ao início desta pesquisa.

Considerando o diagnóstico de DEL (LEONARD ${ }^{33}$, 1998), apresentaram os seguintes fatores de inclusão:

- performance lingüística abaixo do esperado para a idade mental e cronológica, considerando-se a expressão e/ou compreensão da linguagem oral;

- limiares auditivos dentro dos padrões de normalidade;

- ausência de problemas comportamentais e/ou emocionais;

- desempenho cognitivo de acordo com a normalidade, ou ainda, discrepância entre o desempenho das habilidades cognitivas verbais e não-verbais.

Como critério de inclusão neste grupo, além dos anteriormente citados, inerentes ao diagnóstico de DEL, também se exigiu que a criança 
nunca tivesse sido submetida à intervenção fonoaudiológica e possuísse idade igual ou superior a quatro anos, de modo a garantir a persistência das alterações de linguagem.

O Grupo Controle (GC) foi constituído por seis pré-escolares, com desenvolvimento cognitivo, de linguagem e de audição normais para a idade cronológica, os quais foram pareados aos do GE atendendo ao critério idade cronológica. Essas crianças foram selecionadas em escola de educação infantil da cidade de Bauru e submetidas à triagem fonoaudiológica que envolveu entrevista com os pais e análise de linguagem por amostra (conversação). As crianças selecionadas não apresentavam queixas referentes ao desenvolvimento de linguagem, motor, social e escolar, assim como apresentavam desenvolvimento de linguagem compatível com a normalidade segundo as tabelas de desenvolvimento descritas em ZORZI; HAGE, $2004^{53}$.

Importante ressaltar que todos os sujeitos envolvidos nesta pesquisa são pré-escolares de escolas públicas da cidade de Bauru-SP.

As tabelas 1e 2 apresentam a caracterização e comparação das crianças do GE e de seus respectivos pares quanto à idade cronológica (em meses) e gênero. Não foi observada diferença significativa $(p>0,05)$ entre a média de idade dos grupos.

TABELA 1 - Comparação entre a média de idade dos grupos (em meses)

\begin{tabular}{ccc}
\hline GRUPO & MÉDIA & SIGNIFICÂNCIA (P) \\
\hline EXPERIMENTAL & 63,5 & 0,810 \\
CONTROLE & 68,5 & \\
\hline
\end{tabular}


TABELA 2 - Caracterização do grupo controle e experimental quanto à idade cronológica e gênero

\begin{tabular}{ccc}
\hline SUJEITOS & IDADE CRONOLÓGICA & GÊNERO \\
\hline E1 $^{*}$ & 62 & $\mathrm{M}^{* * *}$ \\
C1 $^{* *}$ & 62 & $\mathrm{~F}^{* * *}$ \\
E2 $^{*}$ & 55 & $\mathrm{~F}$ \\
C2 $^{* *}$ & 53 & $\mathrm{~F}$ \\
E3 $^{*}$ & 78 & $\mathrm{~F}$ \\
C3 $^{* *}$ & 77 & $\mathrm{~F}$ \\
E4 & 83 & $\mathrm{~F}$ \\
C4 $^{* *}$ & 87 & $\mathrm{M}$ \\
E5 & 65 & $\mathrm{M}$ \\
$\mathrm{C} 5^{* *}$ & 69 & $\mathrm{~F}$ \\
E6 & 60 & $\mathrm{M}$ \\
$\mathrm{C} 6^{* *}$ & 63 & $\mathrm{M}$ \\
\hline
\end{tabular}

${ }^{*} \mathrm{E}:$ sujeitos do Grupo Experimental

${ }^{* *} \mathrm{C}$ : Sujeitos do Grupo Controle

${ }^{* * *} \mathrm{M}$ : masculino; $\mathrm{F}$ : feminino

\subsection{Metodologia}

\subsubsection{Etapas de desenvolvimento da metodologia}

As crianças do GE realizaram quatro avaliações da linguagem oral ao longo de um ano, sendo: avaliação pré-intervenção 1 (A1), pré-intervenção 2 (A2), pós-intervenção 1 (A3) e pós-intervenção 2 (A4). Já o GC realizou uma avaliação, correspondente a $A 1$ do $G E$ e não foi submetido à terapia. $A$ execução de cada avaliação consumiu, em média, duas sessões de 1 hora, para cada sujeito.

A A1 foi executada três meses antes do início da intervenção, com o intuito de verificar o índice lingüístico e psicolingüístico dos sujeitos do GE e compará-lo ao do GC. Como as crianças ainda se encontravam em fase de 
aquisição de linguagem, a A2 foi realizada três meses após a A1 e imediatamente antes do início do processo terapêutico, a fim de verificar se houve ou não evolução da linguagem nesse período, sem intervenção. Após a A2, as crianças do GE foram distribuídas aleatoriamente em dois grupos (Grupo Experimental 1 e 2 - GE1 e GE2) e submetidas a dois diferentes Modelos terapêuticos (primeiro ciclo), com duração de quatro meses. Ou seja, o GE1 participou da intervenção com enfoque no processamento da informação lingüística (PIL) baseada no Modelo Neuropsicolingüístico, enquanto o GE2 participou da intervenção com base no Modelo de Intervenção no Meio, com enfoque direto nos subsistemas da linguagem.

Ao fim do primeiro ciclo de intervenção, as crianças de ambos os grupos (GE1 e GE2) realizaram a A3, para verificar a taxa de desenvolvimento psicolingüístico nessa etapa. Em seguida à $A 3$, teve início o segundo ciclo de intervenção, em que as crianças de ambos os grupos receberam mais quatro meses de terapia em que os Modelos terapêuticos foram alternados. Ou seja, o GE, que recebeu intervenção com enfoque no processamento da informação lingüística (PIL), no primeiro ciclo, foi submetido ao ED no segundo ciclo, e vice-versa. Posteriormente, a A4 foi realizada e os seus resultados comparados à $\mathrm{A} 3$.

Todo o Programa de Intervenção teve duração de 8 meses, sendo 4 meses para cada ciclo. Durante todo o período foram realizados dois atendimentos semanais de 45 minutos cada. As crianças receberam em média, 24 atendimentos em cada ciclo de intervenção.

É importante ressaltar, que durante a execução dos Programas de intervenção, duas crianças do GE (uma do GE1 e outra do GE2) foram descartadas do estudo em decorrência da falta de assiduidade às sessões de terapia, que comprometeria a obtenção de resultados fidedignos.

A seguir, encontra-se o fluxograma representativo da metodologia utilizada neste estudo (figura 3) 


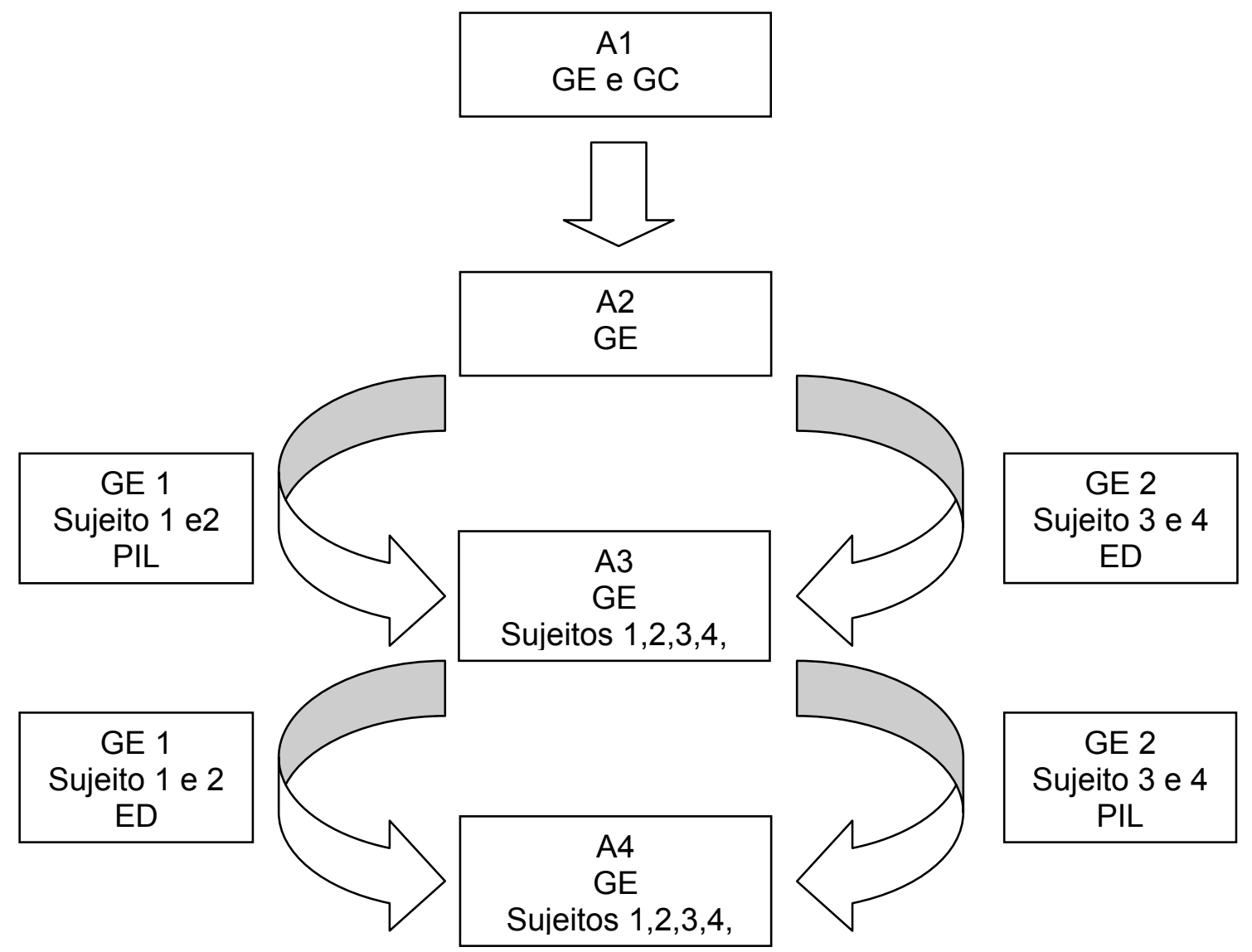

FIGURA 4 - Fluxograma representativo da metodologia do estudo

\subsubsection{Instrumentos de avaliação}

A execução de todas as avaliações envolveu a utilização dos seguintes instrumentos, considerando o Modelo de avaliação Neuropsicolingüístico de CHEVRIE-MULLER ${ }^{11}$, 2005, em que se propõe avaliar o nível primário, secundário e terciário do processamento da informação lingüística. Essa proposta de avaliação foi apresentada por HAGE ${ }^{28}, 2005$, utilizando-se os instrumentos disponíveis no Brasil.

\section{a) Recepção}

1. Nível primário: envolve a avaliação do processamento da informação auditiva desde um nível mais periférico até atingir o córtex auditivo 
primário. Essas investigações não foram todas realizadas neste estudo. Garantiu-se quanto à audição, apenas a presença de limiares auditivos inferiores a $20 \mathrm{~dB}$..

2. Nível secundário: foi verificado o processo de reconhecimento auditivo-fonético. Foi utilizado o Teste de Discriminação Auditiva (SERRANO ${ }^{46}$, 2001).

3. Nível terciário: verificação das habilidades receptivo-fonológicas, morfossintática, lexical e semântica.

3.1. Recepção Fonológica: verificação das habilidades em segmentar a cadeia falada em seguimentos silábicos e subsilábicos. Foi utilizado o teste Perfil de Habilidades Fonológicas (ALVAREZ; CARVALHO; CAETANO², 2004).

3.2. Recepção/compreensão Morfossintática: verificação da compreensão de morfemas de número, gênero e flexões verbais. Foi utilizado o subteste closura gramatical do ITPA Teste Illinois de Habilidades Psicolingüísticas, considerando a padronização brasileira de BOGOSSIAN; SANTOS ${ }^{7}, 1977$. Baseado no total de pontos acumulados por cada sujeito na execução dessa tarefa (escore bruto), foi obtida a idade psicolingüística (IPL), que evidencia que a criança que obtém aquele determinado escore bruto, independentemente de sua idade cronológica ou de seu QI, alcança O rendimento típico esperado para essa faixa etária (BOGOSSIAN; SANTOS ${ }^{7}, 1977$, p. 64).

3.3. Recepção lexical: foi verificado o repertório lexical, por meio do teste de recepção lexical Peabody (DUNN; DUNN ${ }^{20}$, 1981), baseando-se na estandardização preliminar para a população brasileira de CAPOVILLA; CAPOVILLA ${ }^{8}, 1997$.

3.4. Compreensão semântica: verificou-se a compreensão de ordens, sendo utilizado o Token Teste For Children, 


$$
\begin{aligned}
& \text { adaptação de DI SIMIONI }{ }^{18}, \text { 1978, e tradução de } \\
& \text { PEREIRA }^{43}, 2004 .
\end{aligned}
$$

\section{b) Expressão/produção}

1. Nível primário: verificação do inventário fonético. Foi utilizada a prova fonética do ABFW - Teste de Linguagem Infantil (WERTZNER ${ }^{51}$, 2004).

2. Nível secundário: verificou-se as praxias articulatórias e bucofaciais, com uso do Protocolo de Avaliação das Praxias Articulatórias e Bucofaciais de $\mathrm{HAGE}^{25}, 1999$.

3. Nível terciário: verificação da das habilidades expressivas fonológica, morfossintática, lexical e semântica.

3.1. Organização fonológica. Foi utilizada a Prova de Fonologia do ABFW - Teste de Linguagem Infantil (WERTZNER ${ }^{51}$, 2004).

3.2. Organização Morfossintática: verificação do manejo de morfemas de número, gênero e flexões verbais. Foi utilizado para verificar esta habilidade o subteste closura gramatical do ITPA, Teste Illinos de Habilidades Psicolingüísticas, considerando a padronização brasileira de BOGOSSIAN; SANTOS $^{7}, 1977$.

3.3. Léxico: verificação do repertório lexical, por meio da prova de vocabulário do ABFW - Teste de Linguagem Infantil (BÉFI-LOPES ${ }^{5}, 2004$ ).

3.4. Semântica: verificação da habilidade em opor, comparar traços de significação. Para avaliar esta habilidade foi utilizado $O$ subteste associação auditiva do ITPA (BOGOSSIAN; SANTOS ${ }^{7}$, 1977). Baseado no total de pontos acumulados por cada sujeito na execução dessa tarefa (escore bruto), foi obtida sua IPL para esta habilidade. 


\section{c) Memória de curto prazo}

Foi utilizado o subteste de memória seqüencial auditiva do ITPA (BOGOSSIAN; SANTOS ${ }^{7}$, 1977). Baseado no total de pontos acumulados por cada sujeito na execução dessa tarefa (escore bruto), foi obtida sua IPL para essa habilidade.

\section{d) Habilidades pragmáticas}

As habilidades pragmáticas foram avaliadas por meio do registro em vídeo de amostra de linguagem por 20 minutos. Os critérios de análise foram retirados do Protocolo de Avaliação de Linguagem de $\mathrm{HAGE}^{26}, 2000$ e são eles: total de turnos verbais (TTV); total de turnos não verbais (TTNV), número de ocorrências em que a criança iniciou turnos de conversação (ITC), número de ocorrências de turnos em que a criança respondeu e/ou manteve o tópico de conversação (RMC), número de ocorrências em que a criança fez uso de turnos simples (UTS), número de ocorrências em que a criança fez uso de turnos expansivos (UTE). No que se refere às funções comunicativas, foram elencadas as seguintes funções para registro: função instrumental; função heurística, função de nomeação, função informativa, função narrativa, função de protesto, função interativa.

Todas as testagens foram filmadas para posterior análise. A análise da A1 e A2 foi feita pelo mesmo profissional responsável pela intervenção, autora deste trabalho; enquanto que, para a análise da A3 e A4, que propiciou a verificação dos efeitos da terapia fonoaudiológica, foi solicitada a participação de dois juízes com experiência na avaliação e diagnóstico de linguagem infantil. Um terceiro juiz foi convocado nos casos de discordância discrepante nos resultados das análises por aqueles realizadas, e os resultados obtidos pela maioria foram considerados. Essa medida foi adotada de modo a excluir influências da pesquisadora na avaliação da efetividade dos Programas terapêuticos aplicados. 


\subsubsection{Procedimentos dos Programas de intervenção}

\section{a) Programa de Intervenção com enfoque no processamento da informação lingüística baseado no Modelo Neuropsicolingüístico}

De modo geral, o Modelo Neuropsicolingüístico destaca alguns aspectos, considerados componentes-chave do processamento da linguagem, que correspondem ao processamento receptivo das palavras ou percepção, ao armazenamento das informações, à construção das representações mentais das palavras e aos processos envolvidos na produção delas ou programaçãoplanejamento-execução. Presume-se, baseado nesse Modelo, que a aquisição de determinado segmento supõe a interação entre a capacidade de percepção, de produção e de atribuir à informação um valor dentro do código fonológico.

Respeitando-se a importância de todos esses componentes, as estratégias implementadas neste Programa de Intervenção foram desenvolvidas com o intuito de possibilitar às crianças a realização de discriminação entre os sons da fala, promover o desenvolvimento da memória de trabalho, tornar as representações fonológicas das palavras mais precisas, torná-las conscientes dos aspectos estruturais e funcionais da língua (atividades de consciência fonológica, consciência sintática e consciência da palavra), torná-las capazes de acessar as representações no léxico mental e de realizar a programação, planejamento e produção motora de forma satisfatória. Ou seja, visaram intervir junto aos níveis do processamento afetados em cada caso, de modo a abordar indiretamente todos os aspectos da linguagem num mesmo plano de intervenção.

Para cada sujeito, os objetivos da intervenção foram prédeterminados, baseados em avaliação prévia e trabalhados em sessões altamente estruturadas, guiadas prioritariamente pelo terapeuta, em que pouca ênfase foi dada aos contextos naturais. As estruturas de intervenção, ou melhor, o tempo destinado às atividades de recepção, integração, produção e memória, variou, de acordo com as necessidades dos sujeitos e das respostas 
das crianças às estratégias implementadas. Considerando a disposição vertical do Modelo MNPL e a hierarquização dos níveis, o Programa de intervenção abordou inicialmente os níveis mais periféricos do processamento da

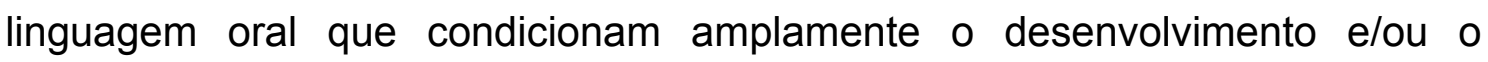
funcionamento dos níveis mais centrais.

\section{b) Programa de Intervenção no Meio (híbrido) com enfoque direto nos níveis da linguagem:}

Neste Programa de intervenção, assim como no anteriormente descrito, os objetivos foram pré-determinados, baseados em avaliação prévia e trabalhados em sessões semi-estruturadas, guiadas prioritariamente pelo terapeuta, em que os contextos naturais foram enfatizados. Contudo, para a seleção dos objetivos foi considerada, unicamente, a sintomatologia ou o nível de competências e dificuldades apresentadas pelos sujeitos no campo da fonologia, morfossintaxe, semântica e pragmática; sem levar em conta os aspectos cognitivos e perceptivos envolvidos com a organização dos subsistemas.

De modo geral, as estratégias foram desenvolvidas para trabalhar diretamente e individualmente cada um dos subsistemas de linguagem, sendo priorizado o trabalho de pelo menos dois subsistemas numa mesma sessão, sendo um deles a fonologia. Ou seja, em todos os atendimentos foi dado um enfoque aos objetivos fonológicos. Com relação aos demais domínios da linguagem, estes foram trabalhados de forma alternada em cada sessão, sendo uma disponibilizada para o trabalho dos objetivos morfossintáticos e a outra disponibilizada para o trabalho no nível semântico-lexical e pragmático.

Este Programa envolveu estratégias que propiciaram o trabalho sobre as regras de ordens das palavras dentro das orações, o uso adequado de preposições e conjunções dentro das orações; a produção de turnos expansivos; estratégias de organização/aquisição de traços semânticos; estratégias voltadas para o desenvolvimento da narrativa e estratégias para o desenvolvimento fonológico 
Com relação à intervenção sobre o sistema fonológico, viu-se a necessidade de se optar por um Modelo de intervenção que ensejaria trabalhar com processos fonológicos ou classes de sons ao invés de trabalhar com cada fonema individualmente, porém sem trabalhar de forma explícita a consciência fonológica. Para tanto, foi selecionado o Modelo de Pares Mínimos, cujo princípio geral é o de que se a criança aprende o traço distintivo ou a combinação de traços que tinha dificuldades, é capaz de transpor a noção aprendida para outros fonemas que também compartilham do mesmo traço ou combinação de traços difíceis, propiciando que mais de um som seja modificado com a estimulação de um traço particular.

O trabalho dos demais subsistemas da linguagem envolveu atividades de estimulação concentrada, de imitação e de produção eliciada por meio de tarefas de escolha forçada dos objetivos selecionados (TYLER et al. ${ }^{49}$, 2003). A estimulação concentrada, uma técnica de ensino da linguagem geralmente associada ao Modelo de intervenção sobre o meio, foi utilizada neste Programa com o propósito de apresentar de forma freqüente e muito concentrada os objetivos lingüísticos selecionados, antes de exigir uma resposta por parte da criança. Já as tarefas de escolha forçada e imitação, visaram exigir da criança uma resposta verbal ao solicitado. Após a estimulação concentrada era solicitada a imitação da estrutura-alvo e, posteriormente, a produção eliciada.

Nas tarefas de escolha forçada, duas questões eram feitas à criança pelo terapeuta, sendo que as respostas de ambas continham os elementos trabalhados, de modo que a criança obrigatoriamente os produzisse (por exemplo: apresentando uma ilustração em que uma menina se aproxima de sua casa, o terapeuta questiona: "A menina vai para a casa ou para o parque?"). Por fim, outras situações foram conduzidas almejando a produção espontânea das estruturas-alvo. 


\subsection{Forma de análise dos resultados}

Para a comparação do desempenho psicolingüístico do GE e GC na A1 foi aplicado o teste estatístico Mann-Whitney. A comparação do desempenho do GE entre A1 e A2 foi obtida por meio do teste estatístico Wilcoxon. Para ambos os testes estatísticos utilizados foi adotado o nível de significância de $5 \%$.

Devido à pequena amostra constituinte deste estudo, os resultados alusivos ao processo terapêutico serão apresentados de forma descritiva, baseados nas pontuações e escores obtidos pelos sujeitos, nas diversas dimensões psicolingüísticas avaliadas e momentos. 
5 - RESULTADOS 


\section{RESULTADOS}

Neste capítulo serão apresentados os resultados obtidos na $\mathrm{A} 1$, pertinentes à comparação do desempenho psicolingüístico do GE e GC; a comparação do desempenho psicolingüístico do GE entre A1 e A2, assim como os resultados obtidos por esse grupo após o Programa de Intervenção.

\subsection{Comparação do desempenho psicolingüístico dos grupos experimental (GE) e controle (GC) na avaliação pré-intervenção 1 (A1)}

Aqui será apresentada a comparação entre o desempenho do GE e GC para cada nível de processamento da informação lingüística avaliado. Os valores de média, mediana e desvio-padrão (DP) foram obtidos por meio de análise estatística descritiva, enquanto os níveis de significância para a comparação entre os grupos foram obtidos por meio do teste estatístico MannWhitney.

\subsubsection{Recepção}

\section{a) Reconhecimento auditivo-fonético / Prova de Discriminação Auditiva}

Com o objetivo de analisar o desempenho dos pré-escolares para realizar o reconhecimento auditivo-fonético, considerou-se o número total de acertos alcançados dentre os pares de palavras apresentados (36 pares). 0 GC atingiu o critério de normalidade estabelecido pelo teste, o que não aconteceu com o GE. A diferença entre o desempenho dos grupos foi estatisticamente significante (tabela 3 ). 
TABELA 3 - Comparação do desempenho dos grupos na prova de discriminação auditiva

\begin{tabular}{lcccccc}
\hline VARIÁVEL & GRUPO & $N^{* *}$ & MEDIANA & MÉDIA & DP & $\begin{array}{c}\text { SIGNIFICÂNCIA } \\
(P)\end{array}$ \\
\hline $\begin{array}{c}\text { DISCRIMINAÇÃO } \\
\text { AUDITIVA }\end{array}$ & EXPERIMENTAL & 6 & 21,0 & 22,0 & 4,64 & \\
& CONTROLE & 6 & 33,0 & 33,0 & 1,89 & \\
\hline
\end{tabular}

${ }^{*} p \leq 0,05$ : estatisticamente significante

** $\mathrm{n}$ : Número de sujeitos em cada grupo

\section{b) Recepção Fonológica / Prova de Consciência Fonológica}

A pontuação total de cada sujeito foi obtida pela soma do número de pontos em cada subteste. Depois de comparadas as médias dos grupos, verificou-se a ocorrência de diferença estatisticamente significante entre eles, com melhor desempenho do GC (tabela 4).

TABELA 4 - Comparação entre os grupos na avaliação da Consciência Fonológica

\begin{tabular}{ccccccc}
\hline VARIÁVEL & GRUPO & $N^{* *}$ & MEDIANA & MÉdIA & DP & $\begin{array}{c}\text { SIGNIFICÂNCIA } \\
(P)\end{array}$ \\
\hline $\begin{array}{c}\text { RECEPÇÃO } \\
\text { FONOLÓGICA }\end{array}$ & EXPERIMENTAL & 6 & 13,0 & 11,6 & 6,08 & \\
& CONTROLE & 6 & 43,0 & 40,5 & 7,71 & \\
\hline
\end{tabular}

${ }^{*} p \leq 0,05$ : estatisticamente significante

** $\mathrm{n}$ : número de sujeitos em cada grupo

\section{c) Recepção morfossintática / Subteste Closura Gramatical do ITPA}

$\mathrm{Na}$ análise da recepção / compreensão morfossintática, o GE apresentou IPL média de 41,1 meses, enquanto a média do GC foi de 86 meses, diferença essa significante. Na tabela 5 é possível visualizar essa comparação. Importante relembrar que a média de idade cronológica dos grupos é de 67,1 meses e 68,5 meses, respectivamente. 
TABELA 5 - Comparação entre Grupo Experimental e Controle na avaliação da recepção morfossintática

\begin{tabular}{ccccccc}
\hline VARIÁVEL & GRUPO & $N^{* *}$ & MEDIANA & MÉdIA & DP & $\begin{array}{c}\text { SIGNIFICÂNCIA } \\
(P)\end{array}$ \\
\hline $\begin{array}{c}\text { RECEPÇÃo } \\
\text { MORFOSSINTÁtICA }\end{array}$ & EXPERIMENTAL & 6 & 35,0 & 41,1 & 12,13 & \\
& CONTROLE & 6 & 78,0 & 86,0 & 27,03 & \\
\hline
\end{tabular}

${ }^{*} p \leq 0,05$ : estatisticamente significante

** $\mathrm{n}$ : Número de sujeitos em cada grupo

\section{d) Recepção lexical / Teste de recepção lexical Peabody}

$\mathrm{Na}$ verificação da recepção lexical, o teste estatístico também revelou diferença significativa no desempenho entre os grupos (tabela 6). Os valores de média e mediana demonstram a deficiência apresentada pelo GE na realização dessa tarefa, em comparação ao GC.

TABELA 6 - Comparação entre Grupo Experimental e Controle na avaliação da recepção lexical

\begin{tabular}{lcccccc}
\hline VARIÁVEL & GRUPO & $N^{* *}$ & MEDIANA & MÉDIA & DP & $\begin{array}{c}\text { SIGNIFICÂNCIA } \\
(\mathrm{P})\end{array}$ \\
\hline $\begin{array}{c}\text { RECEPÇÃO } \\
\text { LEXICAL }\end{array}$ & EXPERIMENTAL & 6 & 62,0 & 67,5 & 15,64 & \\
& CONTROLE & 6 & 102,50 & 97,8 & 15,98 & $0,008^{*}$ \\
\hline
\end{tabular}

${ }^{*} p \leq 0,05$ : estatisticamente significante

** $\mathrm{n}$ : Número de sujeitos em cada grupo

\section{e) Compreensão semântica / Token Test for Children}

Como nos demais níveis da recepção da informação, na avaliação da compreensão semântica, as crianças do GE apresentaram desempenho significativamente pior que seus pares com DTL (tabela 7). Para o cálculo das médias obtidas pelos grupos, uma criança do GE foi descartada por não ter sido capaz de realizar a prova, em decorrência do não conhecimento de cor e forma, necessários para execução da mesma. A pontuação alcançada pelos 
sujeitos baseou-se no número de execuções corretas dentre o total de ordens solicitadas (61 ordens).

TABELA 7 - Comparação entre o Grupo Experimental e Controle na avaliação da compreensão semântica

\begin{tabular}{lcccccc}
\hline VARIÁVEL & GRUPO & $N^{* *}$ & MEDIANA & MÉdIA & DP & $\begin{array}{c}\text { SIGNIFICÂNCIA } \\
(P)\end{array}$ \\
\hline $\begin{array}{c}\text { COMPREENSÃO } \\
\text { SEMÂNTICA }\end{array}$ & EXPERIMENTAL & 5 & 19,0 & 24,0 & 16,55 & \\
& CONTROLE & 6 & 49,5 & 48,3 & 3,97 & $0,013^{*}$ \\
\hline
\end{tabular}

${ }^{*} p \leq 0,05$ : estatisticamente significante

** $\mathrm{n}$ : Número de sujeitos em cada grupo

\subsubsection{Expressão}

\section{a) Verificação do inventário fonético}

Como todos os fonemas já se encontram presentes no inventário das crianças do GC, os resultados concernentes à verificação do inventário fonético serão apresentados de forma descritiva, representados pelos fonemas presentes no inventário de cada pré-escolar do GE (tabela 8). 
TABELA 8 - Descrição dos fonemas presentes no inventário fonético dos pré-escolares do Grupo Experimental

\begin{tabular}{|c|c|}
\hline SUJEITOS DO GE & INVENTÁRIO FONÉTICO \\
\hline E1 & $/ \mathrm{p} / ; / \mathrm{t} / ; / \mathrm{k} / ; / \mathrm{d} / ; / \mathrm{f} / ; / \mathrm{s} / ; / \mathrm{v} / ; / \mathrm{m} / ; / \mathrm{n} / ; / \mathrm{n} / ; / \mathrm{r} /$ \\
\hline E2 & /p/; /b/;/t/; /k/; /s/; / J/R/ /j/; /m/; /n/; /n/; /l/; \\
\hline E3 & $/ \mathrm{p} / ; / \mathrm{b} / ; \mathrm{t} / ; / \mathrm{d} / ; / \mathrm{s} / ; / \mathrm{m} / ; / \mathrm{n} / ; / \mathrm{\eta} / ; / \mathrm{l} / ; / \mathrm{R} / ; / \mathrm{r} /$. \\
\hline E4 & $\begin{array}{c}\text { /p/; /b/; /t/; /d/; /f/; /v/; /s/; /z/; / Jl; /m/; /n/; } \\
/ \mathrm{n} / ; / I / ; / R /\end{array}$ \\
\hline E5 & $\begin{array}{c}\text { /p/; /b/; /t/; /d/; /k/;/g/; /f/; /v/; /s/;/ J/; /j/; } \\
\text { /m/;/n/;/n/;/l/;/R/;/r/ }\end{array}$ \\
\hline E6 & //p/; /b/; /t/; /d/; /f/;/m/; /n/; n/; /R/ \\
\hline
\end{tabular}

\section{b) Praxias articulatórias e buco-faciais}

Por meio do protocolo proposto foram avaliadas as praxias articulatórias (PART), de lábio (PLAB), de língua (PLIN) e de face (PFAC) do GE e GC. A partir da somatória dessas foi obtida a pontuação total dos sujeitos. Apesar de a análise estatística ter revelado uma diferença significativa na comparação entre os grupos, exceto para as praxias de lábio e língua, clinicamente as crianças do GE apresentaram desempenho concorde com a normalidade esperada para a idade, ou seja, não manifestaram alterações práxicas. A tabela 9 demonstra esses resultados. 
TABELA 9 - Comparação entre Grupo Experimental e Controle na avaliação das praxias articulatórias e buco-faciais

\begin{tabular}{|c|c|c|c|c|c|c|}
\hline VARIÁVEL & GRUPO & $\mathrm{N}^{* *}$ & MEDIANA & MÉDIA & DP & SIGNIFICÂNCIA (P) \\
\hline \multirow[t]{2}{*}{ PART } & $E$ & 6 & 3,5 & 3,3 & 0,81 & \multirow[t]{2}{*}{$0,005^{*}$} \\
\hline & C & 6 & 6,0 & 5,6 & 0,81 & \\
\hline \multirow{2}{*}{ PLAB } & $E$ & 6 & 5,5 & 5,5 & 0,51 & \multirow{2}{*}{0,055} \\
\hline & $\mathrm{C}$ & 6 & 6,0 & 6,0 & 0,00 & \\
\hline \multirow{2}{*}{ PLIN } & $E$ & 6 & 4,0 & 3,8 & 0,40 & \multirow{2}{*}{0,338} \\
\hline & $\mathrm{C}$ & 6 & 4,0 & 4,1 & 0,75 & \\
\hline \multirow[t]{2}{*}{ PFAC } & $E$ & 6 & 4,0 & 3,6 & 0,51 & \multirow[t]{2}{*}{$0,001^{*}$} \\
\hline & C & 6 & 5,0 & 5,0 & 0,75 & \\
\hline \multirow[t]{2}{*}{ TOTAL } & $E$ & 6 & 16,0 & 16,3 & 0,81 & \multirow[t]{2}{*}{$0,002^{*}$} \\
\hline & $\mathrm{C}$ & 6 & 21,0 & 20,8 & 0,00 & \\
\hline
\end{tabular}

${ }^{*} p \leq 0,05$ : estatisticamente significante

** $\mathrm{n}$ : Número de sujeitos em cada grupo

c) Organização fonológica / Prova de fonologia do ABFW - Teste de Linguagem Infantil

A análise do sistema fonológico dos participantes deste estudo baseou-se nos critérios propostos no ABFW - Teste de Linguagem Infantil (WERTZNER $\left.{ }^{51}, 2004\right)$, quanto à classificação dos processos fonológicos e idade prevista para o desaparecimento deles.

Todas as crianças do GE apresentaram processos fonológicos produtivos não mais esperados para a idade, enquanto as crianças do GC demonstraram já ter adquirido e organizado todos os fonemas da língua. No GE, além dos processos de simplificação desenvolvimentais, também foi observado o uso de processos desviantes. Por sugestão do estatístico, a apresentação desses dados, relativos à organização do sistema fonológico, 
será apresentada de forma descritiva. Para cada sujeito serão descritos os processos fonológicos utilizados.

TABELA 10 - Descrição dos processos fonológicos produtivos não esperados para a idade apresentados pelos sujeitos do GE

\begin{tabular}{|c|c|}
\hline SUJEITOS & PROCESSOS FONOLÓGICOS \\
\hline E1 & $\begin{array}{l}\text { Frontalização de palatal**; Simplificação de líquida*; } \\
\text { Ensurdecimento de plosivas }{ }^{* * *} ; \text { Ensurdecimento de fricativas }\end{array}$ \\
\hline E2 & $\begin{array}{l}\text { Simplificação de encontro consonantal }\left.\right|^{* *} ; \text { Simplificação de consoante } \\
\text { final }^{* *} ; \text { Simplificação de líquida }{ }^{* *} ; \text { Frontalização de palatal }{ }^{* *} ; \\
\text { Ensurdecimento de fricativas }^{* * *} ; \text { Ensurdecimento de plosivas }^{* *} ; \text { Outros }^{*}\end{array}$ \\
\hline E3 & $\begin{array}{l}\text { Frontalização de velar }{ }^{* *} ; \text { Plosivação de fricativas }{ }^{* *} ; \text { Simplificação de } \\
\text { encontro consonantal }{ }^{* *} ; \text { Simplificação de consoante final } \\
\text { Ensurdecimento de plosivas }^{* * *} ; \text { Simplificação de líquidas }\end{array}$ \\
\hline E4 & $\begin{array}{c}\text { Frontalização de velar**; Plosivação de fricativas }{ }^{* *} ; \text { Simplificação de } \\
\text { encontro consonantal }{ }^{* *} \text { : Ensurdecimento de plosivas } \\
\text { líquidas }{ }^{* *} ; \text { Simplificaçãa de }\end{array}$ \\
\hline E5 & $\begin{array}{c}\text { Redução de sílaba**; Plosivação de fricativas }{ }^{* *} \\
\text { Frontalização de velar*; } \\
\text { Simplificação de líquidas }{ }^{* *} ; \text { Ensurdecimento de fricativas*** }\end{array}$ \\
\hline E6 & $\begin{array}{c}\text { Simplificação de encontro consonantal }{ }^{* *} \text {; Simplificação de consoante } \\
\text { final }^{* *} \text {; Plosivação de fricativas }{ }^{* *} ; \text { Frontalização de velar**; Simplificação } \\
\text { de líquidas }{ }^{* *} ; \text { Outros }^{*}\end{array}$ \\
\hline
\end{tabular}

* processos desviantes

**processos observados durante o desenvolvimento

*** processos não observados freqüentemente durante o desenvolvimento

\section{d) Organização Morfossintática / Subteste Closura Gramatical do ITPA}

Os dados presos à organização morfossintática já foram descritos anteriormente no item alusivo à Closura Gramatical, que avalia a recepção e produção morfossintática. O GE apresentou desempenho significativamente pior que o GC, revelando um comprometimento nesse nível da produção da linguagem oral. 


\section{e) Produção lexical I Prova de Vocabulário do ABFW - Teste de Linguagem Infantil}

A comparação entre as médias de designação verbal usual (DVU), não designação (ND) e processos de substituição (PS) apresentadas pelos dois grupos avaliados revelou diferença estatisticamente significante no desempenho entre os mesmos, exceto para o uso de não-designação (tabela 11). Ou seja, as crianças do GC nomearam corretamente um número significativamente maior de palavras-alvo, enquanto as crianças do GE fizeram maior uso de processos de substituição.

TABELA 11 - Comparação entre Grupo Experimental e Controle na avaliação do vocabulário expressivo

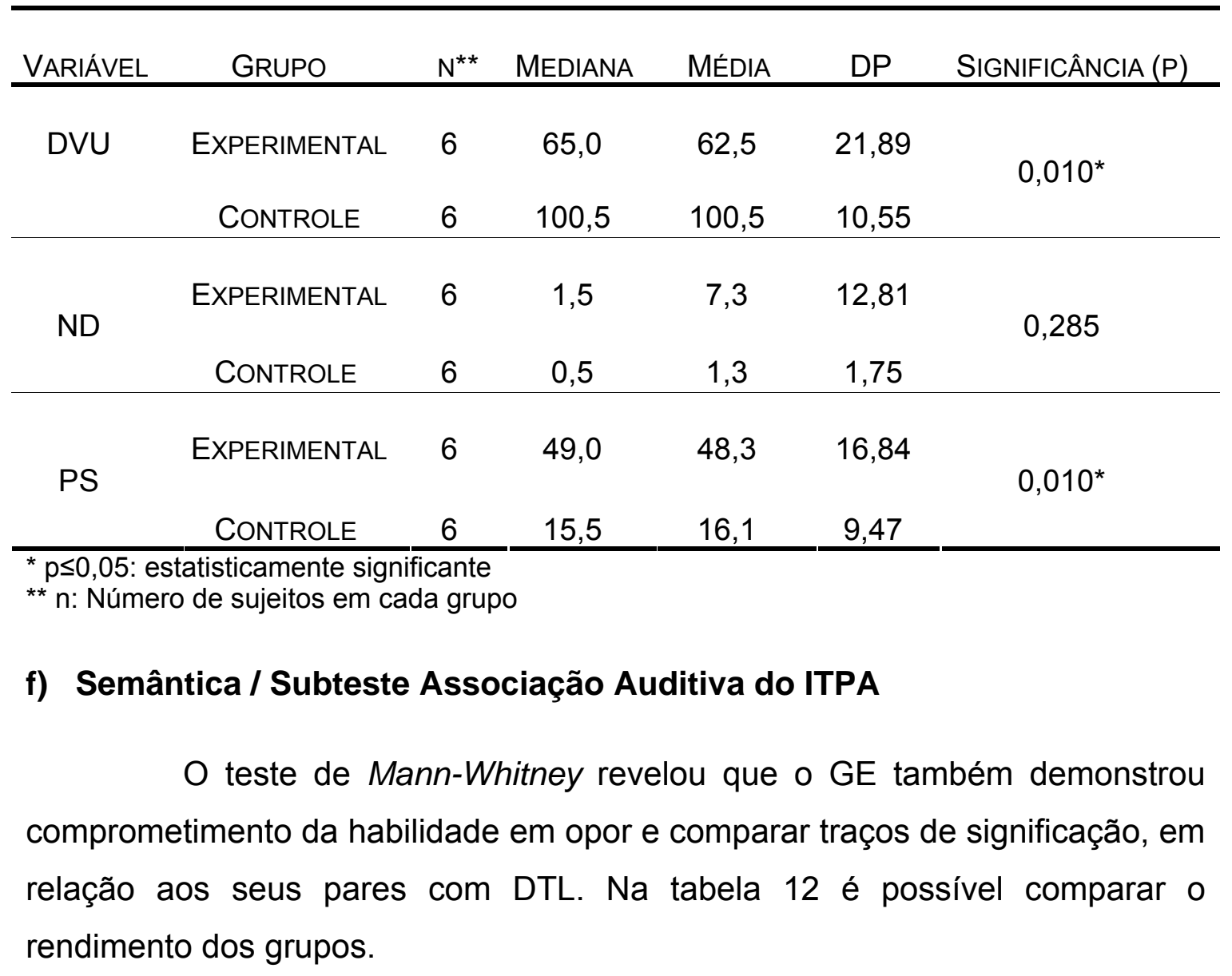


TABELA 12 - Comparação entre Grupo Experimental e Controle na avaliação da semântica (subteste Associação Auditiva do ITPA)

\begin{tabular}{ccccccc}
\hline VARIÁVEL & GRUPOS & $\mathrm{N}^{* *}$ & MEDIANA & MÉDIA & DP & $\begin{array}{c}\text { SIGNIFICÂNCIA } \\
(\mathrm{P})\end{array}$ \\
\hline $\begin{array}{c}\text { ASSOCIAÇÃO } \\
\text { AUDITIVA }\end{array}$ & EXPERIMENTAL & 6 & 35,0 & 40,6 & 12,86 & $0,008^{*}$ \\
\hline
\end{tabular}

${ }^{*} p \leq 0,05$ : estatisticamente significante

** $\mathrm{n}$ : Número de sujeitos em cada grupo

\subsubsection{Memória de Curto Prazo / Subteste Memória Seqüencial Auditiva do ITPA}

As crianças do GE manifestaram maior dificuldade em reter e evocar os estímulos auditivos, quando comparadas às crianças do GC. A IPL média obtida por elas foi inferior à média da idade cronológica e inferior a IPL obtida pelos seus pares com DTL, resultando numa diferença estatisticamente significante entre os grupos, como pode ser visto na tabela 13.

TABELA 13 - Comparação entre Grupo Experimental e Controle na avaliação da memória de curto termo (subteste Memória Seqüencial Auditiva do ITPA)

VARIÁVEL GRUPO N $N^{* *}$ MEDIANA MÉDIA DP $\quad \begin{gathered}\text { SIGNIFICÂNCIA } \\ (P)\end{gathered}$

\begin{tabular}{ccccccc}
\hline \multirow{2}{*}{ MSA $^{* * *}$} & EXPERIMENTAL & 6 & 30,0 & 31,5 & 7,89 & $0,003^{*}$ \\
& CONTROLE & 6 & 58,0 & 69,8 & 31,07 & \\
\hline
\end{tabular}

${ }^{*} p \leq 0,05$ : estatisticamente significante

** $\mathrm{n}$ : Número de sujeitos em cada grupo

*** Memória seqüencial auditiva

\subsubsection{Habilidades Pragmáticas}

Como já descrito no capítulo Metodologia, os critérios de análise das habilidades pragmáticas foram: total de turnos verbais (TTV); total de turnos não verbais (TTNV); número de ocorrências em que a criança iniciou turnos de conversação (ITC); número de ocorrências de turnos em que a criança 
respondeu e/ou manteve o tópico de conversação (RMC); número de ocorrências em que a criança fez uso de turnos simples (UTS); número de ocorrências em que a criança fez uso de turnos expansivos (UTE). No que se refere às funções comunicativas (FUN), foram elencadas sete funções para registro: função instrumental; função heurística; função de nomeação; função informativa; função narrativa; função de protesto; função interativa. A análise estatística, tanto descritiva quanto comparativa, alusiva ao uso das funções comunicativas baseou-se na quantidade/tipos de funções observadas na comunicação da criança e não no número de ocorrências de cada função, como ocorreu na análise das demais habilidades pragmáticas. Assim, cada criança recebeu uma pontuação de 1 a 7 para o critério funções comunicativas.

Considerando todos os critérios analisados descritos, foi observada diferença estatisticamente significante no desempenho entre os grupos, com melhor desempenho para as crianças do GC, somente para o número de ocorrências em que a criança iniciou turnos de conversação e número de ocorrências em que a criança fez uso de turnos expansivos (tabela 14). 
TABELA 14 - Comparação entre Grupo Experimental e Controle na avaliação das habilidades pragmáticas

\begin{tabular}{|c|c|c|c|c|c|}
\hline VARIÁVEL & GRUPO & $\mathrm{N}$ & MÉDIA & DP & $\begin{array}{c}\text { SIGNIFICÂNCIA } \\
(\mathrm{P})\end{array}$ \\
\hline \multirow{3}{*}{ TTV } & $E$ & 6 & 45,0 & 10,5 & \multirow{3}{*}{0,053} \\
\hline & & & & & \\
\hline & C & 6 & 58,0 & 9,25 & \\
\hline \multirow{3}{*}{ TTNV } & $E$ & 6 & 1,8 & 4,49 & \multirow{3}{*}{0,317} \\
\hline & & & & & \\
\hline & $\mathrm{C}$ & 6 & 0,0 & 0,00 & \\
\hline \multirow{3}{*}{ ITC } & $E$ & 6 & 18,3 & 11,18 & \multirow{3}{*}{$0,023^{*}$} \\
\hline & & & & & \\
\hline & C & 6 & 30,6 & 4,41 & \\
\hline \multirow{3}{*}{$\mathrm{RMC}$} & $E$ & 6 & 26,3 & 7,56 & \multirow{3}{*}{0,687} \\
\hline & & & & & \\
\hline & C & 6 & 27,3 & 8,28 & \\
\hline \multirow{3}{*}{ UTS } & $E$ & 6 & 35 & 9,42 & \multirow{3}{*}{0,053} \\
\hline & & & & & \\
\hline & C & 6 & 23,8 & 7,60 & \\
\hline \multirow{3}{*}{ UTE } & $E$ & 6 & 10,0 & 4,00 & \multirow{3}{*}{$0,003^{*}$} \\
\hline & & & & & \\
\hline & C & 6 & 34,1 & 6,61 & \\
\hline \multirow{3}{*}{ FUN } & $E$ & 6 & 6,1 & 1,16 & \multirow{3}{*}{0,210} \\
\hline & & & & & \\
\hline & C & 6 & 6,8 & 0,40 & \\
\hline
\end{tabular}

${ }^{*} p \leq 0,05$ : estatisticamente significante

** $n$ : Número de sujeitos em cada grupo

5.2 Comparação do desempenho psicolingüístico do GE entre a avaliação pré-intervenção 1 (A1) e avaliação pré-intervenção 2 (A2)

A seguir, será apresentada a comparação do desempenho do Grupo Experimental entre as duas avaliações pré-intervenção, para cada nível de processamento da informação lingüística avaliada, de modo a verificar a ocorrência de desenvolvimento lingüístico neste período que precedeu o início do processo terapêutico. 
Os valores de média, mediana e desvio-padrão foram obtidos por meio de análise estatística descritiva, enquanto os níveis de significância para a comparação entre as avaliações foram obtidos por meio do teste estatístico Wilcoxon. Não foi observada diferença estatisticamente significante no rendimento do grupo, entre as duas testagens, para nenhum dos níveis de tratamento psicolingüístico avaliados. As tabelas 15 e 16 demonstram essa comparação.

Não foi observada diferença na comparação do inventário fonético dos sujeitos do GE entre as duas avaliações. A análise da produção fonológica revelou que todos os pré-escolares permaneciam fazendo uso dos mesmos processos fonológicos não mais esperados para a idade, de forma produtiva, tanto na nomeação espontânea quanto na repetição, na A2. Por este motivo, não serão descritos novamente.

Com relação à produção lexical, os valores apresentados na tabela referem-se apenas à nomeação por designação usual (DVU). Contudo, para o uso de processos de substituição e não designação, também não foi observada diferença significativa na avaliação A2. Os níveis de significância (p) foram de 0,892 e 0,248 , respectivamente. 
TABELA 15 - Resultados da comparação do desempenho psicolingüístico do GE entre A1 e A2

\begin{tabular}{|c|c|c|c|c|c|}
\hline VARIÁVEL & TESTAGEM & MEDIANA & MÉDIA & DP & $\begin{array}{l}\text { SIGNIFICÂNCIA } \\
(\mathrm{P})\end{array}$ \\
\hline RECONHECIMENTO & ${ }^{*} \mathrm{~A} 1$ & 21,0 & 22,0 & 4,65 & \multirow{2}{*}{1,000} \\
\hline AUDITIVO-FONÉTICO & ${ }^{* *} \mathrm{~A} 2$ & 22,5 & 21,3 & 5,71 & \\
\hline \multirow{2}{*}{ RECEPÇÃO FONOLÓGICA } & $\mathrm{A} 1$ & 13,0 & 11,6 & 6,09 & \multirow{2}{*}{0,108} \\
\hline & $\mathrm{A} 2$ & 16,5 & 13,6 & 6,94 & \\
\hline \multirow{2}{*}{$\begin{array}{c}\text { RECEPÇÃO/ORGANIZAÇÃO } \\
\text { MORFOSSINTÁTICA }\end{array}$} & A1 & 35,0 & 41,1 & 12,14 & \multirow{2}{*}{0,224} \\
\hline & A2 & 46,5 & 45,1 & 16,76 & \\
\hline \multirow{2}{*}{ RECEPÇÃO LEXICAL } & A1 & 62,0 & 67,5 & 15,64 & \multirow{2}{*}{0,222} \\
\hline & A2 & 66,0 & 71,0 & 13,38 & \\
\hline COMPREENSÃO & A1 & 19,0 & 24,0 & 16,55 & \multirow{2}{*}{0,685} \\
\hline SEMÂNTICA & $\mathrm{A} 2$ & 20,0 & 24,6 & 7,63 & \\
\hline \multirow[b]{2}{*}{ PRAXIAS ARTICULATÓRIAS } & A1 & 16,0 & 16,3 & 0,81 & \multirow{2}{*}{1,000} \\
\hline & A2 & 16,0 & 16,3 & 0,81 & \\
\hline \multirow{2}{*}{$\begin{array}{l}\text { EXPRESSÃO LEXICAL } \\
\text { (DVU) }\end{array}$} & A1 & 65,0 & 62,5 & 21,90 & \multirow{2}{*}{0,144} \\
\hline & $\mathrm{A} 2$ & 67,5 & 66,1 & 25,88 & \\
\hline \multirow{2}{*}{ SEMÂNTICA } & A1 & 35,0 & 40,6 & 12,86 & \multirow{2}{*}{1,000} \\
\hline & A2 & 34,0 & 41,1 & 16,76 & \\
\hline \multirow{2}{*}{$\begin{array}{c}\text { MEMÓRIA DE CURTO } \\
\text { PRAZO }\end{array}$} & A1 & 30,0 & 31,5 & 7,89 & \multirow{2}{*}{0,144} \\
\hline & $\mathrm{A} 2$ & 31,0 & 32,8 & 8,15 & \\
\hline
\end{tabular}

*A1: avaliação pré-intervenção 1

${ }^{* *}$ A2: avaliação pré-intervenção 2

TABELA 16 -Comparação entre as duas testagens pré-intervenção na avaliação das habilidades pragmáticas

\begin{tabular}{|c|c|c|c|c|c|}
\hline CRITÉRIOS & TEStAGEM & MEDIANA & MÉDIA & DP & $\begin{array}{c}\text { SIGNIFICÂNCIA } \\
(\mathrm{P})\end{array}$ \\
\hline \multirow{2}{*}{ TTV } & ${ }^{*} \mathrm{~A} 1$ & 42,5 & 45,0 & 10,51 & \multirow{2}{*}{0,787} \\
\hline & ${ }^{* *} \mathrm{~A} 2$ & 43,0 & 43,5 & 14,97 & \\
\hline \multirow{2}{*}{ TTNV } & $\mathrm{A} 1$ & 0,0 & 1,8 & 4,49 & \multirow{2}{*}{1,000} \\
\hline & $\mathrm{A} 2$ & 0,0 & 0,0 & 0,00 & \\
\hline \multirow{2}{*}{ ITC } & A1 & 22,0 & 18,6 & 11,18 & \multirow{2}{*}{0,715} \\
\hline & $\mathrm{A} 2$ & 15,0 & 20,8 & 15,35 & \\
\hline \multirow{2}{*}{ RMC } & A1 & 24,0 & 26,3 & 7,37 & \multirow{2}{*}{0,465} \\
\hline & A2 & 22,5 & 22,6 & 5,24 & \\
\hline \multirow{2}{*}{ UTS } & A1 & 33,0 & 35,0 & 9,42 & \multirow{2}{*}{0,500} \\
\hline & $\mathrm{A} 2$ & 28,0 & 32,6 & 14,77 & \\
\hline \multirow{2}{*}{ UTE } & A1 & 10,5 & 10,0 & 4,00 & \multirow{2}{*}{0,583} \\
\hline & $\mathrm{A} 2$ & 9,5 & 10,8 & 4,21 & \\
\hline \multirow{2}{*}{ FUN } & A1 & 6,5 & 6,1 & 1,17 & \multirow{2}{*}{0,592} \\
\hline & $\mathrm{A} 2$ & 6,5 & 6,3 & 0,81 & \\
\hline
\end{tabular}

*A1: avaliação pré-intervenção 1

${ }^{* *}$ A2: avaliação pré-intervenção 2 


\subsection{Comparação do desempenho psicolingüístico dos sujeitos do GE após o Programa de Intervenção}

A seguir será apresentada a comparação dos resultados obtidos pelos pré-escolares, nas distintas dimensões psicolingüísticas avaliadas, após serem submetidos aos dois Procedimentos de intervenção. Como já relatado no capítulo Material e Método, esta comparação será apresentada de forma descritiva, em decorrência do tamanho da amostra.

Nas tabelas correspondentes a cada nível do processamento da informação avaliado, serão apresentados os pré-escolares, a seqüência dos Procedimentos de intervenção implementados, os resultados obtidos nas diferentes testagens (A2, A3, A4), bem como o nível de desenvolvimento obtido ao fim de cada ciclo de intervenção (diferença entre A2-A3; diferença entre A3A4, representado por sinais positivos (+) ou negativos (-) que indicam a ocorrência de desenvolvimento ou não entre as testagens. Nos anexos de 2 a 5 encontra-se a descrição completa dos participantes que concluíram todas as etapas do estudo. 


\subsubsection{Recepção}

\section{a) Reconhecimento auditivo-fonético / Prova de Discriminação Auditiva}

A tabela 17 mostra o desempenho alcançado pelos 4 pré-escolares para realizar o desempenho auditivo-fonético de pares de palavras, nos diferentes momentos de avaliação, assim como a comparação do desenvolvimento obtido ao fim de cada ciclo de intervenção.

Os sujeitos obtiveram uma diferença de rendimento maior na realização desta tarefa quando submetidos à intervenção com enfoque no PIL baseado no MNPL, excetuando-se o sujeito 3.

TABELA 17 - Pontuação e desenvolvimento obtido no reconhecimento auditivo-fonético após os ciclos de intervenção

\begin{tabular}{|c|c|c|c|c|c|c|}
\hline \multirow[b]{2}{*}{ SUJEITO } & \multirow{2}{*}{$\begin{array}{l}\text { SEQÜÊNCIA } \\
\text { DOS CICLOS }\end{array}$} & \multicolumn{5}{|c|}{ RECONHECIMENTO AUDITIVO-FONÉTICO } \\
\hline & & A2 & A3 & A4 & $\begin{array}{c}\text { DIFERENÇA } \\
\text { A2-A3 }\end{array}$ & $\begin{array}{c}\text { DIFERENÇA } \\
\text { A3-A4 }\end{array}$ \\
\hline 01 & ${ }^{*} \mathrm{PIL} / \mathrm{ED}$ & 22 & $\overline{33}$ & 34 & +11 & +01 \\
\hline 02 & PIL/ED & 28 & 35 & 34 & +07 & -01 \\
\hline 03 & ${ }^{* *}$ ED/PIL & 24 & 29 & 33 & +05 & +04 \\
\hline 04 & ED/PIL & 23 & 20 & 28 & -03 & +08 \\
\hline
\end{tabular}

\section{b) Recepção Fonológica / Prova de Consciência Fonológica}

A tabela 18 mostra o desempenho alcançado pelos 4 pré-escolares para realizar a análise fonológica nos diferentes momentos de avaliação, assim como a comparação do desenvolvimento obtido ao fim de cada ciclo de intervenção.

Todos os sujeitos apresentaram uma diferença de rendimento maior quando submetidos à intervenção com enfoque no PIL. 
TABELA 18 - Pontuação e desenvolvimento obtido na análise fonológica, nível terciário da análise lingüística, após os ciclos de intervenção

\begin{tabular}{ccccccc}
\hline \multirow{2}{*}{ SUJEITO } & SEQÜÊNCIA & \multicolumn{5}{c}{ RECEPÇÃO FONOLÓGICA } \\
\cline { 3 - 7 } & DOS CICLOS & A2 & A3 & A4 & $\begin{array}{c}\text { DIFERENÇA } \\
\text { A2-A3 }\end{array}$ & $\begin{array}{c}\text { DIFERENÇA } \\
\text { A3-A4 }\end{array}$ \\
\hline 01 & ${ }^{*}$ PIL/ED & 17 & 41 & 45 & $\mathbf{+ 2 4}$ & +04 \\
02 & PIL/ED & 18 & 40 & 48 & $\mathbf{+ 2 2}$ & +08 \\
03 & ${ }^{* * E D / P I L ~}$ & 0 & 18 & 40 & +18 & $\mathbf{+ 2 2}$ \\
04 & ED/PIL & 16 & 16 & 30 & 0 & $\mathbf{+ 1 4}$ \\
\hline
\end{tabular}

*Intervenção com enfoque no processamento da informação lingüística (PIL) seguida da intervenção com enfoque direto nos subsistemas da linguagem oral (ED)

**Intervenção com enfoque direto nos subsistemas da linguagem (ED) seguida da intervenção com enfoque no processamento da informação da linguagem oral (PIL)

\section{c) Recepção morfossintática / Subteste Closura Gramatical do ITPA}

A comparação do nível de desenvolvimento obtido pelos sujeitos após cada procedimento de intervenção encontra-se na tabela 19. Importante relembrar que todos os valores apresentados representam a IPL (em meses) manifestada pelos sujeitos neste subteste. Dessa forma, as diferenças entre as diversas testagens também representam o nível desenvolvimento em meses manifestado pelas crianças.

Para a maioria dos sujeitos, a diferença da taxa de desenvolvimento alcançada também foi maior quando submetidos à intervenção com enfoque no PIL (sujeito 2, 3 e 4).

TABELA 19 - Pontuação e desenvolvimento obtido na recepção morfossintática, nível terciário da análise lingüística, após os ciclos de intervenção

\begin{tabular}{|c|c|c|c|c|c|c|}
\hline \multirow[b]{2}{*}{ SUJEITO } & \multirow{2}{*}{$\begin{array}{l}\text { SEQÜÊNCIA } \\
\text { DOS CICLOS }\end{array}$} & \multicolumn{5}{|c|}{ RECEPÇÃO MORFOSSINTÁTICA } \\
\hline & & A2 & A3 & A4 & $\begin{array}{c}\text { DIFERENÇA } \\
\text { A2-A3 }\end{array}$ & $\begin{array}{c}\text { DIFERENÇA } \\
\text { A3-A4 }\end{array}$ \\
\hline 01 & *PIL/ED & 55 & 61 & 72 & +06 & +11 \\
\hline 02 & PIL/ED & 61 & 69 & 74 & +08 & +05 \\
\hline 03 & ${ }^{* *} \mathrm{ED} / \mathrm{PIL}$ & 30 & 34 & 51 & +04 & +17 \\
\hline 04 & ED/PIL & 38 & 36 & 43 & -02 & +07 \\
\hline
\end{tabular}

*Processamento da informação lingüística (PIL) seguido de enfoque direto (ED)

**Enfoque direto (ED) seguido do processamento da informação lingüística (PIL) 


\section{d) Recepção lexical / Teste de recepção lexical Peabody}

A comparação do nível de desenvolvimento obtido pelos sujeitos após cada procedimento de intervenção, presente na tabela 20 , demonstra que para a maioria deles (excetuando-se o sujeito 4) houve uma diferença maior de desenvolvimento quando submetidos à intervenção com ED nos subsistemas de linguagem.

TABELA 20 - Pontuação e desenvolvimento obtido na recepção lexical, nível terciário da análise lingüística, após os ciclos de intervenção

\begin{tabular}{ccccccc}
\hline \multirow{2}{*}{ SUJEITO } & \multirow{2}{*}{$\begin{array}{c}\text { SEQÜÊNCIA } \\
\text { DOS CICLOS }\end{array}$} & A2 & A3 & A4 & $\begin{array}{c}\text { DIFERENÇA } \\
\text { A2-A3 }\end{array}$ & $\begin{array}{c}\text { DIFERENÇA } \\
\text { A3-A4 }\end{array}$ \\
\hline 01 & *PIL/ED & 68 & 74 & 84 & +06 & $+\mathbf{+ 1 0}$ \\
02 & PIL/ED & 84 & 78 & 102 & -06 & $\mathbf{+ 2 4}$ \\
03 & $* * E D / P I L$ & 61 & 88 & 91 & $\mathbf{+ 2 7}$ & +03 \\
04 & ED/PIL & 58 & 59 & 63 & +01 & $\mathbf{+ 0 4}$ \\
\hline
\end{tabular}

*Processamento da informação lingüística (PIL) seguido de enfoque direto (ED)

${ }^{* *}$ Enfoque direto (ED) seguido do processamento da informação lingüística (PIL)

\section{e) Compreensão semântica / Token Test for Children}

A tabela 21 apresenta o desempenho alcançado pelos 4 préescolares para realizar a compreensão semântica de sentenças, nos diferentes momentos de avaliação, assim como a comparação do desenvolvimento obtido ao fim de cada ciclo de intervenção. Como o sujeito 4 estava adquirindo as noções de forma e cor ao longo do processo de intervenção, suas respostas, na realização dessa tarefa, foram muito assistemáticas, o que impossibilitou a mensuração do nível de compreensão.

O nível de desenvolvimento obtido pelos sujeitos, quando submetidos a cada procedimento de intervenção, foi variado. Porém, parece haver uma tendência deste nível de análise da informação lingüística ter se beneficiado mais da intervenção com enfoque no PIL (sujeitos 2 e 3). 
TABELA 21 - Pontuação e desenvolvimento obtido na compreensão semântica, nível terciário da análise lingüística, após os ciclos de intervenção

\begin{tabular}{ccccccc}
\hline \multirow{2}{*}{ SUJEITO } & \multirow{2}{*}{\begin{tabular}{c} 
SEQÜENNCIA \\
\cline { 3 - 7 }
\end{tabular}} & \multicolumn{6}{c}{ COMPREENSÃO SEMÂNTICA } \\
\hline 01 & \multirow{2}{*}{ DOSIL/ED } & \multirow{2}{*}{ A3 } & A4 & $\begin{array}{c}\text { DIFERENÇA } \\
\text { A2-A3 }\end{array}$ & $\begin{array}{c}\text { DIFERENÇA } \\
\text { A3-A4 }\end{array}$ \\
\hline 02 & PIL/ED & 20 & 28 & 38 & +08 & $\mathbf{+ 1 0}$ \\
03 & $* * E D / P I L$ & 20 & 46 & 46 & +09 & 0 \\
04 & ED/PIL & - & - & - & -03 & $\mathbf{+ 1 7}$ \\
\hline
\end{tabular}

*Processamento da informação lingüística (PIL) seguido de enfoque direto (ED)

${ }^{* *}$ Enfoque direto (ED) seguido do processamento da informação lingüística (PIL)

\subsubsection{Expressão}

\section{a) Verificação do inventário fonético}

Comparando-se o inventário fonético dos sujeitos nas diferentes testagens, pôde-se observar que houve uma expansão dele ao final de todo o período de intervenção, independentemente do Modelo. 
TABELA 22 - Inventário fonético dos sujeitos e número de fonemas apresentados em cada testagem, nível primário da produção lingüística, nas diferentes testagens

\begin{tabular}{lllll}
\hline \multirow{2}{*}{ SUJEITO } & $\begin{array}{l}\text { SEQÜÊNCIA } \\
\text { DOS CICLOS }\end{array}$ & A2 & INVENTÁRIO FONÉTICO & \\
& & A3 & A4 \\
\hline
\end{tabular}

\begin{tabular}{|c|c|c|c|c|}
\hline 01 & ${ }^{*}$ PIL/ED & $\begin{array}{c}/ \mathrm{p} / ; / \mathrm{b} / ; / \mathrm{t} / ; / \mathrm{d} / ; / \mathrm{s} / ; \\
/ \mathrm{m} / ; / \mathrm{n} / ; / \mathrm{n} / ; / \mathrm{l} / ; \\
/ \mathrm{R} / ; / \mathrm{r} / \\
(11)\end{array}$ & $\begin{array}{c}/ \mathrm{p} / ; / \mathrm{b} / ; / \mathrm{t} / ; / \mathrm{d} / ; / \mathrm{f} / ; / \mathrm{v} / \\
/ \mathrm{s} / ; / \mathrm{J} / ; / \mathrm{j} / / \mathrm{m} / ; / \mathrm{n} / ; \\
/ \mathrm{\eta} / ; / \mathrm{Il} / \mathrm{R} / ; / \mathrm{r} / ; / \mathrm{l} / \\
(16)\end{array}$ & $\begin{array}{c}/ \mathrm{p} / ; / \mathrm{b} / ; / \mathrm{t} / ; / \mathrm{d} / ; / \mathrm{l} / ; / \mathrm{g} / ; \\
/ \mathrm{f} / ; / \mathrm{v} / ; / \mathrm{s} / ; / \mathrm{z} / ; / \mathrm{J} / ; / \mathrm{j} / ; \\
/ \mathrm{m} / ; / \mathrm{n} / ; / \mathrm{l} / ; / \mathrm{l} / ; / \mathrm{R} / ; / \mathrm{r} / \\
\text { (18) }\end{array}$ \\
\hline 02 & PIL/ED & $\begin{array}{c}/ / \mathrm{p} / ; / \mathrm{b} / ; / \mathrm{t} / ; / \mathrm{d} / ; / \mathrm{f} / \\
/ \mathrm{m} / ; / \mathrm{n} / ; \mathrm{\eta} / ; / \mathrm{R} / \\
(9)\end{array}$ & 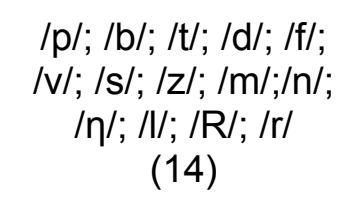 & $\begin{array}{c}\text { /p/; /b/; /t/; /d/; /k/; /g/ } \\
\text { /f/; /v/;/s/; /z/; / / / /j/; } \\
\text { /m/; /n/; /n/;/ll; /R/;/r/ } \\
\text { (18) }\end{array}$ \\
\hline 03 & ${ }^{* *} E D / P I L$ & $\begin{array}{c}/ \mathrm{p} / ; / \mathrm{b} / ; / \mathrm{t} / ; / \mathrm{k} / ; / \mathrm{s} / \\
/ \mathrm{J} / ; / \mathrm{j} / ; / \mathrm{m} / ; / \mathrm{n} / ; / \mathrm{\eta} / ; \\
\mathrm{Il} / ; / \mathrm{R} / \\
(12)\end{array}$ & $\begin{array}{c}/ \mathrm{p} / ; / \mathrm{b} / / \mathrm{tt} / ; / \mathrm{d} / ; / \mathrm{k} / ; / \mathrm{g} / ; \\
/ \mathrm{f} / ; / \mathrm{v} / ; / \mathrm{s} / ; / \mathrm{z} / ; / \mathrm{J} / ; / \mathrm{j} / \\
/ \mathrm{m} / ; / \mathrm{n} / ; / \mathrm{l} / ; / \mathrm{ll} ; / \mathrm{R} / \\
(17)\end{array}$ & $\begin{array}{c}\text { /p/; /b/;/t/; /d/;/k/; /g/; } \\
\text { /f/; /v/;/s/; /z/; / J/; /j/; } \\
\text { /m/; /n/; /n/; /l/; /R/ } \\
\text { (17) }\end{array}$ \\
\hline
\end{tabular}

(17)

$/ \mathrm{p} / ; / \mathrm{b} / ; / \mathrm{tt} / / \mathrm{d} / ; / \mathrm{f} / \quad$ /p/; /b/;/t/;/d/;/f/ $\quad / \mathrm{p} / ; / \mathrm{b} / ; / \mathrm{t} / ; / \mathrm{d} / ; / / \mathrm{k} / / \mathrm{g} / ;$ $04 \quad$ ED/PIL $/ \mathrm{vl} / \mathrm{s} / ; / \mathrm{z} / ; / \mathrm{J} / ; / \mathrm{n} / ; \quad / \mathrm{v} / ; / \mathrm{s} / ; / \mathrm{z} / ; / \mathrm{J} / ; / \mathrm{m} / ; \quad / \mathrm{ff} / ; \mathrm{vl} / \mathrm{s} / ; / \mathrm{z} / ; / \mathrm{J} / ; / \mathrm{r} /$

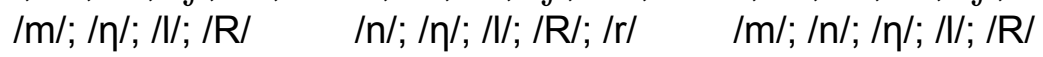

(14)

(15)

(17)

*Processamento da informação lingüística (PIL) seguido de enfoque direto (ED)

${ }^{* *}$ Enfoque direto (ED) seguido do processamento da informação lingüística (PIL)

\section{b) Praxias articulatórias e buco-faciais}

Como os sujeitos não manifestaram alterações no nível práxico, não houve a necessidade de intervir junto a esse nível do processamento da informação. 


\section{c) Organização fonológica / Prova de fonologia do ABFW - Teste de Linguagem Infantil}

Para melhor visualização do nível de desenvolvimento obtido na organização/produção fonológica, nível terciário da produção lingüística, os resultados serão apresentados individualmente, para cada sujeito, por meio da descrição dos processos fonológicos produtivos, em cada avaliação, acompanhados da taxa de produtividade, somente na nomeação espontânea (tabelas 23, 24, 25, 26).

Como se pode observar, todos os sujeitos diminuíram a quantidade de processos de simplificação produtivos no final de todo o processo de intervenção (o sujeito 1 não apresentou mais processos fonológicos produtivos ao fim do processo de intervenção). As diferenças entre A2-A3 ou entre A3-A4 não apontaram benefício maior de um ou outro Modelo.

TABELA 23 - Comparação do nível de desenvolvimento fonológico apresentado pelo sujeito 1 ao fim de cada ciclo de intervenção

\begin{tabular}{|c|c|c|c|}
\hline \multirow[b]{2}{*}{$\begin{array}{l}\text { ORGANIZAÇÃO } \\
\text { FONOLÓGICA }\end{array}$} & \multicolumn{2}{|c|}{ ENFOQUE NO PIL } & ENFOQUE DIRETO \\
\hline & $\begin{array}{l}\text { PROCESSOS } \\
\text { FONOLÓGICOS } \\
\text { PRODUTIVOS* } \\
\text { A2 }\end{array}$ & $\begin{array}{l}\text { PROCESSOS } \\
\text { FONOLÓGICOS } \\
\text { PRODUTIVOS* } \\
\text { A3 }\end{array}$ & $\begin{array}{c}\text { PROCESSOS } \\
\text { FONOLÓGICOS } \\
\text { PRODUTIVOS* } \\
\text { A4 }\end{array}$ \\
\hline $\begin{array}{l}\text { NOMEAÇÃO } \\
\text { ESPONTÂNEA }\end{array}$ & $\begin{array}{ll}\text { Front. Vel. } & (100 \%) \\
\text { Plo. Fric. } & (86,9 \%) \\
\text { Simp. Enc. } & (62,5 \%) \\
\text { Ens. Plos. } & (44,4 \%) \\
\text { Simp. Liq. } & (27,2 \%) \\
\text { Outros } & \end{array}$ & $\begin{array}{ll}\text { Plo. Fric. } & (34,7 \%) \\
\text { Simp. Enc. }(62,5 \%) \\
\text { Ens. Plos. }(28,5 \%) \\
\text { Simp. Liq. }(27,2 \%) \\
\text { Outros }\end{array}$ & --------- \\
\hline
\end{tabular}

*Front. Vel: frontalização de velar; Plo. Fric.: plosivação de fricativas; Simp. Enc.: simplificação de encontro consonantal; Ens. Plos.: ensurdecimento de plosivas; Simp. Liq.: simplificação de líquidas; Outros: processos desviantes. 
TABELA 24 - Comparação do nível de desenvolvimento fonológico apresentado pelo sujeito 2 ao fim de cada ciclo de intervenção

\begin{tabular}{|c|c|c|c|}
\hline \multirow[b]{2}{*}{$\begin{array}{l}\text { ORGANIZAÇÃO } \\
\text { FONOLÓGICA }\end{array}$} & ENFOQUE NO PIL & PIL & ENFOQUE DIRETO \\
\hline & $\begin{array}{c}\text { PROCESSOS } \\
\text { FONOLÓGICOS* } \\
\text { A2 }\end{array}$ & $\begin{array}{c}\text { PROCESSOS } \\
\text { FONOLÓGICOS } \\
\text { PRODUTIVOS* } \\
\text { A3 }\end{array}$ & $\begin{array}{c}\text { PROCESSOS } \\
\text { FONOLÓGICOS } \\
\text { PRODUTIVOS* } \\
\text { A4 }\end{array}$ \\
\hline $\begin{array}{l}\text { NOMEAÇÃO } \\
\text { ESPONTÂNEA }\end{array}$ & 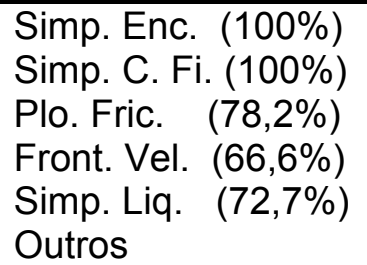 & $\begin{array}{l}\text { Simp. Enc. }(100 \%) \\
\text { Simp. C. Fi. }(100 \%) \\
\text { Front. Vel. }(33,3 \%) \\
\text { Simp. Liq. } \quad(72,7 \%) \\
\text { Front. Pal. }(80 \%) \\
\text { Outros }\end{array}$ & $\begin{array}{ll}\text { Simp. Enc. } & (50 \%) \\
\text { Simp. C. Fi. } & (80 \%) \\
\text { Simp. Liq. } & (50 \%) \\
\text { Outros } & \end{array}$ \\
\hline
\end{tabular}

*Simp. Enc.: simplificação de encontro consonantal; Simp. C. Fi.: simplificação de consoante final; Plo. Fric: plosivação de fricativas; Front. Vel: frontalização de velar; Simp. Liq.: simplificação de líquidas; Front. Pal.; frontalização de palatal; Outros: processos desviantes

TABELA 25 - Comparação do nível de desenvolvimento fonológico apresentado pelo sujeito 3 ao fim de cada ciclo de intervenção

\begin{tabular}{|c|c|c|c|}
\hline \multirow[b]{2}{*}{$\begin{array}{l}\text { ORGANIZAÇÃO } \\
\text { FONOLÓGICA }\end{array}$} & ENFOQUE NO PIL & ગIL & ENFOQUE DIRETO \\
\hline & $\begin{array}{c}\text { PROCESSOS } \\
\text { FONOLÓGICOS* } \\
\text { A2 }\end{array}$ & $\begin{array}{l}\text { PROCESSOS } \\
\text { FONOLÓGICOS } \\
\text { PRODUTIVOS* } \\
\text { A3 }\end{array}$ & $\begin{array}{l}\text { PROCESSOS } \\
\text { FONOLÓGICOS } \\
\text { PRODUTIVOS* } \\
\text { A4 }\end{array}$ \\
\hline $\begin{array}{l}\text { NOMEAÇÃO } \\
\text { ESPONTÂNEA }\end{array}$ & $\begin{array}{ll}\text { Simp. Enc. } & (100 \%) \\
\text { Simp. C. Fi. } & (100 \%) \\
\text { Plo. Fric. } \quad(78,2 \%) \\
\text { Front. Vel. } & (66,6 \%) \\
\text { Simp. Liq. } & (72,7 \%) \\
\text { Outros } & \end{array}$ & $\begin{array}{l}\text { Simp. Enc. }(100 \%) \\
\text { Simp. C. Fi. }(100 \%) \\
\text { Front. Vel. }(33,3 \%) \\
\text { Simp. Liq. } \quad(72,7 \%) \\
\text { Front. Pal. }(80 \%) \\
\text { Outros }\end{array}$ & $\begin{array}{ll}\text { Simp. Enc. } & (50 \%) \\
\text { Simp. C. Fi. } & (80 \%) \\
\text { Simp. Liq. } & (50 \%) \\
\text { Outros } & \end{array}$ \\
\hline
\end{tabular}

*Simp. Enc.: simplificação de encontro consonantal; Simp. C. Fi.: simplificação de consoante final; Simp. Liq.: simplificação de líquida; Front. Pal.: frontalização de palatal; Ens. Fric.: ensurdecimento de fricativa; Ens. Plos.: ensurdecimento de plosiva; Outros: processos desviantes 
TABELA 26 - Comparação do nível de desenvolvimento fonológico apresentado pelo sujeito 4 ao fim de cada ciclo de intervenção

\begin{tabular}{|c|c|c|c|}
\hline \multirow{2}{*}{$\begin{array}{l}\text { ORGANIZAÇÃO } \\
\text { FONOLÓGICA }\end{array}$} & \multicolumn{2}{|c|}{ ENFOQUE DIRETO } & ENFOQUE NO PIL \\
\hline & $\begin{array}{c}\text { PROCESSOS } \\
\text { FONOLÓGICOS } \\
\text { A2 }\end{array}$ & $\begin{array}{c}\text { PROCESSOS } \\
\text { FONOLÓGICOS* } \\
\text { A3 }\end{array}$ & $\begin{array}{c}\text { PROCESSOS } \\
\text { FONOLÓGICOS* } \\
\text { A4 }\end{array}$ \\
\hline $\begin{array}{l}\text { NOMEAÇÃO } \\
\text { ESPONTÂNEA }\end{array}$ & $\begin{array}{l}\text { Simp. Enc. }(100 \%) \\
\text { Front. Vel }(77,8 \%) \\
\text { Front. Pal. }(40,0 \%) \\
\text { Simp. Liq. }(42,8 \%) \\
\text { Simp. C. Fi. }(25,0 \%) \\
\text { Outros }\end{array}$ & $\begin{array}{l}\text { Simp. Enc. }(100 \%) \\
\text { Front. Vel }(77,7 \%) \\
\text { Front. Pal. }(40,0 \%) \\
\text { Simp. Liq. }(36,3 \%) \\
\text { Simp. C. Fi. }(25,0 \%) \\
\text { Outros }\end{array}$ & $\begin{array}{l}\text { Simp. Enc. }(87,5 \%) \\
\text { Simp. Liq. }(27,2 \%) \\
\text { Post. Vel. }(25 \%)\end{array}$ \\
\hline
\end{tabular}

*Simp. Enc.: simplificação de encontro consonantal; Front. Vel.: frontalização de velar; Front. Pal.: frontalização de palatal; Simp. Liq.: simplificação de líquidas; Simp. C. Fi.: simplificação de consoante final; Post. Vel.: posteriorização para velar; Outros: processos desviantes

\section{d) Organização Morfossintática / Subteste Closura Gramatical do ITPA}

Os itens pertinentes à organização morfossintática já foram descritos anteriormente no dado alusivo à Closura Gramatical, que avalia a recepção e também a produção morfossintática. Como foi descrito, para a maioria dos sujeitos, a diferença da taxa de desenvolvimento alcançada também foi maior quando submetidos à intervenção com enfoque no PIL (sujeito 2, 3 e 4).

\section{e) Produção lexical I Prova de Vocabulário do ABFW - Teste de Linguagem Infantil}

Na tabela 27 encontra-se representada a comparação do nível de desenvolvimento obtido pelos sujeitos ao fim de cada ciclo de intervenção, por meio do número de designações por vocábulos usuais (DVU), número de processos de substituição (PS) utilizados e não-designações (ND). De acordo com o teste utilizado, é esperado que o significado das palavras evolua junto ao processo de evolução cognitiva, sendo esperado o aumento no número de DVU e redução dos PS e ND. Desse modo, os valores de DVU acompanhados de sinal positivo (+) e os valores de PS e ND acompanhados de sinal negativo (-) representam que o sujeito apresentou desenvolvimento na produção lexical. 
Como se pode observar, todos os sujeitos apresentaram um aumento do número de DVU, e uma diminuição do número de ND e PS no final de todo o processo de intervenção. As diferenças entre A2-A3 e A3-A4 não apontaram benefício maior de um ou outro Modelo. Para os sujeitos 1 e 2 o maior índice de desenvolvimento foi atingido quando submetidos à intervenção com ED nos subsistemas de linguagem. Já para os sujeitos 3 e 4 o oposto foi observado. Para todos os sujeitos a maior taxa de desenvolvimento ocorreu no final do processo, independente do modelo.

TABELA 27 - Comparação do nível de desenvolvimento obtido na produção lexical ao fim de cada ciclo de intervenção

\begin{tabular}{|c|c|c|c|c|c|c|c|}
\hline \multirow[b]{2}{*}{ SUJEITO } & \multirow[b]{2}{*}{ TIPO } & \multirow{2}{*}{$\begin{array}{c}\text { MECANISMO } \\
\text { DE } \\
\text { NOMEAÇÃO }\end{array}$} & \multicolumn{5}{|c|}{ PRODUÇÃO LEXICAL } \\
\hline & & & $\mathrm{A} 2$ & A3 & A4 & $\begin{array}{c}\text { DIFERENÇA } \\
\text { A2-A3 }\end{array}$ & $\begin{array}{c}\text { DIFERENÇA } \\
\text { A3-A4 }\end{array}$ \\
\hline \multirow{3}{*}{01} & & DVU & 63 & 72 & 95 & +09 & +23 \\
\hline & *PIL/ED & ND & 10 & 05 & 04 & -05 & -01 \\
\hline & & PS & 45 & 41 & 19 & -04 & -22 \\
\hline \multirow{3}{*}{02} & & DVU & 85 & 81 & 99 & -04 & +18 \\
\hline & PIL/ED & ND & 0 & 0 & 0 & 0 & 0 \\
\hline & & PS & 33 & 37 & 18 & +04 & -19 \\
\hline \multirow{3}{*}{03} & & $\overline{D V U}$ & 34 & 50 & 86 & +16 & +36 \\
\hline & ${ }^{* *}$ ED/PIL & ND & 15 & 17 & 04 & +02 & -13 \\
\hline & & PS & 69 & 51 & 28 & -02 & -23 \\
\hline \multirow{3}{*}{04} & & DVU & 41 & 49 & 72 & +08 & +23 \\
\hline & ED/PIL & ND & 40 & 26 & 15 & -14 & -11 \\
\hline & & PS & 37 & 43 & 31 & +06 & -12 \\
\hline
\end{tabular}

${ }^{*}$ Processamento da informação lingüística (PIL) seguido de enfoque direto (ED)

${ }^{* *}$ Enfoque direto (ED) seguido do processamento da informação lingüística (PIL)

\section{f) Semântica / Subteste Associação Auditiva do ITPA}

Neste subteste, assim como no subteste Closura Gramatical, os resultados apresentados na tabela correspondem à IPL obtida pelos sujeitos, derivada do escore bruto alcançado. Do mesmo modo, as diferenças entre as diversas testagens também representam o nível desenvolvimento em meses manifestado pelas crianças.

$\mathrm{Na}$ tabela 28 apresentam-se os dados do subteste associação auditiva. As respostas dos sujeitos mostraram-se variadas. Nos sujeitos 1 e 3 , 
a intervenção com ED propiciou maior desenvolvimento; enquanto que para os sujeitos 2 e 4 não houve diferença nas taxas de desenvolvimento, considerando-se os Modelos de intervenção aplicados. Vale ressaltar que todos os sujeitos tiveram aumento na taxa de desenvolvimento após os 8 meses de intervenção.

TABELA 28 - Comparação do nível de desenvolvimento obtido na associação auditiva ao fim de cada ciclo de intervenção

\begin{tabular}{ccccccc}
\hline \multirow{2}{*}{ SUJEITO } & \multirow{2}{*}{ SEQÜÊNCIA } & \multicolumn{5}{c}{ SEMÂNTICA } \\
\cline { 3 - 7 } & DOS CICLOS & A2 & A3 & A4 & DIFERENÇA & DIFERENÇA \\
& & & & & A2-A3 & A3-A4 \\
\hline 01 & ${ }^{*}$ PIL/ED & 40 & 46 & 63 & +06 & $\mathbf{+ 1 7}$ \\
02 & PIL/ED & 54 & 69 & 84 & $\mathbf{+ 1 5}$ & $\mathbf{+ 1 5}$ \\
03 & ${ }^{* *}$ ED/PIL & 30 & 44 & 48 & $\mathbf{+ 1 4}$ & $\mathbf{+ 0 4}$ \\
04 & ED/PIL & 34 & 40 & 46 & $\mathbf{+ 0 6}$ & $\mathbf{+ 0 6}$ \\
\hline
\end{tabular}

*Processamento da informação lingüística (PIL) seguido de enfoque direto (ED)

**Enfoque direto (ED) seguido do processamento da informação lingüística (PIL)

\subsubsection{Memória de Curto Prazo / Subteste Memória Seqüencial Auditiva do ITPA}

Os resultados presentes na tabela 29 também estão representados pela IPL. Como pode ser observado, os sujeitos aqui também responderam de forma variada à intervenção. Para os sujeitos 2 e 4 houve um maior desenvolvimento desta função cognitiva em função do Procedimento com enfoque no PIL, enquanto para o sujeito 1 o oposto foi observado e para 0 sujeito 3 a mesma taxa de desenvolvimento foi atingida. Vale aqui também ressaltar que todos os sujeitos tiveram aumento na taxa de desenvolvimento após os 8 meses de intervenção. 
TABELA 29 - Comparação do nível de desenvolvimento obtido na avaliação da memória seqüencial auditiva ao fim de cada ciclo de intervenção

\begin{tabular}{ccccccc}
\hline \multirow{2}{*}{ SUJEITO } & \multirow{2}{*}{ SEQÜÊNCIA } & \multicolumn{5}{c}{ MEMÓRIA AUDITIVA DE CURTO PRAZO } \\
\cline { 3 - 7 } & DOS CICLOS & A2 & A3 & A4 & DIFERENÇA & DIFERENÇA \\
& & & & & A2-A3 & A3-A4 \\
\hline 01 & ${ }^{*}$ PIL/ED & 41 & 45 & 56 & +04 & $\mathbf{+ 1 1}$ \\
02 & PIL/ED & 34 & 56 & 68 & $+\mathbf{2 2}$ & +12 \\
03 & $* * E D / P I L ~$ & 24 & 30 & 36 & $\mathbf{+ 0 6}$ & $\mathbf{+ 0 6}$ \\
04 & ED/PIL & 30 & 30 & 39 & 0 & $\mathbf{+ 0 9}$ \\
\hline
\end{tabular}

*Processamento da informação lingüística (PIL) seguido de enfoque direto (ED)

${ }^{* *}$ Enfoque direto (ED) seguido do processamento da informação lingüística (PIL)

\subsubsection{Habilidades Pragmáticas}

Como apresentado no início deste capítulo, a comparação do GE e GC no que diz respeito no nível de desenvolvimento das habilidades pragmáticas, revelou uma defasagem do GE somente para o total de vezes em que esse grupo iniciou turnos de conversação e para o total de vezes em que seus integrantes fizeram uso de turnos expansivos. Desse modo, será apresentada na tabela 30 a taxa de desenvolvimento alcançada nesses dois critérios de análise.

Os resultados aqui não apontaram tendência para um ou outro Modelo em função do aumento da diferença das respostas dos sujeitos.

Todavia vale ressaltar que a maioria dos sujeitos (três dos quatro) melhorou seu desempenho nas habilidades pragmáticas no que tange aos critérios IC (iniciar conversação) e UTE (uso de turnos expansivos) ao final de todo o período do processo de intervenção. 
TABELA 30 -Comparação do nível de desenvolvimento obtido no desenvolvimento das habilidades pragmáticas ao fim de cada ciclo de intervenção

\begin{tabular}{|c|c|c|c|c|c|c|c|}
\hline \multirow[b]{2}{*}{ SUJEITO } & \multirow[b]{2}{*}{ TIPO } & \multirow{2}{*}{$\begin{array}{c}\text { CRITÉRIOS } \\
\text { DE } \\
\text { ANÁLISE }\end{array}$} & \multicolumn{5}{|c|}{ HABILIDADES PRAGMÁTICAS } \\
\hline & & & A2 & A3 & A4 & $\begin{array}{c}\text { DIFERENÇA } \\
\text { A2-A3 }\end{array}$ & $\begin{array}{c}\text { DIFERENÇA } \\
\text { A3-A4 }\end{array}$ \\
\hline \multirow{2}{*}{01} & \multirow{2}{*}{ *PIL/ED } & IC & 25 & 39 & 57 & +14 & +18 \\
\hline & & UTE & 15 & 20 & 55 & +05 & +35 \\
\hline \multirow{2}{*}{02} & \multirow{2}{*}{${ }^{*}$ PIL/ED } & IC & 25 & 53 & 70 & +28 & +17 \\
\hline & & UTE & 13 & 31 & 45 & +18 & +14 \\
\hline \multirow{2}{*}{03} & \multirow{2}{*}{${ }^{* *} \mathrm{ED} / \mathrm{PIL}$} & IC & 20 & 86 & 100 & +66 & +14 \\
\hline & & UTE & 10 & 40 & 55 & +30 & +15 \\
\hline \multirow{2}{*}{04} & \multirow{2}{*}{${ }^{* *} \mathrm{ED} / \mathrm{PIL}$} & $\mathrm{IC}$ & 10 & 04 & 08 & -06 & +04 \\
\hline & & UTE & 07 & 04 & 08 & -03 & +04 \\
\hline
\end{tabular}

*Processamento da informação lingüística (PIL) seguido de enfoque direto (ED)

**Enfoque direto (ED) seguido do processamento da informação lingüística (PIL) 
6 - DISCUSSÃO 


\section{DISCUSSÃO}

\subsection{Comparação do desempenho psicolingüístico dos grupos experimental (GE) e controle (GC) na avaliação pré-intervenção 1 (A1)}

As avaliações da linguagem oral, baseadas em Modelos Psicolingüísticos e/ou Neuropsicolingüístico propõem que se avalie, não somente a manifestação das dificuldades de linguagem apresentadas pela criança, mas que também que sejam investigados os vários níveis de processamento da linguagem oral que possibilitam 0 desenvolvimento satisfatório dos vários subsistemas lingüísticos (CHEVRIE-MULLER ${ }^{11}$, 2005).

Assim, os resultados das avaliações realizadas demonstraram que as crianças com Distúrbio Específico de Linguagem deste estudo são significativamente inferiores que seus pares com Desenvolvimento Típico de Linguagem em seu rendimento lingüístico e psicolingüístico. Como relatado em outros estudos (BISHOP ${ }^{6}$, 1992, CRESPO-EGUÍLAZ; NARBONA ${ }^{16}, 2003$, NAVARRETE et al. ${ }^{39}$, 2004, MUÑOZ-LÓPEZ; CARBALLO-GARCIA ${ }^{38}, 2005$, MONTGOMERY ${ }^{37}$, 2006, ARCHIBALD; GATHERCOLE ${ }^{3}$, 2006), elas apresentam uma ampla variedade de dificuldades envolvendo tanto o domínio lingüístico como o processamento da informação.

Analisando os níveis de significância obtidos na análise estatística (valores de p), é possível observar que tais dificuldades são mais significativas na realização de tarefas que envolvem a discriminação auditiva ( $p=0,003$ ), análise fonológica $(p=0,003)$, recepção e organização morfossintática ( $p=$ $0,003)$, memória de curto prazo $(p=0,003)$ e número de ocorrências em que as crianças fizeram uso de turnos expansivos $(p=0,003)$.

O estudo de CRESPO-EGUÍLAZ; NARBONA ${ }^{16}, 2003$, relatou que as características mais importantes no DEL, especificamente no subtipo fonológico-sintático, são dificuldades de discriminação auditiva, de compreensão e expressão morfossintática e fonológica e dificuldades no vocabulário expressivo, corroborando os achados desta dissertação. Vale 
ressaltar que, apesar do desempenho em prova de vocabulário expressivo nesta dissertação não ter sido tão significativo quanto os demais, também foi encontrado comprometimento neste domínio da linguagem $(p=0,010)$.

Todas elas (crianças com DEL) apresentaram dificuldades significativas relacionadas à recepção e organização do sistema fonológico da língua, manifestadas pelo pobre desempenho em consciência fonológica, inventário fonético reduzido, atraso na aquisição dos fonemas, uso de combinações silábicas simples e/ou de processos fonológicos desviantes. Considerando o nível receptivo do processamento da informação verbal, essas crianças demonstraram que discriminam auditivamente mal pares de palavras, o que está de acordo com os trabalhos que apontam que a dificuldade de discriminação auditiva encontra-se intimamente relacionada às dificuldades de recepção e organização do sistema fonológico das crianças com DEL (CERVERA; YGUAL ${ }^{9}$, 1994, CRESPO-EGUÍLAZ; NARBONA ${ }^{16}, 2003$, NAVARRETE et $\mathrm{al}^{39}$, 2004, MUÑHOZ-LOPEZ; CARBALLO-GARCIA ${ }^{39}$, 2005). No nível expressivo, a melhora ou não na repetição de algumas palavras indicou dificuldades na recuperação da informação fonológica no léxico mental, dificuldades ao nível de representação e/ou na produção articulatória dos fonemas. Apesar de o GE ter apresentado pior desempenho que o GC na avaliação das praxias articulatórias e buco-faciais, dificuldades no nível secundário da expressão, de programação motora foram excluídas. Ou seja, as dificuldades vinculadas ao desenvolvimento do sistema fonológico, nível terciário do processamento receptivo e expressivo, encontram-se, nestes casos, relacionadas às dificuldades nos níveis mais periféricos da análise e produção lingüística, mais especificamente, no nível secundário da análise lingüística (processo de reconhecimento auditivo-fonético) e nível primário da produção (processo de articulação dos sons).

Com relação às habilidades de consciência fonológica, os resultados coincidiram com os estudos sobre o tema que abordam as relações entre desenvolvimento lingüístico e metalingüística (MAJOR; BERNHARDT ${ }^{34}, 1998$, HIRSCHMAN $^{30}, 2000$, GILLON ${ }^{24}$, 2002). Como esperado, as crianças com DEL desempenharam-se significativamente pior que seus pares na avaliação da 
consciência fonológica, assim como ocorreu no estudo de ORTIZ; TIRAPEGUI ${ }^{41}, 2004$.

Como se sabe, os desenvolvimentos cognitivo e metalingüístico ocorrem de forma conjunta e inter-relacionada. A partir da estruturação do seu sistema fonológico e da possibilidade de produzir corretamente os sons da fala, a criança mostra-se apta a realizar algumas tarefas, as quais serão aprimoradas a partir da aquisição do código escrito. Assim, se a criança apresenta dificuldades na produção fonológica, dificilmente poderá fazer reflexões sobre esse componente, uma vez que, para realizar as tarefas metafonológicas é necessário que, além de refletir, a criança acesse as representações fonológicas ao nível de fonema, sílaba, palavras ou frases. Logo, se essas representações não se encontram bem estabelecidas, o acesso às estruturas requisitadas fica comprometido.

Alguns autores como, MAJOR; BERNHARDT ${ }^{34}$, 1998, também apontaram relações entre o desenvolvimento fonológico, metafonológico e morfossintático, sugerindo que as crianças que apresentam somente distúrbio fonológico tendem a uma melhor performance metalingüística comparado a crianças em que o distúrbio de linguagem envolve também a recepção e produção morfossintática. O distúrbio de linguagem apresentado pelas crianças do GE associou fonologia e morfossintaxe, o que pode ter agravado o pobre desempenho metafonológico delas. Logo, as deficiências manifestadas, para realizar a análise fonológica das palavras, também se encontram associadas às dificuldades no nível mais alto do processamento da informação lingüística, neste caso, o desempenho morfossintático. Este achado reflete a colocação de CHEVRIE-MULLER ${ }^{11}$, 2005, no que diz respeito à representação do Modelo Neuropsicolingüístico no nível terciário, vertente receptiva, sobre a existência de um funcionamento em paralelo, com as unidades de tratamento trabalhando de maneira encaixada e não independente.

Além de ser necessário que as operações e processamentos lingüísticos fonológicos, semânticos, lexicais ocorram de forma adequada, o desempenho metafonológico também se encontra relacionado aos aspectos cognitivos não lingüísticos, como a memória de trabalho. Em atividades 
metafonológicas é necessário que a criança retenha os estímulos por um breve período de tempo enquanto faz um julgamento a respeito da estrutura fonológica das palavras. De acordo com MONTGOMERY ${ }^{36}, 2003$, as crianças com DEL são deficitárias em tarefas de memória operacional, que envolvem o armazenamento de um estímulo verbal, enquanto a informação está sendo processada. Como o GE também apresentou desempenho ruim na avaliação da memória auditiva de curto prazo comparado ao GC, assim como aconteceu em outros estudos (CONTI-RAMSDEN; BOTTING; FARAGHER ${ }^{14}, 2001$, CONTI-RAMSDEN ${ }^{15}$, 2003, NAVARRETE et al. ${ }^{39}$, 2004, AGUADO et al. ${ }^{1}$, 2006), é possível que o déficit nessa habilidade tenha contribuído para um pobre desempenho metafonológico.

O déficit na memória de trabalho também tem sido associado às dificuldades morfossintáticas e de compreensão das crianças com DEL (MONTGOMERY ${ }^{36}$, 2003). Essa proposição pode, então, estar relacionada ao pobre rendimento do grupo na realização de tarefas de recepção lexical, morfossintática e semântica. Nesta última, especialmente, foi observado um mau desempenho de acordo com o aumento da complexidade sintática e extensão dos enunciados, o que reflete a dificuldade dessas crianças para exercer as funções duplas de armazenamento e processamento de uma informação verbal. Esses achados estão a favor do trabalho de ARCHIBALD; GATHERCOLE ${ }^{3}$, 2006, que referiram que a limitação na capacidade da memória de trabalho resulta em quebras dentro e entre os diferentes domínios lingüísticos, de modo a aumentar a demanda necessária para o processamento semântico e sintático, resultando em dificuldades nesses e outros domínios.

O pobre desempenho no subteste Closura Gramatical revelou as dificuldades enfrentadas por essas crianças para receber, organizar e produzir elementos morfológicos, as quais foram relacionadas a problemas de percepção auditiva, memória funcional e imprecisão das representações fonológicas (CRESPO-EGUÍLAZ; NARBONA ${ }^{16}$, 2003, MONTGOMERY ${ }^{36}, 2003$, MUÑOZ-LÓPEZ; CARBALLO-GARCIA ${ }^{38}$, 2005, ARCHIBALD; GATHERCOLE ${ }^{3}$, 2006). Para utilizar e aprender uma regra, a criança deve analisar fonologicamente as condições em que devem ocorrer essas formas gramaticais particulares, armazená-las na memória verbal de curto prazo, a qual permitirá a 
transferência das informações para a memória de longo prazo. Assim, esse processo vem a ser dificultado quando existe comprometimento nesses aspectos do processamento da informação.

O desempenho do GE na avaliação do vocabulário expressivo confirmou os achados de outros estudos de que a alteração da aquisição lexical faz parte do quadro de crianças com DEL. MUÑOZ-LÓPEZ; CARBALLO-GARCIA ${ }^{38}$, 2005, ARCHIBALD; GATHERCOLE ${ }^{3}$, 2006 referiram que, no plano, lexical as crianças com DEL apresentam dificuldades para aprender novas palavras de modo incidental, problemas para armazenar na memória de curto prazo as formas fonológicas de palavras novas e para criar e armazenar representações lexicais elaboradas. Como as representações fonológicas encontram-se pouco especificadas e, é a partir delas que o acesso ao significado e às demais representações das palavras acontece, as crianças deixam de nomear de modo usual e fazem uso de substituições ou recursos de significação na tentativa de nomear uma palavra-alvo.

Com relação às habilidades pragmáticas, a análise dos resultados revelou que os grupos diferenciaram-se no que diz respeito ao número de ocorrências em que a criança iniciou turnos de conversação e número de ocorrências em que a criança fez uso de turnos expansivos, comportamentos mais freqüentes nas amostras do GC. Não foi observada diferença significante concernente aos tipos de funções comunicativas utilizadas pelos grupos. Contudo, é importante frisar que estas foram utilizadas com muito mais freqüência pelas crianças do GC, principalmente a função de narrativa, que além de ser mais utilizada, demonstrou ser mais desenvolvida neste grupo. Esses achados podem ser atribuídos ao próprio desempenho lingüístico dos grupos. Se o desenvolvimento dos diferentes subsistemas lingüísticos ocorre de forma conjunta e interdependente, é esperado que a dificuldade ou atraso em um dos subsistemas lingüísticos - fonologia, sintaxe, semântica - possa resultar no uso diminuído ou prejudicado da pragmática. Ou seja, essas dificuldades pragmáticas provavelmente ocorrem em decorrência de déficit lingüístico apresentado pelas crianças, como o reduzido desenvolvimento lexical e morfossintático e a grande ocorrência de processos fonológicos. 


\subsection{Comparação do desempenho psicolingüístico dos sujeitos do GE após os distintos Programas de intervenção}

Baseado na revisão de literatura apresentada a respeito dos diferentes Procedimentos propostos para a intervenção fonoaudiológica junto aos distúrbios de linguagem, parte deste estudo dedicou-se à comparação da eficácia de dois distintos Modelos de Intervenção no desenvolvimento psicolingüístico de crianças com DEL que manifestaram, numa avaliação inicial, uma ampla variedade de deficiências nos aspectos situados nos vários níveis da análise e produção lingüística. Mais especificamente, procurou-se investigar se essas crianças se beneficiariam mais de um Programa de Intervenção tradicional, com enfoque direto (ED) sobre os subsistemas da linguagem oral ou de um Programa que considera as bases perceptivas e cognitivas implicadas com o processamento da informação lingüística (PIL).

Para facilitar a compreensão dos aspectos discutidos a seguir, será apresentado um quadro comparativo dos Procedimentos de intervenção estudados nesta pesquisa, construído a partir da literatura consultada e de uma análise reflexiva pessoal. 


\begin{tabular}{|c|c|}
\hline Semi-estruturado com ED & Estruturado com enfoque no PIL \\
\hline Contextos naturais são enfatizados & Pouca ênfase em contextos naturais \\
Objetivos lingüísticos pré-determinados & Objetivos lingüísticos pré-determinados \\
$\begin{array}{c}\text { A interação é dirigida prioritariamente } \\
\text { pelo terapeuta, mas a criança também é } \\
\text { estimulada a iniciar a interação }\end{array}$ & A interação é dirigida prioritariamente \\
pelo terapeuta
\end{tabular}

FIGURA 5 -Comparação entre o procedimento semi-estruturado com ED nos subsistemas de linguagem e o procedimento estruturado com enfoque no PIL

A análise dos resultados envoltos no processo de reconhecimento auditivo-fonético de pares de palavras ou capacidade de discriminação auditiva revelou que, de modo geral, os sujeitos obtiveram uma diferença de rendimento melhor na realização desta tarefa, quando submetidos à intervenção com enfoque no processamento da informação lingüística (PIL), baseado no MNPL.

Assim como nos estudos de WOLFE; PRESLEY; MESARIS ${ }^{52}, 2003$ e RVACHEW; NOWAK; CLOUTER ${ }^{44}$, 2004, em que a capacidade de percepção auditiva de sujeitos submetidos ao treino foi testada e comparada à de um GC, sendo obtidos melhores resultados para aqueles, estes resultados sugerem que, para aprimorar esta habilidade, um treino específico, com enfoque neste nível da análise da informação, é necessário. Os resultados também refletem a efetividade das estratégias implementadas neste estudo 
para desenvolver a capacidade de discriminação auditiva das crianças, visto a grande diferença no nível de desenvolvimento obtido pela maioria delas em função da intervenção com enfoque no PIL.

A observação da tabela 17 permite visualizar que o sujeito número 3, ao contrário dos demais, obteve uma taxa de desenvolvimento similar em função dos dois Procedimentos de intervenção, o que pode ser atribuído ao Modelo de intervenção fonológica utilizado neste estudo - Modelo de Pares Mínimos - que usa como unidade de análise e de trabalho os traços distintivos.

Também foi observado um efeito do Modelo de intervenção com enfoque no PIL, no desempenho de todos os sujeitos, em atividades metafonológicas. Ou seja, quando submetidos a esse Modelo de intervenção, a taxa de desenvolvimento alcançada foi maior em relação àquela atingida quando a intervenção abordou, diretamente, os subsistemas da linguagem. Esses resultados estão de acordo com os encontrados nos estudos de MAJOR; BERNHARDT ${ }^{34}$, 1998, GILLON²3, 2000, GILLON ${ }^{24}, 2002$ e SEGERS; VERHOEVEN ${ }^{45}, 2004$, em que as crianças submetidas ao treino da consciência fonológica atingiram desempenho satisfatório nessas tarefas em comparação àquelas submetidas a outras formas de tratamento, confirmando que a presença de dificuldades fonológicas severas não restringe o acesso dessas crianças aos benefícios da intervenção metafonológica.

Contudo, é importante discutir aqui a respeito do nível de desenvolvimento alcançado pelo sujeito 3 em cada ciclo de intervenção. Como demonstra a tabela 18, os valores foram bem próximos. Mais uma vez, esta particularidade pode ter ocorrido em decorrência do Modelo de intervenção fonológica utilizado - Pares Mínimos - que mesmo de uma forma menos implícita, trabalhou a consciência fonológica (STACKHOUSE et al. ${ }^{48}$, 2002). Os resultados apresentados também concordam com o estudo de MAJOR; BERNHARDT ${ }^{34}$, 1998, em que os autores sugeriram que mesmo que a intervenção fonológica direta seja eficaz para desenvolver a consciência fonológica, um treino metafonológico específico é necessário para melhor desenvolvimento de tais habilidades. Diante dos resultados apresentados, também se pode dizer que as estratégias selecionadas e implementadas foram 
ao encontro das necessidades dos pacientes, o que atesta que a hipótese inicial levantada foi condizente com as habilidades e deficiências das crianças e confirma a necessidade de implementação de estratégias individuais para o desenvolvimento metafonológico (BAKER et al. ${ }^{4}, 2001$, STACKHOUSE et al. ${ }^{48}$, 2002).

No estudo de CERVERA; YGUAL ${ }^{9}$, 1994, em que se apresenta uma metodologia para a intervenção fonológica com base em Modelos Psicolingüísticos, foi relatado que, para desenvolver a capacidade de análise fonológica das crianças - geralmente estimulada por meio de tarefas que obriguem a criança a selecionar estímulos apresentados de acordo com uma categoria fonológica, assim como acontece nas atividades metafonológicas - a capacidade de percepção é imprescindível. Considerando a mesma tendência de resultados referentes ao processo de reconhecimento auditivo-fonético (nível secundário da análise lingüística) e de análise fonológica (nível terciário da análise lingüística), pode-se dizer que essa colocação, assim como a apresentada por CHEVRIE-MULLER ${ }^{11}, 2005$, de que os níveis mais periféricos condicionam amplamente os mais centrais, foi confirmada neste estudo.

Com relação à recepção e produção morfossintática, que também corresponde a um nível mais central do tratamento da informação, foi observado que, para a maioria dos sujeitos, a diferença da taxa de desenvolvimento alcançada foi maior quando submetidos à intervenção com enfoque no PIL (sujeito 2, 3 e 4). Esse Modelo enfoca de maneira específica a capacidade de percepção auditiva e de consciência metalingüística, seja fonológica ou sintática, o que certamente favoreceu a realização da tarefa de identificação/recepção sintática de enunciados. HIRSCHMAN ${ }^{30}, 2000$, numa tentativa de aprimorar as habilidades sintáticas de crianças com DEL, desenvolveu junto a elas um Programa de remediação metalingüística e concluiu que esse método consiste uma ferramenta eficaz para a superação das dificuldades dessas crianças.

Contudo, esses dados devem ser interpretados com cautela, de modo a não desmerecer ou exaltar um ou outro procedimento de intervenção. Como pôde ser visto na literatura consultada, mais especificamente, nos 
estudos de FEY et al. ${ }^{21}$, 1993, FEY et al. ${ }^{22}$, 1994 e NELSON et al. ${ }^{40}$, 1996, em que os objetivos morfossintáticos foram trabalhados por meio de Procedimentos estruturados e/ou híbridos com ED nos subsistemas, as crianças tratadas foram beneficiadas com a implementação desses Programas, confirmando a eficácia dos mesmos. CONNELL ${ }^{13}, 1987$, inclusive, sugeriu a utilização de Procedimentos que façam uso da imitação como primeiro passo nos Programas de treinamento para o ensino das regras da língua.

No que tange à compreensão semântica, verificada pelo Token Test, o nível de desenvolvimento obtido pelos sujeitos quando submetidos a cada procedimento de intervenção foi variado. Contudo, houve uma tendência deste nível de análise da informação lingüística ter se beneficiado mais da intervenção com enfoque no PIL (sujeitos 2 e 3). Considerando a organização do MNPL (CHEVRIE-MULLER $\left.{ }^{11}, 2005\right)$, seus diferentes níveis e unidades de tratamento, verificamos que a compreensão semântica corresponde ao fim do processo de análise da informação lingüística. Assim, para que ela seja estabelecida, é necessário que uma série de mecanismos tenham sido executados de forma satisfatória, previamente, como por exemplo, o processo de reconhecimento auditivo-fonético, a análise fonológica, identificação lexical e sintática. Logo, os resultados deste nível de análise da informação, em função da intervenção com enfoque no PIL, podem ser atribuídos à capacidade deste procedimento de remediação em abordar os diferentes níveis do processamento, implicados à atividade lingüística (STACKHOUSE; WELLS ${ }^{47}$, 1993), neste caso especificamente, com a análise da informação.

Em relação à produção fonológica, pôde-se observar que houve uma diminuição do número de processos fonológicos utilizados pelos os sujeitos no final de todo o processo de intervenção. As diferenças entre A2-A3 e entre A3A4, não apontaram benefício maior de um ou de outro Modelo. O mesmo resultado foi encontrado na comparação do inventário fonético dos sujeitos. Constatou-se que houve uma expansão deste inventário para todos os sujeitos ao final de todo o período de intervenção, sem diferenças que indicassem benefício maior de um ou outro Modelo. 
Estes resultados já eram previstos, na medida em que o Modelo de Pares Mínimos, utilizado na intervenção com enfoque direto na Fonologia, apesar de não ser considerado um Modelo que trabalha de forma explícita os diferentes níveis do processamento, aborda em intervenção, mesmo que de forma implícita, alguns desses componentes necessários para o desenvolvimento do sistema fonológico. O trabalho envolvendo esses componentes, certamente auxiliou as crianças a formarem representações fonológicas das palavras mais precisas, acarretando em melhoras na produção fonológica.

Já o Modelo MNPL, explicitamente, se utiliza estratégias como exercícios articulatórios, colocação de fonemas com pistas táteis e sinestésicas e treino das habilidades de discriminação auditiva, como as descritas nos estudos de WATERS; HOWKES; BURNETT ${ }^{50}$, 1998. CERVERA; YGUAL ${ }^{9}$, 1994, CERVERA-MÉRIDA; YGUAL-FÉRNANDEZ ${ }^{10}, \quad 2003$, PASCOE; STACKHOUSE; WELLS ${ }^{42}, 2005$.

DODD; BRADFORD ${ }^{19}$, 2000 e CROSBIE; HOLM; DODD ${ }^{17}, 2005$ realizaram estudos em que diferentes tipos de intervenção foram aplicados no tratamento de crianças com distúrbio fonológico de naturezas distintas e concluíram que o tratamento que enfoca o nível de processamento da fala subjacente ao distúrbio resulta numa eficiente mudança no sistema fonológico delas. Através dos resultados obtidos, pode-se dizer que a intervenção baseada no MNPL conseguiu enfocar, por meio de treinos individuais e específicos, os níveis do processamento da informação comprometidos, promovendo a melhora dos aspectos psicolingüísticos relacionados ao distúrbio, mais especificamente da discriminação auditiva, análise fonológica e memória de trabalho, e que se encontravam relacionados às dificuldades fonológicas das crianças.

Com relação à eficácia da intervenção no desenvolvimento do vocabulário expressivo (tabela 27), todos os sujeitos tiveram um aumento do número de DVU e uma diminuição do número ND e PS no final de todo o processo de intervenção. As diferenças entre A2-A3 e entre A3-A4 não 
apontaram benefício maior de um ou outro Modelo, sugerindo que, também neste aspecto, as crianças se beneficiaram do processo como um todo.

No caso da intervenção com enfoque no PIL, as estratégias do Programa buscaram acionar os mecanismos relacionados com 0 processamento da informação, tornando-o mais eficaz quanto ao acesso ao léxico, já que foi enfocado na intervenção, memória de trabalho, consciência fonológica e precisão das representações fonológicas, aspectos importantes para a estabilização lexical. Quanto aos resultados obtidos com a intervenção direta sobre os subsistemas, é imprescindível lembrar, que esta envolveu a utilização de Procedimentos semi-estruturados/híbridos, com aplicação de técnicas como imitação, estimulação concentrada e produção eliciada em contextos naturais. Logo, a demanda pragmática solicitada neste Modelo de intervenção, provavelmente facilitou a generalização das palavras trabalhadas em terapia, conforme também descrito por KOURY ${ }^{31}$, 2005. Neste sentido, um Programa auxiliou o outro na melhora da produção lexical.

No que tange ao critério recepção lexical (Teste de vocabulário por Imagens Peabody), para a maioria dos sujeitos, excetuando-se o quarto, houve uma diferença maior de desenvolvimento quando submetidos à intervenção com ED nos subsistemas de linguagem. Esse resultado foi distinto dos demais descritos anteriormente, o que pode reforçar a idéia apresentada na introdução deste trabalho de que mesmo que uma criança aprenda e domine perfeitamente a execução das tarefas de processamento básico, ela não necessariamente vai melhorar as suas dificuldades lingüísticas por meio da utilização exclusiva do MNPL (MENDOZA ${ }^{35}$, 2006). KOURY ${ }^{31}$, 2005, relatou que a demanda pragmática envolvida nas sessões de intervenção exerce influência na aquisição lexical das crianças. Baseado nesta informação e nos resultados relacionados ao critério recepção lexical, pode ser que a combinação das estratégias desse Modelo de intervenção (MNPL), associada aos Procedimentos semi-estruturados da intervenção com ED, em que uma maior demanda pragmática é solicitada, seja o melhor caminho quando se deseja intervir junto a este subsistema de linguagem. 
Quanto às habilidades semânticas, MCP e habilidades pragmáticas as respostas dos sujeitos mostraram-se variadas, não apontando tendência para um ou outro Modelo, apesar de todos os sujeitos terem melhorado o desempenho nestes aspectos supracitados ao fim do processo. Especialmente no que concerne ao desempenho em atividade de MCP, é importante ressaltar aqui que resultados mais consistentes, apontando para um maior benefício da intervenção com enfoque no PIL eram esperados, uma vez este tipo de intervenção propõe a implementação de estratégias específicas para o desenvolvimento desta função cognitiva. Como pôde ser observado no capítulo Revisão de Literatura, os artigos apresentados referentes ao processo de intervenção baseado em MNPL, de uma maneira geral, são estudos de caso ou estudos teóricos. Apesar de eles apontarem para a necessidade de envolver em intervenção o trabalho com esta função, muito pouco é discutido a respeito de como estimular o desenvolvimento da mesma, que tipo de estratégias utilizar ou sobre momento do processo de intervenção em que elas devem ser enfatizadas quando existe uma gama de outros aspectos a serem trabalhados, o que dificulta a implementação das estratégias de intervenção, bem como a discussão de resultados terapêuticos relacionados.

MONTGOMERY ${ }^{36}, 2003$, descreveu, em revisão de literatura, que o envolvimento de tarefas metafonológicas em intervenção seria bem sucedido para a promoção da memória de trabalho. Nos resultados desta dissertação, como descrito anteriormente, as tarefas metafonológicas foram implementadas, com bons resultados para o desempenho metafonógico dos sujeitos, sem contudo ter sido acompanhada do mesmo nível de desenvolvimento da MCP. Diante desse achado, questiono quanto a utilização de atividades metafonológicas, realmente, constitui uma forma efetiva para desenvolver a memória de trabalho e qual a explícita relação entre esses componentes do processamento fonológico.

Os resultados relacionados aos critérios habilidades semânticas e pragmáticas também se mostraram variados, sem tendência para um ou outro Modelo. Neste sentido, apontam-se aqui algumas dificuldades e particularidades deste trabalho. A revisão de literatura consultada relativa ao processo de intervenção fez referência a estudos mais pontuais no que diz 
respeito aos critérios de análise, ou seja, ao verificar e/ou comparar a eficácia da intervenção junto aos distúrbios de linguagem, um único subsistema ou habilidade foi trabalhado e analisado. A inserção de vários critérios de análise neste estudo - que ocorreu em decorrência da necessidade de se investigar os vários níveis do processamento da linguagem - pode ter dificultado a obtenção de resultados mais uniformes, bem como a discussão de determinados achados, particularmente, daqueles relacionados aos critérios citados acima.

É importante alertar para o fato de que os resultados referentes à comparação da eficácia dos Procedimentos de Intervenção devem ser interpretados cautelosamente, em decorrência da amostra restrita do estudo, que não permitiu análise estatística e ainda por não haver sido encontrado um padrão mais uniforme dos resultados, o que impossibilita a generalização dos dados. Entretanto, isso não elimina a possibilidade de esses Procedimentos serem utilizados em futuras investigações.

Diante de todas as informações apresentadas neste e outros estudos, acredita-se que pesquisas com Programas de intervenção, apesar de trabalhosas e arriscadas, em função do grande número de variáveis a serem controladas e por se tratarem de estudos longitudinais, são fundamentais, não só para a verificação da eficácia do(s) procedimento(s) de interesse, mas também para o entendimento deste universo que são os mecanismos envolvidos numa função tão complexa e especificamente humana, como é a linguagem. 
7 - CONCLUSÕES 


\section{CONCLUSÕES}

1. A avaliação de linguagem, baseada no Modelo Neuropsicolingüístico, permitiu concluir que as crianças com DEL deste estudo apresentaram deficiências significativas no desenvolvimento psicolingüístico, em comparação a seus pares com Desenvolvimento Típico de Linguagem, que envolve aspectos situados em vários níveis de análise e produção lingüística. Essas dificuldades demonstraram ser mais significativas na realização de tarefas que envolvem a discriminação auditiva, análise fonológica, recepção e organização morfossintática, memória de curto prazo e habilidades pragmáticas quanto ao uso de turnos expansivos.

2. A eficácia do Programa de intervenção fonoaudiológica realizado neste estudo foi confirmada mediante o desempenho superior dos sujeitos na avaliação realizada ao fim de todo o processo de intervenção. Já a comparação da eficácia dos Modelos de intervenção propostos apontou que as distintas habilidades psicolingüísticas responderam de forma diferente aos mesmos.

No que tange à expressão lexical e fonológica, a maior taxa de desenvolvimento ocorreu ao final de todo o processo de intervenção, não sendo possível apontar benefício maior de um ou outro Modelo, sugerindo que nestes aspectos, as crianças se beneficiaram do processo integralmente. Quanto às habilidades semânticas, habilidades pragmáticas e memória de curto prazo, as respostas dos sujeitos mostraram-se variadas, não apontando tendência para um ou outro Modelo. Para as demais habilidades testadas (discriminação auditiva, análise fonológica, recepção e produção morfossintática, compreensão semântica) a diferença da taxa de desenvolvimento alcançada pelos sujeitos foi maior quando submetidos à intervenção com enfoque no processamento da informação lingüística. Somente para o critério recepção lexical houve uma diferença maior de desenvolvimento quando submetidos à intervenção com enfoque direto nos subsistemas de linguagem. 
Neste sentido, parece que a combinação das estratégias do Modelo Neuropsicolingüístico, associadas aos procedimentos da Intervenção no Meio, seja o melhor caminho quando se deseja intervir nos quadros de DEL de crianças cujas dificuldades encontram-se situadas nos níveis de análise e produção psicolingüística investigados neste trabalho. 
ANEXOS 
ANEXO 1 - Carta de Informação ao sujeito da pesquisa e Termo de Consentimento Livre e Esclarecido submetidos ao Comitê de Ética em Pesquisa da Faculdade de Odontologia de Bauru - USP

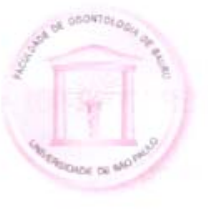

\author{
Universidade de São Paulo \\ Faculdade de Odontologia de Bauru \\ Al. Dr. Octávio Pinheiro Brisolla, 9-75 - Bauru-SP - CEP 17012-901 - \\ C.P. 73 \\ PABX (0XX14)235-8000 - FAX (0XX14)223-4679
}

\title{
CARTA DE INFORMAÇÃO
}

Bauru, 30 de setembro de 2005.

Caro responsável,

Estamos solicitando a participação da criança no estudo "Eficácia da intervenção fonoaudiológica em crianças com Distúrbio Específico de Linguagem".

Esta pesquisa quer verificar quanto as crianças com diagnóstico de Distúrbio Específico de Linguagem beneficiam-se, no que diz respeito ao desenvolvimento da linguagem oral, de um tratamento fonoaudiológico. Também participarão crianças que apresentem desenvolvimento normal de linguagem, pois elas fornecerão comparação, no que diz respeito ao desenvolvimento da linguagem. Todas as crianças passarão por três etapas de avaliação da linguagem oral, que implica no uso de testes verbais simples (falar ou entender palavras e/ou frases; apontar figuras). As crianças com diagnóstico de Distúrbio Específico de Linguagem participarão de um programa de tratamento fonoaudiológico, com duração de oito meses, em sessões de 45 minutos, duas vezes /semana. O trabalho envolverá uso de brinquedos, figuras para falar, comparar sons, entender frases. $O$ tratamento não causa dor e nem desconforto para a criança. Após o período de 8 meses, havendo ainda necessidade de tratamento, as crianças continuarão em tratamento na Clínica pelo período que for necessário.

Todos os procedimentos apresentados serão realizados na Clínica de Fonoaudiologia da Faculdade de Odontologia de Bauru - USP e o custo com o transporte, para a criança e um responsável, será de total responsabilidade da autora do projeto, bolsista CAPES.

Não haverá identificação do nome da criança e, caso você não aceite participar ou interrompa a sua participação durante a pesquisa, esta decisão será respeitada, sem prejuizos futuros para a criança, caso venha a necessitar dos atendimentos da Clínica em questão.

Você receberá o resultado de todos os procedimentos realizados, assim como todas suas dúvidas serão esclarecidas quando possivel. Além disso, a criança receberá os encaminhamentos e atendimentos, se necessários.

Desde já agradecemos a sua colaboração e colocamo-nos à disposição para mais esclarecimentos que se fizerem necessários.

"Caso os responsáveis pelas crianças apresentares dúvidas, poderá entrar em contato com a orientadora da pesquisa Profa. Dr ${ }^{\mathrm{a}}$. Simone Rocha de Vasconcellos Hage pelo telefone 32358232 , ou caso queiram apresentar alguma reclamação favor entrar em contato com o Comitê de Ética em Pesquisa em Seres Humanos, da FOB-USP, pelo endereço da Al. Dr. Octávio Pinheiro Brizolla, 9-75 (sala no prédio da Biblioteca, FOB-USP) ou pelo telefone (14) 3235-8356." 


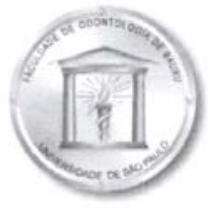

\author{
Universidade de São Paulo \\ Faculdade de Odontologia de Bauru \\ Al. Dr. Octávio Pinheiro Brisolla, 9-75 - Bauru-SP - CEP 17012-901 - \\ C.P. 73 \\ PABX (0XX14)235-8000 - FAX (0XX14)223-4679
}

TERMO DE CONSENTIMENTO LIVRE E ESCLARECIDO

Pelo presente instrumento que atende às exigências legais, o $\mathrm{Sr}$. (a)

portador da cédula de identidade responsável pelo menor após leitura minuciosa da CARTA

DE INFORMAÇÃO AO SUJEITO DA PESQUISA, devidamente explicada pelos profissionais em seus minimos detalhes, ciente dos serviços e procedimentos a serem realizados, não restando quaisquer dúvidas a respeito do lido e explicado, firma seu CONSENTIMENTO LIVRE E ESCLARECIDO para participar da pesquisa "Eficácia da intervenção fonoaudiológica em crianças com Distúrbio Específico de Linguagem."

Fica claro que o sujeito ou seu representante legal, pode a qualquer momento retirar seu CONSENTIMENTO LIVRE E ESCLARECIDO e deixar de participar desta pesquisa ciente de que todas as informações prestadas tornaram-se confidenciais e guardadas por força de sigilo profissional (Art. $29^{\circ}$ do Código de Ética do Fonoaudiólogo).

Por estarem de acordo assinam o presente termo.

Bauru-SP, de de 2005 
ANEXO 2 - Descrição dos resultados obtidos pelo sujeito 1 nas diversas dimensões psicolingüísticas avaliadas ao longo do processo de intervenção

- Descrição do sujeito 1:

Gênero: feminino / Idade no início do estudo: 6:6 anos (78 meses)

\begin{tabular}{|c|c|c|c|c|c|c|}
\hline \multirow{2}{*}{$\begin{array}{c}\text { HABILIDADES } \\
\text { PSICOLINGÜÍSTICAS }\end{array}$} & \multicolumn{3}{|c|}{ ENFOQUE NO PIL } & \multicolumn{3}{|c|}{ ENFOQUE DIRETO } \\
\hline & $\mathrm{A} 2$ & A3 & $\begin{array}{c}\text { DIFERENÇA } \\
\text { A2-A3 }\end{array}$ & A3 & A4 & $\begin{array}{c}\text { DIFERENÇA } \\
\text { A3-A4 }\end{array}$ \\
\hline RECONHECIMENTO & & & & & & \\
\hline AUDITIVO-FONÉTICO & 22 & 33 & 09 & 33 & 34 & 01 \\
\hline RECEPÇÃO & & & & & & \\
\hline FONOLÓGICA & 17 & 41 & 24 & 41 & 45 & 04 \\
\hline RECEPÇÃO E & & & & & & \\
\hline $\begin{array}{c}\text { ORGANIZAÇÃO } \\
\text { MORFOSSINTÁTICA }\end{array}$ & 55 & 61 & 06 & 61 & 72 & 11 \\
\hline RECEPÇÃO LEXICAL & 68 & 74 & 06 & 74 & 84 & 10 \\
\hline COMPREENSÃO & & & & & & \\
\hline SEMÂNTICA & 20 & 28 & 08 & 28 & 38 & 10 \\
\hline PRAXIAS & 18 & 20 & 02 & 20 & 20 & 0 \\
\hline DVU & 63 & 72 & 09 & 72 & 95 & 23 \\
\hline ND & 10 & 05 & -05 & 05 & 04 & -01 \\
\hline PS & 45 & 41 & -04 & 41 & 19 & -29 \\
\hline SEMÂNTICA & 40 & 46 & 06 & 46 & 63 & 17 \\
\hline $\begin{array}{c}\text { MEMÓRIA DE CURTO } \\
\text { PRAZO }\end{array}$ & 41 & 45 & 04 & 45 & 56 & 11 \\
\hline
\end{tabular}




\begin{tabular}{|c|c|c|c|}
\hline \multirow{2}{*}{$\begin{array}{l}\text { ORGANIZAÇÃO } \\
\text { FONOLÓGICA }\end{array}$} & ENFOQUE NO PIL & & ENFOQUE DIRETO \\
\hline & $\mathrm{A} 2$ & A3 & $\mathrm{A} 4$ \\
\hline & Front. Vel. (100\%) & Front. Vel. $(0 \%)$ & Front. Vel. (0\%) \\
\hline & Plo. Fric. $\quad(86,9 \%)$ & Plo. Fric. $\quad(34,7 \%)$ & Plo. Fric. $\quad(0 \%)$ \\
\hline NOMEAÇÃO & Simp. Enc. $(62,5 \%)$ & Simp. Enc. $(62,5 \%)$ & Simp. Enc. (0\%) \\
\hline \multirow[t]{6}{*}{ ESPONTÂNEA } & Ens. Plos. $(44,4 \%)$ & Ens. Plos. $(28,5 \%)$ & Ens. Plos. (0\%) \\
\hline & Simp. Liq. $\quad(27,2 \%)$ & Simp. Liq. $(27,2 \%)$ & Simp. Liq. $(18,8 \%)$ \\
\hline & Outros & Outros & Outros \\
\hline & Front. Vel. $(70,5 \%)$ & Front. Vel. (0\%) & Front. Vel. (0\%) \\
\hline & Plo. Fric. $\quad(81,8 \%)$ & Plo. Fric. $\quad(32,7 \%)$ & Plo. Fric. $\quad(0 \%)$ \\
\hline & Simp. Enc. $(62,5 \%)$ & Simp. Enc. $(41,6 \%)$ & Simp. Enc. (0\%) \\
\hline \multirow[t]{3}{*}{ REPETIÇÃO } & Ens. Plos. (16,6\%) & Ens. Plos. $(28,5 \%)$ & Ens. Plos. (0\%) \\
\hline & Simp. Liq. $(27,2 \%)$ & Simp. Liq. $(14,2 \%)$ & Simp. Liq. $(18,8 \%)$ \\
\hline & Outros & Outros & Outros $\quad(0 \%)$ \\
\hline
\end{tabular}

\begin{tabular}{cccc|ccc}
\hline \multirow{2}{*}{$\begin{array}{c}\text { HABILIDADES } \\
\text { PRAGMÁTICAS }\end{array}$} & \multicolumn{3}{c}{ ENFOQUE NO PIL } & \multicolumn{3}{c}{ ENFOQUE DIRETO } \\
\cline { 2 - 7 } TTV & A3 & $\begin{array}{c}\text { DIFERENÇA } \\
\text { A2-A3 }\end{array}$ & A3 & A4 & $\begin{array}{c}\text { DIFERENÇA } \\
\text { A3-A4 }\end{array}$ \\
\hline TTNV & 45 & 84 & $\mathbf{3 9}$ & 84 & 130 & $\mathbf{4 6}$ \\
IC & 0 & 01 & $\mathbf{0 1}$ & 01 & 11 & $\mathbf{1 0}$ \\
RMC & 25 & 39 & $\mathbf{1 4}$ & 39 & 57 & $\mathbf{1 8}$ \\
UTS & 20 & 45 & $\mathbf{2 5}$ & 45 & 75 & $\mathbf{3 0}$ \\
UTE & 30 & 66 & $\mathbf{3 6}$ & 66 & 75 & $\mathbf{0 9}$ \\
\hline
\end{tabular}


ANEXO 3 - Descrição dos resultados obtidos pelo sujeito 2 nas diversas dimensões psicolingüísticas avaliadas ao longo do processo de intervenção

- Descrição do sujeito 2:

Gênero: masculino / Idade no início do estudo: 6:0 anos (60 meses)

\begin{tabular}{ccccccc}
\hline HABILIDADES & \multicolumn{3}{c}{ ENFOQUE NO PIL } & \multicolumn{3}{c}{ ENFOQUE DIRETO } \\
\cline { 2 - 7 } PSICOLINGUÍSTICAS & A2 & A3 & $\begin{array}{c}\text { DIFERENÇA } \\
\text { A2-A3 }\end{array}$ & A3 & A4 & $\begin{array}{c}\text { DIFERENÇA } \\
\text { A3-A4 }\end{array}$ \\
\hline $\begin{array}{c}\text { RECONHECIMENTO } \\
\text { AUDITIVO-FONÉTICO } \\
\text { RECEPÇÃO }\end{array}$ & 28 & 35 & $\mathbf{0 7}$ & 35 & 34 & $\mathbf{- 0 1}$ \\
$\begin{array}{c}\text { FONOLÓGICA } \\
\text { RECEPÇÃO E }\end{array}$ & 18 & 40 & $\mathbf{2 2}$ & 40 & 48 & $\mathbf{0 8}$ \\
$\begin{array}{c}\text { ORGANIZAÇÃO } \\
\text { MORFOSSINTÁTICA }\end{array}$ & 61 & 69 & $\mathbf{0 8}$ & 69 & 74 & $\mathbf{0 5}$ \\
$\begin{array}{c}\text { RECEPÇÃO LEXICAL } \\
\text { COMPREENSÃO }\end{array}$ & 84 & 78 & $\mathbf{- 0 6}$ & 78 & 102 & $\mathbf{2 4}$ \\
$\begin{array}{c}\text { SEMÂNTICA } \\
\text { PRAXIAS }\end{array}$ & 27 & 46 & $\mathbf{1 9}$ & 46 & 46 & $\mathbf{0}$ \\
DVU & 16 & 16 & $\mathbf{0}$ & 16 & 16 & $\mathbf{0}$ \\
ND & 85 & 81 & $\mathbf{- 0 4}$ & 81 & 99 & $\mathbf{1 8}$ \\
PS & 0 & 0 & $\mathbf{0}$ & 0 & 01 & $\mathbf{0 1}$ \\
$\begin{array}{c}\text { SEMÂNTICA } \\
\text { MEMÓRIA DE CURTO }\end{array}$ & 54 & 69 & $\mathbf{1 5}$ & 69 & 84 & $\mathbf{1 5}$ \\
\hline PRAZO & 34 & 56 & $\mathbf{2 2}$ & 56 & 68 & $\mathbf{1 2}$ \\
\hline
\end{tabular}




\begin{tabular}{|c|c|c|c|}
\hline \multirow[t]{2}{*}{$\begin{array}{l}\text { ORGANIZAÇÃO } \\
\text { FONOLÓGICA }\end{array}$} & \multicolumn{2}{|c|}{ ENFOQUE NO PIL } & IFOQUE DIRETO \\
\hline & $\mathrm{A} 2$ & A3 & $\mathrm{A} 4$ \\
\hline $\begin{array}{l}\text { NOMEAÇÃO } \\
\text { ESPONTÂNEA }\end{array}$ & $\begin{array}{ll}\text { Simp. Enc. } & (100 \%) \\
\text { Simp. C. Fi. }(100 \%) \\
\text { Plo. Fric. } \quad(78,2 \%) \\
\text { Front. Vel. } \quad(66,6 \%) \\
\text { Simp. Liq. } & (72,7 \%) \\
\text { Outros } & \end{array}$ & $\begin{array}{ll}\text { Simp. Enc. } & (100 \%) \\
\text { Simp. C. Fi. }(100 \%) \\
\text { Plos. Fric } \quad(0 \%)- \\
\text { Front. Vel. } & (33,3 \%) \\
\text { Simp. Liq. } & (72,7 \%) \\
\text { Front. Pal. } & (80 \%) \\
\text { Outros } & \end{array}$ & $\begin{array}{ll}\text { Simp. Enc. } & (50 \%) \\
\text { Simp. C. Fi. } & (80 \%) \\
\text { Plos. Fric } & (0 \%)- \\
\text { Front. Vel. } & (0 \%) \\
\text { Simp. Liq. } & (50 \%) \\
\text { Front. Pal. } & (0 \%) \\
--.-- & \end{array}$ \\
\hline REPETIÇÃO & $\begin{array}{ll}\text { Simp. Enc. } & (100 \%) \\
\text { Simp. C. Fi } & (100 \%) \\
\text { Plo. Fric. } & (63,6 \%) \\
\text { Front. Vel. } & (60,6 \%) \\
\text { Simp. Liq. } & (45,4 \%) \\
\text { Outros } & \end{array}$ & $\begin{array}{l}\text { Simp. Enc. }(100 \%) \\
\text { Simp. C. Fi. }(100 \%) \\
\text { Plos. Fric. } \quad(0 \%) \\
\text { Front. Vel. } \\
(33,0 \%) \\
\text { Simp. Liq. } \\
(71,4 \%) \\
\text { Front. Pal. } \quad(0 \%) \\
\text { Outros }\end{array}$ & $\begin{array}{ll}\text { Outros } & \\
\text { Simp. Enc. } & (50 \%) \\
\text { Simp. C. Fi. } & (50 \%) \\
\text { Plos. Fric } & (0 \%)- \\
\text { Front. Vel. } & (0 \%) \\
\text { Simp. Liq. } & (50 \%) \\
\text { Front. Pal. } & (0 \%) \\
\text { Outros } & \end{array}$ \\
\hline
\end{tabular}

\begin{tabular}{ccccccc}
\hline \multirow{2}{*}{$\begin{array}{c}\text { HABILIDADES } \\
\text { PRAGMÁTICAS }\end{array}$} & \multicolumn{3}{c}{ ENFOQUE NO PIL } & \multicolumn{3}{c}{ ENFOQUE DIRETO } \\
\cline { 2 - 7 } TTV & A3 & $\begin{array}{c}\text { DIFERENÇA } \\
\text { A2-A3 }\end{array}$ & A3 & A4 & $\begin{array}{c}\text { DIFERENÇA } \\
\text { A3-A4 }\end{array}$ \\
\hline TTNV & 54 & 130 & $\mathbf{7 6}$ & 130 & 145 & $\mathbf{1 5}$ \\
IC & 0 & 02 & $\mathbf{0 2}$ & 02 & 02 & $\mathbf{0}$ \\
RMC & 27 & 53 & $\mathbf{2 6}$ & 53 & 70 & $\mathbf{1 7}$ \\
UTS & 27 & 77 & $\mathbf{4 0}$ & 77 & 75 & $\mathbf{0 2}$ \\
& 41 & 99 & $\mathbf{5 8}$ & 99 & 100 & $\mathbf{0 1}$ \\
UTE & 13 & 31 & $\mathbf{1 8}$ & 31 & 45 & $\mathbf{1 4}$ \\
\hline
\end{tabular}


ANEXO 4 - Descrição dos resultados obtidos pelo sujeito 3 nas diversas dimensões psicolingüísticas avaliadas ao longo do processo de intervenção

- Descrição do sujeito 3:

Gênero: feminino / Idade no início do estudo: 4:7 anos (55 meses)

\begin{tabular}{|c|c|c|c|c|c|c|}
\hline \multirow{2}{*}{$\begin{array}{c}\text { HABILIDADES } \\
\text { PSICOLINGUÍSTICAS }\end{array}$} & \multicolumn{3}{|c|}{ ENFOQUE NO DIRETO } & \multicolumn{3}{|c|}{ ENFOQUE NO PIL } \\
\hline & $\mathrm{A} 2$ & A3 & $\begin{array}{c}\text { DIFERENÇA } \\
\text { A2-A3 }\end{array}$ & A3 & A4 & $\begin{array}{c}\text { DIFERENÇA } \\
\text { A3-A4 }\end{array}$ \\
\hline $\begin{array}{l}\text { RECONHECIMENTO } \\
\text { AUDITIVO-FONÉTICO }\end{array}$ & 24 & 29 & 05 & 29 & 33 & 04 \\
\hline $\begin{array}{l}\text { RECEPÇÃO } \\
\text { FONOLÓGICA }\end{array}$ & 0 & 18 & 18 & 18 & 40 & 22 \\
\hline $\begin{array}{c}\text { RECEPÇÃO E } \\
\text { ORGANIZAÇÃO } \\
\text { MORFOSSINTÁTICA }\end{array}$ & 30 & 34 & 04 & 34 & 51 & 17 \\
\hline RECEPÇÃO LEXICAL & 61 & 88 & 27 & 88 & 91 & 03 \\
\hline $\begin{array}{l}\text { COMPREENSÃO } \\
\text { SEMÂNTICA }\end{array}$ & 20 & 17 & -03 & 17 & 34 & 17 \\
\hline PRAXIAS & 16 & 16 & 0 & 16 & 16 & 0 \\
\hline DVU & 34 & 50 & 16 & 50 & 86 & 36 \\
\hline ND & 15 & 17 & 02 & 17 & 04 & -13 \\
\hline PS & 69 & 51 & -18 & 51 & 28 & -28 \\
\hline SEMÂNTICA & 30 & 44 & 14 & 44 & 48 & 04 \\
\hline $\begin{array}{c}\text { MEMÓRIA DE CURTO } \\
\text { PRAZO }\end{array}$ & 24 & 30 & 06 & 30 & 36 & 06 \\
\hline
\end{tabular}




\begin{tabular}{|c|c|c|c|}
\hline \multirow[t]{2}{*}{$\begin{array}{l}\text { ORGANIZAÇÃO } \\
\text { FONOLÓGICA }\end{array}$} & \multicolumn{2}{|c|}{ ENFOQUE DIRETO } & ENFOQUE NO PIL \\
\hline & $\mathrm{A} 2$ & A3 & $\mathrm{A} 4$ \\
\hline $\begin{array}{l}\text { NOMEAÇÃO } \\
\text { ESPONTÂNEA }\end{array}$ & $\begin{array}{ll}\text { Simp. Enc. } & (100 \%) \\
\text { Simp. C. Fi } & (100 \%) \\
\text { Simp. Liq. } & (82,0 \%) \\
\text { Front. Pal. } & (60,0 \%) \\
\text { Ens. Fric. } & (44,4 \%) \\
\text { Ens. Plos. } & (35,7 \%) \\
\text { Outros } & \end{array}$ & $\begin{array}{ll}\text { Simp. Enc. } & (100 \%) \\
\text { Simp. C. Fi } & (100 \%) \\
\text { Simp. Liq. } & (50,0 \%) \\
\text { Front. Pal. } & (60,0 \%) \\
\text { Ens. Fric. } & (0 \%) \\
\text { Ens. Plos. } & (57,1 \%) \\
\text { Outros } \quad(0 \%)\end{array}$ & $\begin{array}{ll}\text { Simp. Enc. } & (75 \%) \\
\text { Simp. C. Fi }(0 \%) \\
\text { Simp. Liq. } & (36,3 \%) \\
\text { Front. Pal. } & (0 \%) \\
\text { Ens. Fric. } & (22,2 \%) \\
\text { Ens. Plos. } & (28,5 \%) \\
\text { Outros } & (0 \%)\end{array}$ \\
\hline REPETIÇÃO & $\begin{array}{l}\text { Simp. Enc. }(100 \%) \\
\text { Simp. C. Fi }(100 \%) \\
\text { Simp. Liq. }(82,0 \%) \\
\text { Front. Pal. }(57 \%) \\
\text { Ens. Fric. }(44,4 \%) \\
\text { Ens. Plos. }(34,0 \%) \\
\text { Outros }\end{array}$ & $\begin{array}{ll}\text { Simp. Enc. } & (100 \%) \\
\text { Simp. C. Fi } & (100 \%) \\
\text { Simp. Liq. } & (50,0 \%) \\
\text { Front. Pal. } & (50,0 \%) \\
\text { Ens. Fric. } & (0 \%) \\
\text { Ens. Plos. } & (22,2 \%) \\
\text { Outros } & (0 \%)\end{array}$ & $\begin{array}{l}\text { Simp. Enc. }(75 \%) \\
\text { Simp. C. Fi } 14,2 \%) \\
\text { Simp. Liq. }(14,2 \%) \\
\text { Front. Pal. }(16,6 \%) \\
\text { Ens. Fric. } \quad(22,2 \%) \\
\text { Ens. Plos. }(28,5 \%) \\
\text { Outros } \quad(0 \%)\end{array}$ \\
\hline
\end{tabular}

\begin{tabular}{ccccccc}
\hline \multirow{2}{*}{$\begin{array}{c}\text { HABILIDADES } \\
\text { PRAGMÁTICAS }\end{array}$} & \multicolumn{3}{c}{ ENFOQUE DIRETO } & \multicolumn{3}{c}{ ENFOQUE NO PIL } \\
\cline { 2 - 7 } TTV & 70 & 152 & $\mathbf{8 2}$ & 152 & 155 & $\mathbf{0 3}$ \\
\hline TTNV & 0 & 01 & $\mathbf{0 1}$ & 01 & 0 & $\mathbf{0 1}$ \\
A2-A3 & A3 & A4 & $\begin{array}{c}\text { DIFERENÇA } \\
\text { A3-A4 }\end{array}$ \\
IC & 50 & 86 & $\mathbf{3 6}$ & 86 & 100 & $\mathbf{1 4}$ \\
RMC & 20 & 83 & $\mathbf{6 3}$ & 83 & 55 & $\mathbf{- 2 8}$ \\
UTS & 60 & 112 & $\mathbf{6 2}$ & 112 & 100 & $\mathbf{- 1 2}$ \\
UTE & 10 & 40 & $\mathbf{3 0}$ & 40 & 55 & $\mathbf{1 5}$ \\
FUN & 06 & 07 & $\mathbf{0 1}$ & 07 & 07 & $\mathbf{0}$ \\
\hline
\end{tabular}


ANEXO 5 - Descrição dos resultados obtidos pelo sujeito 4 nas diversas dimensões psicolingüísticas avaliadas ao longo do processo de intervenção.

- Descrição do sujeito 4:

Gênero: feminino / Idade no início do estudo: 6:11 anos (83 meses)

\begin{tabular}{|c|c|c|c|c|c|c|}
\hline \multirow{2}{*}{$\begin{array}{c}\text { HABILIDADES } \\
\text { PSICOLINGUÍSTICAS }\end{array}$} & \multicolumn{3}{|c|}{ ENFOQUE NO DIRETO } & \multicolumn{3}{|c|}{ ENFOQUE NO PIL } \\
\hline & $\mathrm{A} 2$ & A3 & $\begin{array}{c}\text { DIFERENÇA } \\
\text { A2-A3 } \\
\end{array}$ & A3 & A4 & $\begin{array}{c}\text { DIFERENÇA } \\
\text { A3-A4 } \\
\end{array}$ \\
\hline $\begin{array}{l}\text { RECONHECIMENTO } \\
\text { AUDITIVO-FONÉTICO }\end{array}$ & 23 & 20 & -03 & 20 & 28 & 08 \\
\hline $\begin{array}{l}\text { RECEPÇÃO } \\
\text { FONOLÓGICA }\end{array}$ & 16 & 16 & 0 & 16 & 30 & 14 \\
\hline $\begin{array}{c}\text { RECEPÇÃO E } \\
\text { ORGANIZAÇÃO } \\
\text { MORFOSSINTÁTICA }\end{array}$ & 38 & 36 & -02 & 36 & 43 & 07 \\
\hline RECEPÇÃO LEXICAL & 58 & 59 & 01 & 59 & 63 & 04 \\
\hline $\begin{array}{l}\text { COMPREENSÃO } \\
\text { SEMÂNTICA }\end{array}$ & - & - & - & - & - & - \\
\hline PRAXIAS & 16 & 16 & 0 & 16 & 17 & 01 \\
\hline DVU & 41 & 49 & 08 & 49 & 72 & 23 \\
\hline ND & 40 & 26 & -14 & 26 & 15 & -11 \\
\hline PS & 37 & 43 & 06 & 43 & 31 & 12 \\
\hline SEMÂNTICA & 34 & 40 & 06 & 40 & 46 & 06 \\
\hline $\begin{array}{c}\text { MEMÓRIA DE CURTO } \\
\text { PRAZO }\end{array}$ & 30 & 30 & 0 & 30 & 39 & 09 \\
\hline
\end{tabular}




\begin{tabular}{|c|c|c|c|}
\hline \multirow[t]{2}{*}{$\begin{array}{l}\text { ORGANIZAÇÃO } \\
\text { FONOLÓGICA }\end{array}$} & \multicolumn{2}{|c|}{ ENFOQUE DIRETO } & NFOQUE NO PIL \\
\hline & $\bar{A} 2$ & $\overline{A 3}$ & $\overline{\mathrm{A} 4}$ \\
\hline \multirow{6}{*}{$\begin{array}{l}\text { NOMEAÇÃO } \\
\text { ESPONTÂNEA }\end{array}$} & Simp. Enc.(100\%) & Simp. Enc. $(100 \%)$ & Simp. Enc. $(87,5 \%)$ \\
\hline & Front. Vel $(77,8 \%)$ & Front. Vel $(77,7 \%)$ & Front. Vel. $(22,2 \%)$ \\
\hline & Front. Pal. $(40,0 \%)$ & Front. Pal. $(40,0 \%)$ & Front. Pal. $(20,0 \%)$ \\
\hline & Simp. Liq. $(42,8 \%)$ & Simp. Liq. $(36,3 \%)$ & Simp. Liq. $(27,2 \%)$ \\
\hline & Simp. C. F. $(25,0 \%)$ & Simp. C. F. $(25,0 \%)$ & Simp.C.F. $(20,0 \%)$ \\
\hline & Outros & Outros & $\begin{array}{ll}\text { Post. Vel. } & (25 \%) \\
\text { Outros } & (0 \%)\end{array}$ \\
\hline \multirow{6}{*}{ REPETIÇÃO } & Simp. Enc. $(75,0 \%)$ & Simp. Enc. $(75,0 \%)$ & Simp. Enc. $(66,6 \%)$ \\
\hline & Front. Vel $(77,8 \%)$ & Front. Vel. $(40,0 \%)$ & Front. Vel. $(23,5 \%)$ \\
\hline & Front. Pal. $(40,0 \%)$ & Front. Pal. $(40,0 \%)$ & Front. Pal. $(16,6 \%)$ \\
\hline & Simp. Liq . (36,3\%) & Simp. Liq. $(30,0 \%)$ & Simp. Liq. $(14,28 \%)$ \\
\hline & Simp. C. F. $(25,0 \%)$ & Simp. C. Fi. $(28,5 \%)$ & Simp.C.F. $(28,5 \%)$ \\
\hline & Outros & Outros & $\begin{array}{ll}\text { Post. Vel. } & (7,89 \%) \\
\text { Outros } & (0 \%)\end{array}$ \\
\hline
\end{tabular}

\begin{tabular}{|c|c|c|c|c|c|c|}
\hline \multirow{2}{*}{$\begin{array}{l}\text { HABILIDADES } \\
\text { PRAGMÁTICAS }\end{array}$} & \multicolumn{3}{|c|}{ ENFOQUE DIRETO } & \multicolumn{3}{|c|}{ ENFOQUE NO PIL } \\
\hline & $\mathrm{A} 2$ & A3 & $\begin{array}{c}\text { DIFERENÇA } \\
\text { A2-A3 }\end{array}$ & A3 & A4 & $\begin{array}{c}\text { DIFERENÇA } \\
\text { A3-A4 }\end{array}$ \\
\hline TTV & 25 & 36 & 11 & 36 & 38 & 02 \\
\hline TTNV & 0 & 10 & 10 & 10 & 10 & 0 \\
\hline IC & 10 & 04 & -06 & 04 & 08 & 04 \\
\hline $\mathrm{RMC}$ & 15 & 42 & 27 & 42 & 40 & -02 \\
\hline UTS & 18 & 32 & 14 & 32 & 30 & -02 \\
\hline UTE & 07 & 04 & -03 & 04 & 08 & 04 \\
\hline FUN & 05 & 06 & 01 & 06 & 06 & 0 \\
\hline
\end{tabular}


REFERÊNCIAS 


\section{REFERÊNCIAS}

1 AGUADO, G. et al. Repetición de pseudopalavras em niños españoles com transtorno específico del lenguaje: marcador psicolingüístico. Rev Neurol, Barcelona, v. 43, p. 201-208, 2006. Suplemento 1.

2 Alvarez, A. M.; CARVAlho, I. A. M. de; CAetano, A. L. Perfil de Habilidades Fonológicas. 2. ed. São Paulo: Via Lettera, 2004.

3 ARCHIBALD, L. M. D.; GATHERCOLE, S. E. Short term memory in specific language impairment. Int J Lang Commun Disord, London, v. 41, n. 6, p. 675-693, Nov./Dec. 2006.

4 BAKER, E. et al. Psycholinguistic models of speech development and their application to clinical practice. J Speech Lang Hear Res, Rockville, v. 44, n. 3, p. 685-702, Jun. 2001.

5 BÉFI-LOPES, D. M. Vocabulário. In: ANDRADE, C. R. F. de et al. ABFW: Teste de linguagem infantil nas áreas de fonología, vocabulário, fluência e pragmática. 2. ed. Carapicuíba: Pró-Fono, 2004. cap. 2, p. 41-59.

6 BISHOP, D. M. V. The underlying nature of Specific Language Imapirment. J Chil Psychol Psychiatry, Cambridge, v. 33, n. 1, p. 366, Jan-Mar. 1992.

7 BOGOSSIAN, M. A.; SANTOS, M. J. Teste Illinois de habilidades psicolingüísticas. Rio de Janeiro: EMPSI, 1977. 75 p.

8 8. CAPOVILLA, F. C.; CAPOVILLA, A. G. S. Desenvolvimento lingüístico na criança Brasileira dos dois aos seis anos: tradução e estandardização do Peabody Picture Vocabulary Test de Dunn \& Dunn e da Language Development Survey de Rescorla. Ciência Cognitiva: teoria, pesquisa e aplicação, São Paulo, v. 1, n. 1, p. 353380, jan./jun. 1997.

9 CERVERA, J. F.; YGUAL, A. Metodologia para la intervención logopédica em los transtornos del habla. Rev Logop Fon Audiol, v. 14, n. 1, p. 19-26. 1994.

10 CERVERA-MÉRIDA, J. F.; YGUAL-FÉRNANDEZ, A. Intervención logopédica em los transtornos fonológicos desde el paradigma psicolinguístico del processamento del habla. Rev Neurol, Barcelona, v. 36, p. 39-53, 2003. Supl. 1.

11 CHEVRIE-MULLER, C. Exploração da linguagem oral. In: CHEVRIEMULLER, C.; NARBONA, J. A linguagem da criança: aspectos normais e patológicos. 2. ed. Porto Alegre: Artmed, 2005. cap. 5, p. 101-133. 
12 COLE, K.N.; DALE, P. Direct language instruction and interative language instruction with language delayed preschool children: a comparison study. J Speech Hear Res, Rockville, v. 29, n. 2, p. 206-217, Jun. 1986.

13 CONNELL, P.J. An effect of modeling and imitation teaching procedures on children with and without specific language impairment. J Speech Hear Res, Rockville, v. 30, n. 1, p. 105-113, Mar. 1987.

14 CONTI-RAMSDEN, G.; BOTTING, N.; FARAGHER B. Psycholinguistic markers for Specific Language Impairment (SLI). J Chil Psychol Psychiatry, Cambridge, v. 42, n. 6, p. 741-748, Sep. 2001.

15 CONTI-RAMSDEN, G. Processing and linguistic markers in young children with Specific Language Impairment. J Speech Hear Res, Rockville, v. 46, n. 5, p. 1029-1037, Oct. 2003.

16 CRESPO-EGUÍLAZ, N.; NARBONA, J. Perfiles clínicos y evolutivos en el espectro del transtorno específico del desarrlollo del lenguaje. Rev Neurol, Barcelona, v. 36, p. 29-35, 2003. Suplemento 1.

17 CROSBIE, S.; HOLM, A.; DODD, B. Intervention for children with severe speech disorder: a comparison of two approaches. Int J Lang Commun Disord, London, v. 40, n. 4, p. 467-491, Oct./Dec. 2005.

18 DI SIMIONI, F. G. The Token Test for children. Texas: Pro-ed, 1978. $63 \mathrm{p}$.

19 DODD, B.; BRADFORD, A. A comparison of three therapy methods for children with different types of developmental phonological disorder. Int J Lang Commun Disord, London, v. 35, n. 2, p. 189-209, Apr./Jun. 2000

20 DUNN, L. M.; DUNN, L. M. Peabody Picture Vocabulary Test-revised. Circle Pines, MN: American Guidance Service, 1981.

21 FEY, M. E. et al. Two approaches to the facilitation of grammar in children with language impairment: an experimental evaluation. J Speech Hear Res, Rockville, v. 36, n. 1, p. 141-157, Feb. 1993.

22 FEY, M. E. et al. Effects of grammar facilitation on the phonological performance of children with speech and language impairments. $\mathbf{J}$ Speech Hear Res, Rockville, v. 37, n. 3, p. 594-607, Jun. 1994.

23 GILLON, G. T. The efficacy of phonological awareness intervention for chidren with spoken language impairment. Lang Speech Hear Serv Sch, Washington, v. 31, n. 2, p. 126-141, Apr. 2000.

24 GILLON, G. T. Follow-up study investigating the benefits of phonological awareness intervention for children with spoken language impairment. Int J Lang Commun Disord, London, v. 37, n. 4, p. 381-400, Oct./Dec. 2002. 
25 HAGE, S. R. V. Dispraxia articulatória: correlações com o desenvolvimento da linguagem. In: MARCHESAN, I. Q.; ZORZI, J. L. Anuário CEFAC de fonoaudiologia. Rio de Janeiro: Revinter, 1999. p. 119-130.

26 HAGE, S. R. V. Protocolo de anamnese e avaliação fonoaudiológica. Bauru, 2000. 27 p.

27 HAGE, S. R. V.; GUERREIRO, M. M. Distúrbio específico de linguagem: aspectos lingüísticos e neurobiológicos. In: FERREIRA, L. P.; BÉFILOPES, D. M.; LIMONGI, S. C. O. Tratado de Fonoaudiologia. São Paulo: Roca, 2004. cap. 78, p. 977-986.

28 HAGE, S.R.V. Processos de avaliação fonoaudiológica. In: Rev Soc Bras Fonoaudiol. São Paulo, 2005. 1 CD-ROM. Suplemento.

29 HART, B.; ROGER-WARREN, A. K. A milieu approach to teaching language. In: SCHIEFEBUSH. Language intervention strategies. Baltimore: University Park Press, 1978. p. 63-88.

30 HIRSCHMAN, M. Language repair via metalinguistic means. Int J Lang Commun Disord, London, v. 35, n. 2, p. 251-268, July/Aug. 2000.

31 KOURY, T. A. Lexical training through modeling and elicitation procedures with late talkers who have specific language impairment and developmental delays. J Speech Lang Hear Res, Rockville, v. 48, n. 1, p. 157-171, Feb. 2005.

32 LE NORMAND, M.T. Modelos psicolingüísticos do desenvolvimento da linguagem. In: CHEVRIE-MULLER, C; NARBONA, J. A linguagem da criança: aspectos normais e patológicos. 2. ed. Porto Alegre: Artmed, 2005. cap. 2, p. 52-70.

33 LEONARD, L. Children with Specific Language Impairment. Cambridge: MIT Press, 1998. 339 p.

34 MAJOR, E. M.; BERNHARDT, B. H. Metaphonological skills of children with phonological disorders before and after phonological and metaphonological intervention. Int $\mathbf{J}$ Lang Commun Disord, London, v. 33, n. 4, p. 413-444, Oct. 1998.

35 MENDOZA, E. El tratamiento del TEL. In: Trantornos Específicos de Lenguaje. Madrid: Ediciones Pirâmide, 2006. cap. 12 , p. $299-335$

36 MONTGOMERY, J. W. Working memory and comprehension in children with specific language impairment: what we know so far. J Commun Disord, Amsterdan, v. 36, n. 3, p. 221-231, May/June 2003.

37 MONTGOMERY, J. W. Real-time language processing in school-age children with specific language impairment. Int $\mathbf{J}$ Lang Commun Disord, London, v. 41, n. 3, p. 275-291, May/June 2006. 
38 MUÑOZ-LÓPEZ, J.; CARBALLO-GARCIA, G. Alteraciones lingüisticas en el transtorno específico del lenguaje. Rev Neurol, Barcelona, v. 41, p. 57-63. 2005. Suplemento 1.

39 NAVARRETE, J. J. B. et al. Evaluación de marcadores psicolingüísticos en el diagnóstico de ninõs con transtorno específico del lenguaje. Rev Logop Fon Audiol, v. 24, n. 4, p. 142-155. 2004.

40 NELSON, K. E. et al. Effects of imitative and conversational recasting treatment on the acquisition of grammar in children with specific language impairment and younger language-normal children. $\mathbf{J}$ Speech Hear Res, Rockville, v. 39, n. 4, p. 850-859, Aug. 1996.

41 ORTIZ, Z. B.; TIRAPEGUI, C. J. C. La conciencia fonológica en niños con transstorno específico de lenguage, Rev Logop Fon Audiol, v. 24, n. 4. p. 156-163. 2004.

42 PASCOE, M.; STACKHOUSE, J.; WELLS, B. Phonological therapy within a psycholinguistic framework: promoting change in a child with persisting speech difficulties. Int $\mathbf{J}$ Lang Commun Disord, London, v. 40, n. 2, p. 189-220, Apr./June 2005.

43 PEREIRA, R. A. S. Avaliação da compreensão de ordens verbais em crianças de nove e dez anos de idade. 2004. $51 \mathrm{f}$. Monografia (Aperfeiçoamento/Especialização em Fonoaudiologia - Área de Concentração Linguagem) - Universidade do Sagrado Coração, Bauru, 2004.

44 RVACHEW, S.; NOWAK, M.; CLOUTIER, G. Effect of phonemic perception training on the speech production and phonological awareness skills of children with expressive phonological delay. Am J Speech Lang Pathol, Rockville, v. 13, n. 3, p. 250-263, Aug. 2004.

45 SEGERS, E.; VERHOEVEN, L. Computer-supported phonological awareness intervention for kindergarten children with specific language impairment. Lang Speech Hear Serv Sch, Washington, v. 35, n. 3, p. 229-239, July 2004

46 SERRANO, B. Informática na fonoaudiologia: teste de discriminação auditiva. Disponível em:

<http:www.informaticanafonoaudiologia.hpg.ig.com.br/004discriminaca oauditiva.htm>. Acesso em: 03 out. 2005.

47 STACKHOUSE, J.; WELLS, B. Psycholinguistic assessment of developmental speech disorders. Eur J Disord Commun, London, v. 28, n. 4, p. 331-348. 1993

48 STACKHOUSE, J. et al. From phonological therapy to phonological awareness. Semin Speech Lang, New York, v. 23, n. 1, p. 27-42, Feb. 2002. 
49 TYLER, A. A. et al. Outcomes of different speech and language goal attack strategies. J Speech Lang Hear Res, Rockville, v. 46, n. 5, p. 1077-1094, Oct. 2003.

50 WATERS, D.; HAWKES, C.; BURNETT, E. Targeting speech processing strengths to facilitate pronunciation change. Int $\mathbf{J}$ Lang Commun Disord, London, v. 33, p. 469-474, Oct. 1998.

51 WERTZNER, H. F. Fonologia. In: ANDRADE, C. R. F. de et al. ABFW: teste de linguagem infantil nas áreas de fonologia, vocabulário, fluência e pragmática. 2 ed. Carapicuíba: Pró-Fono, 2004. cap. 1, p. $1-40$.

52 WOLFE, V.; PRESLEY, C.; MESARIS, J. The importance of sound identification training in phonological intervention. Am J Speech Lang Pathol, Rockville, v.12, n. 3, p. 282-288, Aug. 2003.

53 ZORZI, J. L.; HAGE, S. R. V. Desenvolvimento normal da linguagem e de aspectos cognitivos ligados ao simbolismo. In: Protocolo de observação comportamental: avaliação de linguagem e aspectos cognitivos infantis. São José dos Campos: Pulso, 2004. cap. 4, p. 5171. 
ABSTRACT 


\begin{abstract}
Effectiveness of language intervention for children with Specific Language Impairment
\end{abstract}

This study aimed to compare the psycholinguistic performance of children with Specific Language Impairment (SLI) to children with Typical Language Development (TLD), pointing out the most significant psycholinguistic markers, and to compare the effectiveness of two intervention methods, Milieu Teaching Approach and Neuropsycholinguistic Model, in the psycholinguistic performance of children with SLI. The subjects were 12 pre-school boys and girls, 4:00 to 6:11 years old; half of them took part in the experimental group children with SLI submitted to intervention - and the others in the control group children with TLD not submitted to intervention. The subject performance quantification in distinct psycholinguistic dimensions was obtained through several tools in order to evaluate the primary, secondary and tertiary levels of linguistic reception and production. After pre-intervention evaluations, the experimental group was randomly distributed into two study groups and submitted to two different therapeutic models (first cycle) during four months. At the end of this cycle, it was evaluated again, submitted to four-month therapy with alternating Models and re-evaluated. Statistical analysis showed the existence of statistically significant difference in the performance between the experimental group and the control one in several levels of linguistic analysis and production. The most significant markers involve auditory discrimination, phonological analysis, morphosyntactic reception and production, short-term memory and pragmatic abilities in relation to the use of expansive turns. The comparison of the effectiveness between the two proposed Models showed that distinct psycholinguistic abilities responded differently to themselves, which suggests that the combination of strategies of the studied Models be the best way to intervene in the performance of children whose difficulties lie in the investigated analysis and linguistic production levels of this study. 
Keywords: Language development disorders. Language therapy. Specific Language Impairment. Language Tests. 
APÊNDICE 
APÊNDICE 1 - Ofício de aprovação do projeto de pesquisa pelo Comitê de Ética em Pesquisa, da Faculdade de Odontologia de Bauru da Universidade de São Paulo (Proc. № 109/2005)

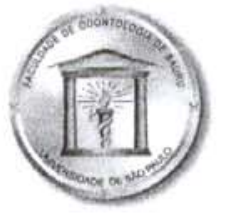

\author{
Universidade de São Paulo \\ Faculdade de Odontologia de Bauru \\ Al. Dr. Octávio Pinheiro Brisolla, 9-75 - Bauru-SP - CEP 17012-901 - C.P. 73 \\ PABX (0XX14)3235-8000 - FAX (0XX14)3223-4679 \\ Comitê de Ética em Pesquisa
}

Processo $n^{\circ}$ 109/2005

Bauru, 31 de outubro de 2005

Senhora Professora

O projeto de pesquisa encaminhado a este Comitê de Ética em Pesquisa em Seres Humanos, denominado "Eficácia da intervenção fonoaudiológica em crianças com Distúrbio Específico de linguagem", de autoria de Dáphine Luciana Costa Gahyva, que será desenvolvido sob sua orientação, foi enviado ao relator para avaliação.

$\mathrm{Na}$ reuniäo de 26 de outubro de 2005 o parecer do relator, aprovando o projeto, foi aceito pelo Comitê, considerando que nāo existem infraçōes éticas pendentes.

Informamos que após o envio do trabalho concluido, este Comitê enviará o parecer final, que será utilizado para publicaçäo do trabalho.

Atenciosamente,

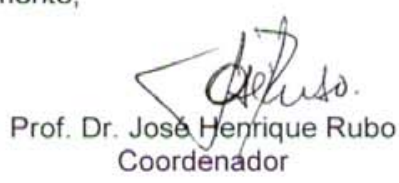

$\| m^{\mathrm{a}} \mathrm{Sr}^{\mathrm{a}}$ Profa $\mathrm{Dr}^{\mathrm{a}}$ Simone Rocha de Vasconcellos Hage

DD. Docente do Departamento de Fonoaudiologia 